\title{
MARKeT-TIMING AND AgenCy Costs: \\ EVIDENCE FROM PRIVATE EQUITY
}

\author{
Oleg Gredil
}

A dissertation submitted to the faculty of the University of North Carolina at Chapel Hill in partial fulfillment of the requirements for the degree of Doctor of Philosophy in the Department of Finance.

Chapel Hill

2015

Approved by:

Gregory W. Brown

Nickolay Gantchev

Eric Ghysels

Chotibhak (Pab) Jotikasthira

Christian T. Lundblad 
(C) 2015

Oleg Gredil

ALL RIGHTS RESERVED 


\section{ABSTRACT \\ OLEG GREDIL: Market-timing and Agency Costs: \\ Evidence from Private Equity. (Under the direction of Gregory W. Brown)}

Private equity (PE) funds operate at the interface of private and public capital markets. This paper investigates whether PE fund managers have private information about the valuations of publicly traded securities. Using a dataset of cash flows from 941 buyout and venture funds, I show that PE funds' distribution patterns predict returns of public securities in the industries of the funds' specialization, but fund managers tend to sell at the market peaks only when they have performance fees to harvest. I find that the cost of this agency tension increases in the manager's survival risk and that the managers' knowledge pertains to the public firms' future earnings rather than the discount-rates. My tests distinguish market-timing from reactions to the variation in risk premia and spillover effects of PE activity on public firms. The results help better understand PE performance and have strong implications for PE manager selection. It follows that PE activity embeds private information into the prices of public securities. 
To my loving wife and children: Ekaterina, Vasilisa and Mark. Thank you for your continuing inspiration and support! 


\section{ACKNOWLEDGMENTS}

I would like to especially thank Gregory Brown for his support and guidance. I am grateful to my Dissertation Committee Members: Gregory Brown, Pab Jotikasthira, Nickolay Gantchev, Eric Ghysels, and Christian Lundblad. Helpful comments and suggestions were provided by Nicholas Crain, Victoria Ivashina, Steven Kaplan, Stas Khrapov, Cami Kuhnen, Paige Ouimet, Urs Peyer, Adam Reed, Merih Sevilir, Morten Sørensen, Geoffrey Tate, William Waller and seminar participants at the 2013 Global Private Investing Conference. I am grateful to Burgiss for data access and to Wendy Hu for providing research assistance. This research has benefited

from the support of the Private Equity Research Consortium (PERC) and the UAI Foundation. All errors are my own. 


\section{TABLE OF CONTENTS}

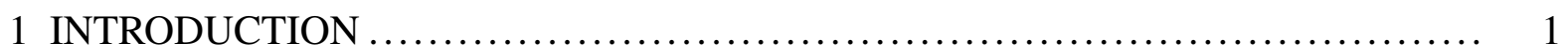

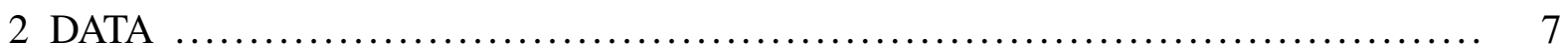

3 A SIMPLE MEASURE OF GPS' MARKET TIMING ........................ 12

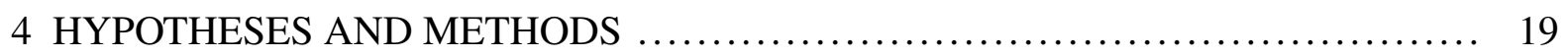

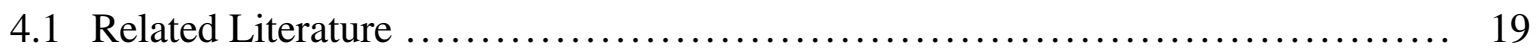

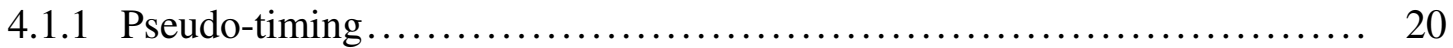

4.1.2 Footprints of PE Activity ....................................... 21

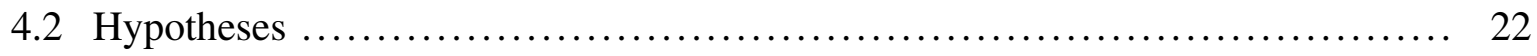

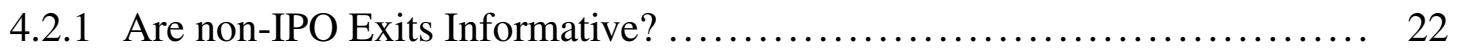

4.2.2 Exploring Agency Costs for Identification ........................ 22

4.2.3 When Do Exits Convey Less Information?........................ 23

4.2.4 Potential Power Drains .......................................... 24

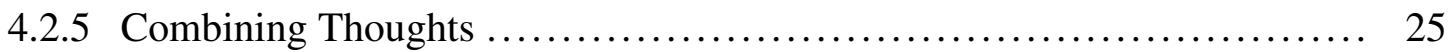

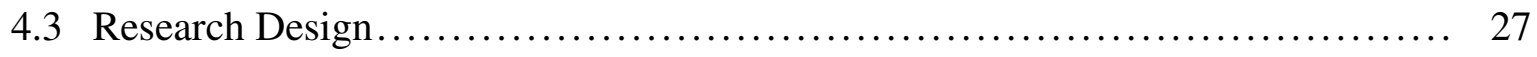

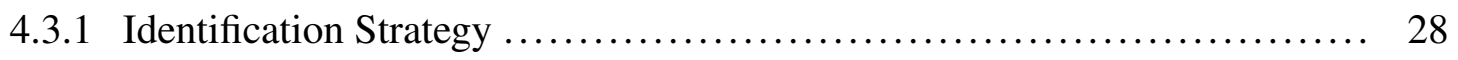

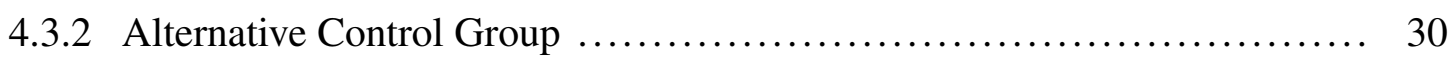

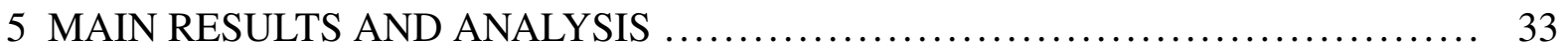

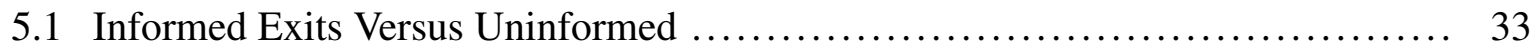

5.1.1 Does Rush Hurt Holding Period Returns? ........................... 39

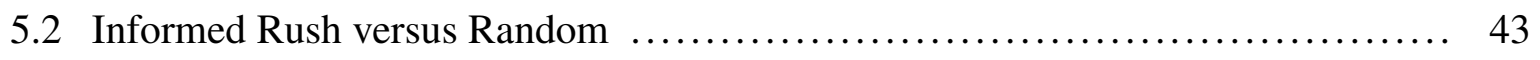

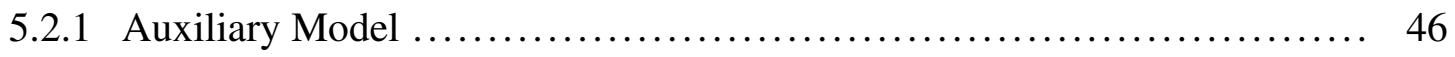




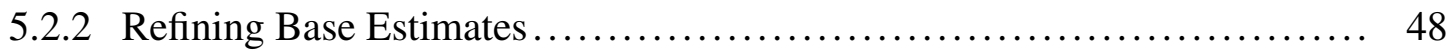

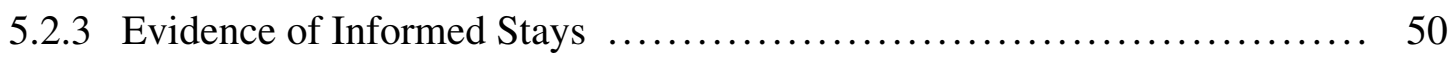

5.3 What Are GPs Informed about: Cash-flows or Discount-rates? ............... 56

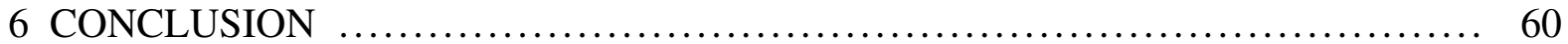

A.1 Additional Data and Discussion of the Institutional Background $\ldots \ldots \ldots \ldots \ldots \ldots .62$

A.2 Simulation-related Supplements and Discussions $\ldots \ldots \ldots \ldots \ldots \ldots \ldots \ldots \ldots \ldots .72$

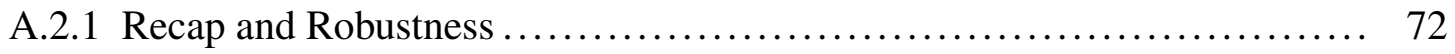

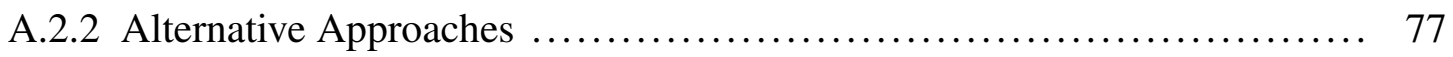

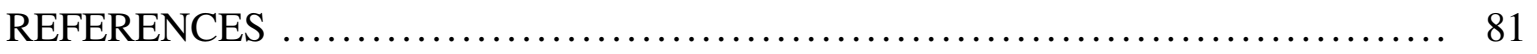




\section{LIST OF TABLES}

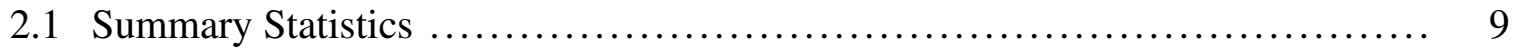

3.1 Timing Track Record: Associations and Persistence $\ldots \ldots \ldots \ldots \ldots \ldots \ldots \ldots . \ldots \ldots$

5.1 Informed Rush versus Uninformed ................................. 37

5.1 Does Informed Rush Sacrifice Holding Period Returns? ..................... 41

5.2 Actual Rush versus Random ............................................... 49

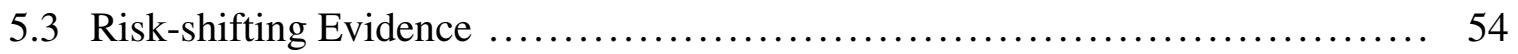

5.4 What Are PE Managers Informed About: Cash Flows or Discount Factor ...... 58

A.1 TTR Cross-Section: Robustness and Placebo $\ldots \ldots \ldots \ldots \ldots \ldots \ldots \ldots \ldots \ldots \ldots \ldots$

A.2 Do Exits Cause Downturns? ......................................... 70

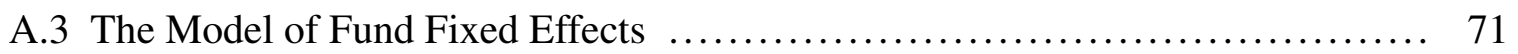




\section{LIST OF FIGURES}

2.1 Private Equity Fund Cash-flows: Cross-Section $\ldots \ldots \ldots \ldots \ldots \ldots \ldots \ldots \ldots \ldots \ldots$

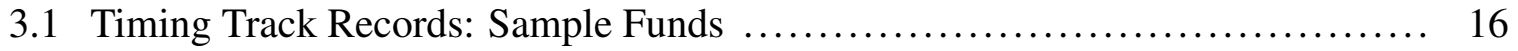

5.1 Informed Rush and Industry returns: Event Studies ................... 34

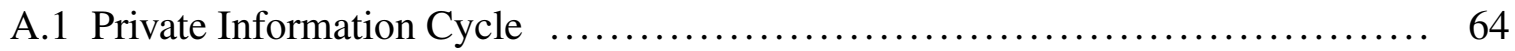

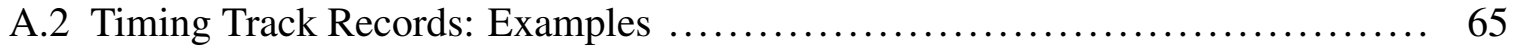

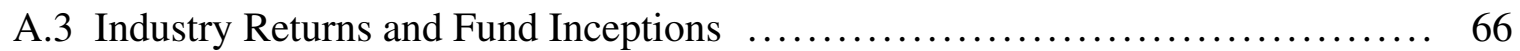

A.4 Timer's Rush and Industry Returns: Additional Event Studies ................ 67

A.5 Timer's Rush and Industry Returns: Quarterly Portfolios ................... 68

A.6 Actual Exits versus Simulated ......................................... 78

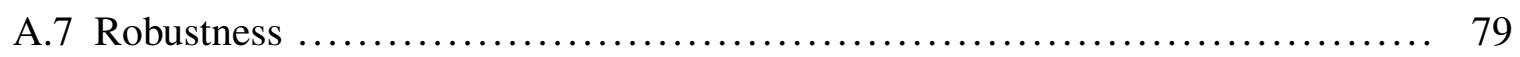

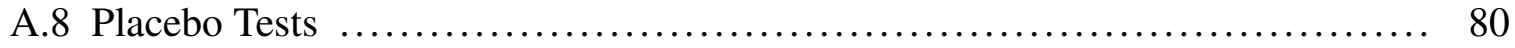




\section{INTRODUCTION}

Although by their nature private equity (PE) funds invest in private companies, their performance often depends crucially on the interface with public capital markets. Whether or not the fund's exit (or entry) involves a public transaction, comparable public market valuations affect the price. Prior research shows that PE managers are causing changes in policies of the investee companies as well as the industries in which these companies operate in, while being highly responsive to conditions in capital markets. ${ }^{1}$ Yet, there is little evidence of how informed PE managers are about the valuations of public equities and what role this information plays in their investment outcomes. In this paper, I examine whether PE managers can really buy low and sell high. I rely on the agency of PE intermediation to identify a private information-based market-timing from the alternative explanations. Since the counterfactual with market-timing actions is relatively observable, I am also able to quantify some agency costs of delegated money management. My results suggest that expected flows from future funds restrain managers from "destroying value" (consistent with the theoretical framework of Chung et al., 2011), but they fall short of inducing enough incentives.

Participation in private equity funds requires the investors (the limited partners, or LPs) to provide a pre-specified amount of cash over a multi-year period on short notice. The schedule of these outlays is ex-ante unknown and determined by the managers of the funds (the general partners, or GPs). In addition to fixed fees, GPs receive performance fees (carried-interest),

\footnotetext{
${ }^{1}$ For example, see Bernstein, Lerner, Sørensen and Strömberg (2011) and Aldatmaz (2012) for the spillover effects on the industry-wide corporate policies and efficiency; see Gompers, Kovner, Lerner, and Scharfstein (2008), Axelson, Jenkinson, Strömberg, and Weisbach (2010), Ball, Chiu, and Smith (2011) for the reactions to market conditions.
} 
a fraction of the fund life-time profits, and decide when to return capital to LPs. ${ }^{2}$ Such a near-absence of control over the timing of investments and divestments on the part of investors distinguishes the private equity funds from other forms of delegated asset management. The ceding of contribution and distribution timing to PE managers is commonly viewed as necessary given that PE funds hold non-traded assets. Yet, the delegation of these rights is also perceived as a source of liquidity risk for LPs. Recent studies have shown that GPs may be extracting agency benefits from these control rights over the fund cash-flow schedule. ${ }^{3}$

Less understood is the potential benefit to LPs of ceding these cash-flow timing rights. ${ }^{4}$ GPs specialize in certain types of businesses, know as much as the companies' management and, at the same time, have a first-hand read on the portfolio demands of financial and corporate investors. ${ }^{5}$ Consequently, in this analysis I empirically focus on two closely-related issues. First, I examine if PE managers have an informational advantage relative to public market prices. I show that PE managers do appear to learn valuable private information about the valuation of certain public equities and that the potential gains to LPs of delegating cashflow timing decisions to GPs can outweigh illiquidity costs. The economic magnitude of the effect is large. An inter-quartile increase in the rate of funds' distributions to investors predicts approximately $6 \%$ lower 12-month returns for the fund's primary S\&P500 sector.

Second, I examine the effects of the agency relationship between LPs and GPs. I show that unless GPs have "skin-in-the-game" via positive performance fees to harvest, they appear to not be using their private information to exit the fund investments near the market peaks while

\footnotetext{
${ }^{2}$ Despite a large degree of flexibility, distributions are subject to contractual limits on the fund life which are typically 10 to 13 years since inception. While the period of possible capital outlays from investors is largely limited to the first 5 years since fund inception.

${ }^{3}$ See Robinson and Sensoy (2013), Phalippou (2009), Degeorge, Martin, and Phalippou (2013).

${ }^{4} \mathrm{PE}$ fund managers oversee operations of dozens of companies. In comparison to most investors in public companies, PE managers are relatively unrestricted in information sharing with the companies' managers.

${ }^{5}$ The potential counterparties include professionally managed pools of capital (both, private and public) as well as non-financial firms with strategic interests in certain output producing assets. Even attempts to raise a follow-on fund may be informative about the exit prospects for the existing fund holdings.
} 
not delivering better holding-period abnormal returns either. ${ }^{6}$ I also show that GPs with a good market-timing track record, but nonetheless facing a particularly high survival risk (beyond the current fund term), are more likely to delay distributions to LPs when industry return volatility is about to rise. $^{7}$ In these situations, GPs may decrease distributions because they own outof-the-money options on the current and future funds' assets, and increasing industry volatility makes these options more valuable. These results contribute to the growing literature on private equity governance and, more broadly, on optimal contracting. ${ }^{8}$

I conduct my analysis using a sample of 941 U.S.-focused buyout and venture funds incepted between 1979 and 2006. The data comes from the Burgiss database of private equity funds that previous studies have found to be representative of the universe that has been available for institutional investors. ${ }^{9}$ Besides the precise amounts and dates of capital calls and distributions for each fund, I observe quarterly net asset values as well as various characteristics including GP-affiliation and the industry of specialization. My research design examines public market return (mean and variance) predictability as a function of the relative size and timing of PE fund distributions while accounting for the time-varying supply of mature funds (i.e., those with portfolio companies that are ready for exits). Using difference-in-difference tests, I disentangle the industry timing skills of GPs from alternative explanations such as timevarying exit conditions or causal effects of PE activity on the public companies.

The key identifying assumption is that alternative explanations to the timing skill (or the

\footnotetext{
${ }^{6}$ Normally, performance fees in PE are subject to a claw-back if the fund's remaining assets value decreases. Meanwhile, early exits may reduce the amount of asset management and monitoring fees that GPs collect from the fund, and also forgo a chance to improve the performance rank amongst peer-funds.

${ }^{7}$ These results obtain through the simulation-based estimation which controls for vintage-X-industry variation as well as other GP-specific and fund-specific attributes.

${ }^{8}$ For example, Barrot (2012) finds that remaining fund life determines the type of venture fund investments which can run counter to LPs' objectives. Degeorge, Martin and Phalippou (2013) find evidence consistent with GPs "going-for-broke" with secondary buyout investments. On the other hand, the results in Fang, Ivashina, and Lerner (2014) suggest that GPs intermediation might not be as costly. The authors find essentially no outperformance of private investments implemented by LPs directly while the co-investments run by GPs significantly underperform.

${ }^{9}$ See Harris, Jenkinson, and Kaplan (2013).
} 
existence relevant private information) do not depend on the changes in a GP's own wealth exposure to the industry valuations. I verify this assumption via a series of placebo tests and event studies. Consistent with the private information hypothesis, returns predictability from fund cash flows vanishes outside of the industries in which the GPs specialize and relates to the industry aggregate earnings news. I develop a new metric of GP's cash-flow Timing Track Record that contains valuable information about a fund's future propensity to sell close to industry highs and buy around lows. Consistent with the predictability being related to GP skill, these market-timing track records appear to be just as important a signal as financial incentives. To examine the robustness of my results and remove potentially confounding effects in my primary tests, I conduct simulations that allow for a better control for variation in exit conditions (e.g., time-varying expected returns by industry). The inference is robust to errors clustered in calendar-time, as well as to exclusions of particularly dramatic market episodes and certain fund groups.

While this paper is the first to directly examine the relation between PE manager private information and public market returns, there exists anecdotal and indirect evidence consistent with market-timing ability of PE managers (or, at least, efforts thereof). ${ }^{10}$ In a survey of 79 buyout firms by Gompers, Kaplan and Mukharlyamov (2014), "facilitating a high value exit" is among the top three ways buyout funds seek to create value. Recently, prominent private equity firms have launched actively managed mutual funds citing their private investing expertise as a managerial advantage. ${ }^{11}$ Yet, to-date there is no direct evidence supporting the PE private information-based market-timing hypothesis, clear of the alternative explanations which notably confound the economic implications of the results. ${ }^{12}$

\footnotetext{
${ }^{10}$ Anecdotal evidence of positive informational spillovers from investing in private companies includes examples of successful public "stock pickers" that heavily invest in private companies: Warren Buffet of Berkshire Hathaway, Charles Coleman of Tiger Global, among many others.

${ }^{11}$ For example, see "Following KKR, Blackstone Chases Retail With Mutual Fund", Forbes, 07/16/2013.

${ }^{12}$ Lerner (1994), Kalpan and Strömberg (2008), Guo, Hotchkiss, and Song (2011) do not disentangle private information-based market-timing from reacting to the observable exit condition variation, time-varying expected returns, and causal effects of PE activities on the public company valuations.
} 
My findings suggest that an LP's choice of a fund manager should incorporate a GP's market-timing track record since the expected gains persist across funds by the same GP and are of the same order of magnitude as private equity illiquidity costs. ${ }^{13}$ However, to the extent a given GP is at risk of not raising a next fund (e.g., due to lack of a long-term reputation), the expected gains from market-timing decreases and may turn negative as the probability of the aforementioned "asset-hoarding" increases. Provided that some GPs' market-timing skill would therefore require lower (or higher) liquidity premium for the funds they manage, my analysis speaks to a few important questions in the investments literature: (i) why investors choose to allocate to PE, (ii) how they select GPs, and (iii) what contract they have with a particular GP.

As per Harris, Jenkinson and Kaplan (2013), the data indicate that in large samples, both buyout and venture funds on average outperform public markets (on the holding period basis). My findings suggest that the portfolio abnormal performance attributable to PE is likely even better in aggregate, given the additional value from market-timing. ${ }^{14}$ However, the returns on a strategy of picking the best PE managers from the past might be diminishing as suggested by Harris, Jenkinson, Kaplan and Stucke (2013) as well as by Sensoy, Wang, and Weisbach (2013). Both studies find less persistence in holding period returns by GPs and LPs than in earlier samples. ${ }^{15}$ Thus, I contribute to the understanding of why LPs may still prefer PE fund managers with the best past track records even if holding periods returns of their funds are not much different from those run by less established competitors. ${ }^{16}$

\footnotetext{
${ }^{13}$ Franzoni, Nowak, and Phalippou (2012) and Sørensen, Wang, and Yang (2014) using very different approaches estimate the illiquidity costs for PE to be $2-3 \%$ per annum. However, neither of the studies consider the cash-flow timing dimension of fund returns. Similarly in Ang, Chen, Goetzmann and Phalippou (2013), private equity time-varying abnormal returns capture only the portfolio company selection and nurturing effects (i., holding period returns).

${ }^{14}$ Even without active management on the part of an LP, private equity fund distributions near industry peaks induces fluctuations in portfolio weights that result in higher Sharpe-ratios for the LP. Meanwhile, LPs may also consider optimizing allocations in their public equity portfolio based on the signals from the private equity part.

${ }^{15}$ See Kaplan and Schoar (2005), and Lerner, Schoar, and Wang (2007).

${ }^{16}$ For example, LPs may do so because (1) they learn more market-timing signals from such GPs; (2) this
} 
The results in this paper also imply broader roles for private equity in the modern capital markets. In settings such as Grossman and Stiglitz (1980), GPs' learning through private investing constitutes a "costly arbitrage" that improves the informational efficiency of public markets. For example, the tech-bubble of the late 1990s might have gotten greater if not for the flood of private equity exits trying to preempt (the GPs' carried interest being hit by) the bust. Specifically, venture funds incepted between 1995 and 1998 have divested considerably more than invested during the later stage of the NASDAQ boom. Even for the funds with not fully drawn capital commitments as of the beginning of 1999, the ratio of total distributions to capital calls during the following 12 months was 7-to- $1 .{ }^{17}$ This fact is hard to reconcile with a popular wisdom that venture capitalists' activity tends to amplify the valuation cycle. ${ }^{18}$

The dissertation proceeds as follows. Section 2 describes the data. Section 3 provides preliminary evidence of the market-timing skill presence among private equity GPs and motivates the hypotheses development and methods choice in Section 4 which also reviews the related literature. Section 5 reports main results. Section 6 concludes. Additional details, robustness and placebo tests are in the Appendix.

reduces the ex-ante probability of their GPs having difficulty with raising a follow-on fund and, thus, the aforementioned risk-shifting incentives.

${ }^{17}$ While the same ratio for the funds specializing in Internet Technology was in excess of 9-to-1.

${ }^{18}$ For example, see "Venture capital funding soars to levels last seen in dot-com bubble" by Chris O'Brien, Los Angeles Times, April 18, 2014. 


\section{DATA}

Private equity data for this study come from Burgiss, a leading provider of portfolio management software, services, and analytics to private capital investors. The dataset is sourced exclusively from about 300 investors in private capital funds (LPs) that collectively have made over 20,000 fund commitments, and includes the complete cash flow and valuation history with these funds ${ }^{1}$ The underlying LP universe consists of approximately $60 \%$ pension funds (a mix of public and private), $20 \%$ endowments and $20 \%$ other investors (such as sovereign wealth funds and funds-of funds). ${ }^{2}$ Harris, Jenkinson, and Kaplan (2013) compare several private equity datasets and conclude that the Burgiss dataset is representative of the buyout and venture funds investable universe.

I limit the sample to U.S.-focused buyout and venture funds with more than 25 and 10 million in capital commitments (respectively) incepted between 1979-2006. In total, the sample includes 349 (592) buyout (venture) funds of which 126 (169) continue operations as of March 2013. For each fund I observe: (1) the primary industry sector according to Global Industry Classification Standard (henceforth industry); (2) the amount of capital committed; (3) the strategy description; (4) the dated amounts of cash inflows and outflows as well as Net Asset Values (NAVs) reported quarterly. ${ }^{3}$

Panel A of Table 2.1 reports basic summary statistics for buyout and venture subsamples.

\footnotetext{
${ }^{1}$ Thus, the sample does not include co-investments or direct private investments studied in Fung et al.(2014).

${ }^{2}$ The dataset maintains confidentiality by removing all names and identifications.

${ }^{3}$ The cash-flow information is net of all fees allowing for accurate computation of returns to LPs. I do not know the gross-of-fees performance of investments, nor the fee terms. Fortunately, the only contractual term essential for my tests, the minimum rate of return to LPs beyond which GPs start to earn carry, has almost no variation within fund type according to other studies. For example, see Metric and Yasuda (2010), Robinson and Sensoy (2013). For buyouts (venture) funds this "hurdle rate" is almost always 8 (0) percent.
} 
The results suggest high within-type variation in fund life duration, size, and returns. ${ }^{4} 85 \%$ of funds are affiliated with a private equity firm (GPs) with multiple funds. For these funds, I observe the fund's chronological order (by inception date) within GP and GP-industry. ${ }^{5}$ Thus, the median fund in the dataset is the second by a GP and within a given industry while about a quarter of funds are fourth or higher in a sequence. Mature venture GPs are somewhat less likely to operate in multiple industries, unlike those specializing in buyouts.

${ }^{4}$ Returns are as of the last cash flow or valuation date in the sample.

${ }^{5}$ Where GPs' affiliation is absent, I impute zero for Overall and Industry Sequence. 


\section{Table 2.1: Summary Statistics}

This table reports summary statistics for the data used in this study. Panel A reports sequence order, vintage year, life since inception, size, and the last-most performance statistics for 349 (592) U.S.-focused buyout (venture) funds of which 126 (169) continue operations as of March 2013. Overall and Industry Sequence report the fund chronological order of the inception date within GP and GP-industry respectively or zeros when fund's GP data is not available ( $15 \%$ of sample funds). IRR stands for internal rate of return. PME vs Market (Industry) denotes Kaplan and Schoar (2005) Public Market Equivalent Index versus broad market (S\&P500 subindex corresponding to the GICS Industry Sector of the fund specialty). Panel B reports statistics for monthly returns, price-to-earningand book-to-market-ratios of these subindexes for the period from January 1989 through October 2013. Panel C reports statistics for the rest of the variables as described in Section 4.2.

Panel A: Private Equity Funds

\begin{tabular}{lccccccccc}
\hline \multicolumn{1}{c}{ Variable } & Mean & SD & $\mathrm{p} 1$ & $\mathrm{p} 5$ & $\mathrm{p} 25$ & $\mathrm{p} 50$ & $\mathrm{p} 75$ & $\mathrm{p} 95$ & $\mathrm{p} 99$ \\
\hline Overall Sequence & 3.0 & 2.7 & 0.0 & 0.0 & 1.0 & 2.0 & 4.0 & 9.0 & 12.0 \\
Industry Sequence & 2.1 & 1.7 & 0.0 & 0.0 & 1.0 & 2.0 & 3.0 & 6.0 & 8.0 \\
Vintage Year & 1996 & 5 & 1982 & 1986 & 1994 & 1997 & 2000 & 2003 & 2005 \\
Life in Quarters & 48 & 11 & 20 & 30 & 41 & 48 & 55 & 65 & 81 \\
Fund Size $(\$ \mathrm{mln})$ & 745 & 955 & 25 & 60 & 160 & 400 & 910 & 2920 & 5000 \\
IRR & 0.165 & 0.227 & -0.195 & -0.077 & 0.060 & 0.130 & 0.225 & 0.488 & 1.017 \\
Money Multiple & 13.32 & 181.21 & 0.52 & 1.00 & 1.69 & 2.28 & 3.44 & 8.69 & 51.92 \\
PME vs Market & 1.34 & 0.92 & 0.29 & 0.51 & 0.90 & 1.22 & 1.61 & 2.29 & 3.87 \\
PME vs Industry & 1.34 & 0.87 & 0.26 & 0.48 & 0.87 & 1.24 & 1.63 & 2.48 & 3.08 \\
& & & & & & & & & \\
Overall Sequence & 3.1 & 2.8 & 0.0 & 0.0 & 1.0 & 2.0 & 4.0 & 9.0 & 13.0 \\
Industry Sequence & 2.7 & 2.5 & 0.0 & 0.0 & 1.0 & 2.0 & 4.0 & 8.0 & 11.0 \\
Vintage Year & 1993 & 6 & 1980 & 1982 & 1987 & 1994 & 1999 & 2001 & 2003 \\
Life in Quarters & 49 & 11 & 23 & 33 & 42 & 49 & 56 & 68 & 78 \\
Fund Size (\$mln) & 156 & 178 & 11 & 19 & 47 & 98 & 190 & 510 & 850 \\
IRR & 0.227 & 0.524 & -0.248 & -0.155 & 0.004 & 0.094 & 0.222 & 1.107 & 2.735 \\
Money Multiple & 4.42 & 6.49 & 0.36 & 0.78 & 1.69 & 2.69 & 4.33 & 13.74 & 37.65 \\
PME vs Market & 1.46 & 2.13 & 0.12 & 0.25 & 0.59 & 0.94 & 1.39 & 3.99 & 12.40 \\
PME vs Industry & 1.38 & 1.69 & 0.13 & 0.32 & 0.62 & 0.99 & 1.45 & 3.68 & 10.22 \\
\hline
\end{tabular}

Panel B: Industry Benchmarks

\begin{tabular}{|c|c|c|c|c|c|c|c|c|c|}
\hline \multirow[t]{2}{*}{ GICS Sector } & \multicolumn{3}{|c|}{ Returns } & \multicolumn{3}{|c|}{ Book-to-Market } & \multicolumn{3}{|c|}{ Price-to-Earnings } \\
\hline & Mean & SD & Skew & Mean & $\mathrm{p} 25$ & p75 & Mean & $\mathrm{p} 25$ & p75 \\
\hline $\begin{array}{l}\text { Consumer } \\
\text { tionary }\end{array}$ & 0.009 & 0.052 & -0.737 & 0.379 & 0.319 & 0.438 & 27.0 & 15.7 & 22.9 \\
\hline Consumer Staples & 0.009 & 0.040 & -1.047 & 0.238 & 0.178 & 0.291 & 20.1 & 15.9 & 21.1 \\
\hline Energy & 0.010 & 0.053 & -0.397 & 0.438 & 0.358 & 0.521 & 17.6 & 12.4 & 19.4 \\
\hline Financials & 0.007 & 0.065 & -0.984 & 0.629 & 0.467 & 0.840 & 24.6 & 12.8 & 17.7 \\
\hline Healthcare & 0.010 & 0.047 & -0.461 & 0.247 & 0.165 & 0.320 & 20.0 & 15.9 & 21.3 \\
\hline Industrials & 0.009 & 0.046 & -1.107 & 0.323 & 0.283 & 0.369 & 23.3 & 16.7 & 27.2 \\
\hline Internet Technology & 0.008 & 0.072 & -0.796 & 0.327 & 0.224 & 0.451 & 27.5 & 15.2 & 35.6 \\
\hline Materials & 0.008 & 0.057 & -0.627 & 0.424 & 0.359 & 0.460 & 23.6 & 14.8 & 28.4 \\
\hline Telecommunications & 0.007 & 0.055 & -0.402 & 0.406 & 0.280 & 0.509 & 21.0 & 15.6 & 23.0 \\
\hline Utilities & 0.008 & 0.044 & -0.616 & 0.554 & 0.484 & 0.678 & 15.2 & 12.3 & 16.7 \\
\hline
\end{tabular}


Panel C: Other Variables

\begin{tabular}{lccccccccc}
\hline \multicolumn{1}{c}{ Variable } & Mean & SD & p1 & p5 & p25 & p50 & p75 & p95 & p99 \\
\hline Market Return $(* 100)$ & 0.92 & 4.58 & -10.22 & -7.60 & -1.74 & 1.52 & 3.93 & 7.66 & 10.20 \\
CAY Ratio $(* 100)$ & 0.26 & 2.28 & -3.35 & -3.13 & -2.04 & 0.52 & 2.25 & 3.46 & 3.96 \\
CBOE VIX & 20.7 & 7.8 & 11.1 & 11.8 & 15.3 & 19.4 & 24.1 & 35.1 & 46.4 \\
BBB-AAA spread & 0.99 & 0.40 & 0.55 & 0.60 & 0.75 & 0.91 & 1.16 & 1.46 & 3.00 \\
AAA-UST spread & 1.32 & 0.48 & 0.49 & 0.71 & 0.90 & 1.24 & 1.69 & 2.12 & 2.53 \\
10-year yield $(* 100)$ & 5.55 & 2.01 & 1.68 & 1.98 & 4.10 & 5.50 & 7.17 & 8.86 & 9.26 \\
3-month yield $(* 100)$ & 3.69 & 2.41 & 0.02 & 0.05 & 1.33 & 4.34 & 5.40 & 7.69 & 8.43 \\
\hline
\end{tabular}

Figure 2.1 demonstrates high variation in fund cash-flow schedules for both buyout and venture funds. As shown in Panel A, a quarter of buyout funds call $61 \%$ or less of committed capital by the 30th month since inception while another quarter are fully invested by that time. Distributions from buyout funds are even more variable. Among buyout funds, a quarter had $40 \%$ of total distributions completed 30 months prior to resolution whereas another quarter had over $80 \%$ distributed. ${ }^{6}$ Panel B reports similar charts for venture funds and indicates even wider variation in both contributions and distributions.

I utilize the CRSP value-weighted index as a proxy for public market equity returns. For equity industry returns, I use returns on S\&P500 industry sectors because these map directly to the classification in the Burgiss data and represent widely-followed benchmarks by practitioners. ${ }^{7}$ The list of industries and summary statistics for monthly total returns, price-earnings and book-to-market ratios from January 1989 through September 2013 are reported in Panel B of Table 2.1. Panel A of Table 2.1 also reports the PME measure of market-adjusted fund performance as described by Kaplan and Schoar (2005), as well as a similar indicator calculated against the industry benchmark $P M E v s$. Industry. ${ }^{8}$ Summary statistics for other variables of

${ }^{6}$ I define "resolution" as funds older than 5 years since inception with remaining $N A V \leq 1 \%$ of fund size.

${ }^{7}$ Results are similar if I use industry subindexes of the S\&P600 (small capitalization stocks).

${ }^{8} \mathrm{~S} \& \mathrm{P} 500$ returns were used in place of sector returns in periods before 1989. 


\section{Figure 2.1: Private Equity Fund Cash-flows: Cross-Section}

This figure reports the $5^{t h}, 25^{t h}, 75^{t h}$, and $95^{\text {th }}$ percentiles for the fraction of to-date capital calls (distributions) in the total amount eventually to be called (distributed) by each fund during the first (last) 60 months of its operation. Panel A plots results for the buyout subsample. For example, according to the left-chart, a quarter of buyout funds by the $30^{t h}$ month since inception would call $61 \%$ of its capital or less while another quarter would be fully invested by that time. From the right-chart we learn that among almost fully resolved buyout funds, a quarter had about $40 \%$ of total distributions completed 30 months before last while another quarter had over $80 \%$ already distributed. Panel B reports this analysis for the venture subsample.

\section{Panel A: Buyout}
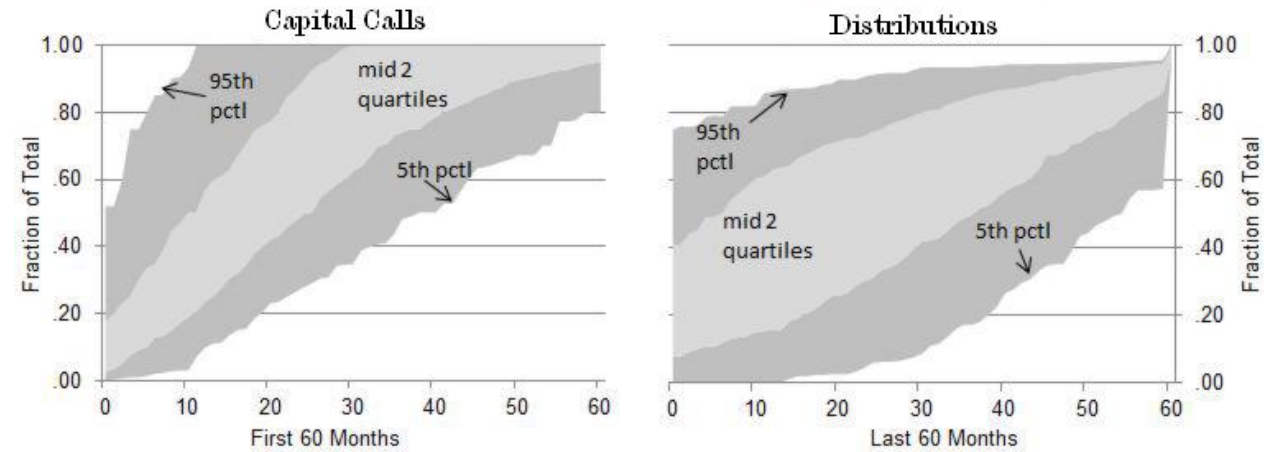

Panel B: Venture
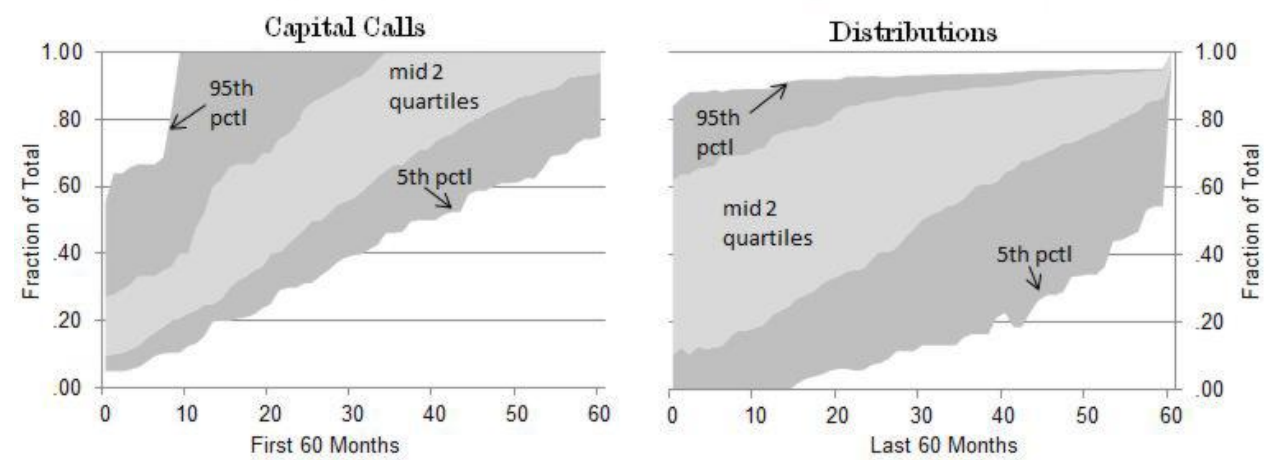

interest are reported in Table 2.1 Panel C. CAY Ratio is the cointegrated consumption-wealth ratio from Lettau and Ludvigson (2001). VIX is the CBOE volatility index for the S\&P500. $B B B-A A A$ spread and AAA-UST spread are, respectively, difference between Moody's Baa and Aaa yields, and Aaa yield and 10-year constant maturity U.S. Treasury yield, 10-year yield. 3-month yield is the U.S. Treasury bill rate. 


\section{A SIMPLE MEASURE OF GPS' MARKET TIMING}

The information that a GP obtains through the investment cycle and public markets valuations are closely related. ${ }^{1}$ Public markets prices reflect cash flow expectations and investor preferences while also affecting the fund's investment entry and exit prices, regardless of the deal sourcing and exit route. As an example, consider an exit through a sale to a public corporation. Bargaining over price would normally evolve around an assortment of valuation ratios of comparable publicly traded firms as indications of a fair price, even though the business characteristics might not exactly match those of the target company. Thus, GPs may be able to take advantage of superior knowledge of industry trends even when the fund portfolio companies have, in fact, relatively small exposures to these trends.

The ability of GPs to act on company-specific information advantage is likely to be limited by adverse-selection concerns of the prospective buyers. A need to make concessions with regards to idiosyncratic returns would be consistent with buyout- and venture-backed IPO outperformance, particularly against characteristics-matched portfolios, as documented in Brav and Gompers (1997), Cao and Lerner (2006), and Harford and Kolasinski (2013). However, this adverse selection is much less relevant with regards to industry-wide risk realizations since those who typically buy from (sell to) private equity funds care more about the relative performance of the asset, not absolute performance as do private equity GPs. ${ }^{2}$ In general, GPs informational advantage should dissipate beyond the industry of specialization.

I begin my analysis with suggestive evidence that GP access to information relevant to

\footnotetext{
${ }^{1}$ A detailed discussion of the institutional details supporting this statement is provided in Appendix A.1.

${ }^{2}$ GPs receive a fixed fee of $1-2 \%$ of fund size over the course of its contractual life and typically $20 \%$ of the fund absolute profits if they exceed a predetermined threshold. See Metric and Yasuda (2009), Robinson and Sensoy (2013) for details.
} 
industry valuations manifests in PE fund cash flows. To analyze the timing track records and obtain a proxy for a presence of such a skill, I propose a measure of a gross return over a fund's life-time due to selling at market highs and buying at market lows. Computationally it is very similar to the Public Market Equivalent (PME) of Kaplan and Schoar (2005). However, the Timing Track Record (henceforth TTR) measures the timing component of a fund's total returns that $P M E$ explicitly disregards. Specifically, I define,

$$
\begin{aligned}
T T R & =\frac{\overline{P M E}}{P M E} \\
& =\frac{\sum_{t=1}^{T} D_{t} e^{r_{1, T} \cdot(1-t / T)} / \sum_{1}^{T} C_{t} e^{r_{1, T} \cdot(1-t / T)}}{\sum_{t=1}^{T} D_{t} e^{r_{t, T}} / \sum_{1}^{T} C_{t} e^{r_{t, T}}}
\end{aligned}
$$

where $r_{t, T}$ is the market return from the cash flow date (t) until the fund's resolution (T), while $D_{t}\left(C_{t}\right)$ denotes the fund's distributions (capital calls). In essence, TTR is a ratio of two profitability indexes with different discount rates. The discount rates in the denominator reflect investment periods opportunity costs while the discount rates in the numerator reflects the commitment period opportunity costs. Thus, a TTR value above one indicates that the NPV is greater if measured against the fund commitment period opportunity cost. In other words, a TTR greater than one is consistent with value-added from the market-timing by GP. ${ }^{3}$ Just as $P M E, T T R$ can be computed on a to-date basis by assuming the respective period to be the last and the NAV at that date to be a liquidating distribution. See Brown, Gredil, and Kaplan (2013) for to-date-PME definitions. Importantly, the mean market return for $\overline{P M E}$ computation will also be last date specific.

To better understand the intuition behind TTR, consider the following stylized example. Two funds, A and B, start at the same time with $\$ 30$ in committed capital and have to 2 years to invest. Both funds liquidate at year 4. For simplicity we assume that neither fund has portfolio company selection skill and so earns the market rate of return on investments, thus

\footnotetext{
${ }^{3}$ Also, $\ln (T T R) / F$ undDuration can be viewed as the annual rate of timing alpha.
} 
$\mathrm{PME}=1.0$ for both funds by definition. However, fund A chooses to draw capital in equal installments over 3 years whereas fund B, correctly anticipating a market downturn, draws less capital initially.

\begin{tabular}{|c|c|c|c|c|}
\hline \multicolumn{5}{|c|}{ Entry Timing Example } \\
\hline Year & $r_{m k t}$ & Fund A Cash Flow & Fund B Cash Flow & Fund A NAVs \\
\hline 0 & - & -10 & -5 & 10 \\
\hline 1 & $5.0 \%$ & -10 & -5 & $20.50=10 \cdot 1.05+10$ \\
\hline 2 & $-13.6 \%$ & -10 & -20 & 27.71 \\
\hline 3 & $5.0 \%$ & 0 & 0 & 29.09 \\
\hline \multirow[t]{3}{*}{4} & $5.0 \%$ & 30.55 & 31.81 & 0 \\
\hline & $P M E$ & 1.00 & 1.00 & \\
\hline & $\overline{P M E}$ & $1.02=30.55 / 30$ & $1.06=31.81 / 30$ & \\
\hline$T T R$ & $\overline{M E} / P M E$ & $\mathbf{1 . 0 2}=1.02 / 1.00$ & $\mathbf{1 . 0 6}=1.06 / 1.00$ & \\
\hline
\end{tabular}

While both funds have $P M E$ equal to one, fund $\mathrm{B}$ creates more value for its LPs than fund A: 1.81 versus 0.55 . This added value is reflected in a higher $\overline{P M E}$ for fund $\mathrm{B}$ and thus a higher $T T R$ for fund $\mathrm{B}$. In this way $T T R$ measures the market timing ability of the managers of fund B. Appendix A.2 provides examples with more realistic cash flows and market returns that show how TTR captures the timing of exits as well.

The money-multiple (i.e., ratio of nominal distributions to contributions) is an absolute performance measure widely utilized by practitioners and would reflect the difference in returns to LPs from funds A and B. In fact, the money-multiples of A and B are 1.02 and 1.06, respectively. In this specific case, they are the same as TTRs because the cumulative market return is zero and the $P M E$ of each fund is 1.0. However, in practice money-multiples also reflect differences in market returns over fund lives, as well as differences in fund holding period abnormal returns. Thus, Equation (3.1) essentially strips-out the prevailing market trend from the money-multiple and deflates it by the gross life-time return due to portfolio companies' selection (and nurturing) effects. In addition to its simplicity, TTR also benefits from a robustness 
to risk misspecification by virtue of its relation to $P M E .{ }^{4}$ Specifically, risk-related errors will tend to cancel out in TTR because $\overline{P M E}$ will have beta-related estimation errors positively correlated with those in PME.

Panel A of Figure 3.1 plots distributions of end-of-life TTRs for the sample funds against the broad market and the respective fund industry, separately for buyout and venture subsamples. First, the dispersion of $T T R$ is comparable with that of $P M E$, suggesting that $T T R$ is indeed a potentially important dimension of fund performance. Second, the means are statistically different from one and are larger for the industry benchmark case albeit the distances are economically small, corresponding to average industry timing alpha of about $1 \%$ per year since inception. ${ }^{5}$ Nonetheless, almost a third of funds in both subsamples have a TTR of 1.18 or higher which exceeds the 2\% per year "break-even" alpha estimates in Sørensen et al.(2013).

Panel B of Figure 3.1 plots to-date TTRs as of the 5th anniversary against the end-of-life TTRs (for funds that exist at least 9 years). By the 5th year TTR would tend to reflect mostly the entry timing. Examples in Figure A.2 suggest that bad exit timing can offset the effect of the entry and vice versa. Nonetheless, from Panel B it appears that funds that have a good timing track record as of mid-life normally continue to do so through the remainder of their lives and, thus, tend to exhibit good exit timing.

Panel A of Table 3.1 reports associations of industry TTRs with GP characteristics that proxy for institutional quality. ${ }^{6}$ Fund size (size-squared) is positively (negatively) related to end-of-life TTR. However, the size effect is insignificant when temporal variation is controlled for through vintage year fixed effects. Fund sequence is positively related to TTR computed using industry returns indicating that funds raised by GPs with more experience in a given industry are likely to better navigate industry peaks and troughs. These results are not present

\footnotetext{
${ }^{4}$ See Korteweg and Nagel (2013) and Sørensen and Jagannathan (2013) for details. Robinson and Sensoy (2011) provide empirical assessment of the question by examining sensitivity of cross-sectional mean $P M E$ to different beta/benchmark assumption).

${ }^{5}$ Since $T T R$ is limited by the benchmark volatility over the period, Sharpe-ratios may be more comparable across time and industries.

${ }^{6}$ See, for example, Kaplan and Schoar (2005), Robinson and Sensoy (2011).
} 


\section{Figure 3.1: Timing Track Records: Sample Funds}

This figure plots Timing Track Record (TTR) values for the sample private equity funds. TTR is defined in Section 3 and measures the gross-return due to selling near the market peaks during the fund life-time and buying near the troughs. Panel A plots univariate distributions. Top-left (right) chart shows TTRs against the broad market index for the buyout (venture) funds, while bottom-left (right) charts shows TTRs for the respective subsample against (S\&P500 subindex of) GICS industry sector that the respective fund specializes in (Industry TTRs). Panel B compares end-of-5th-year and final Industry TTRs values for the buyout (venture) subsamples of funds that were for at least 9 years old.

Panel A: End-of-Life Values

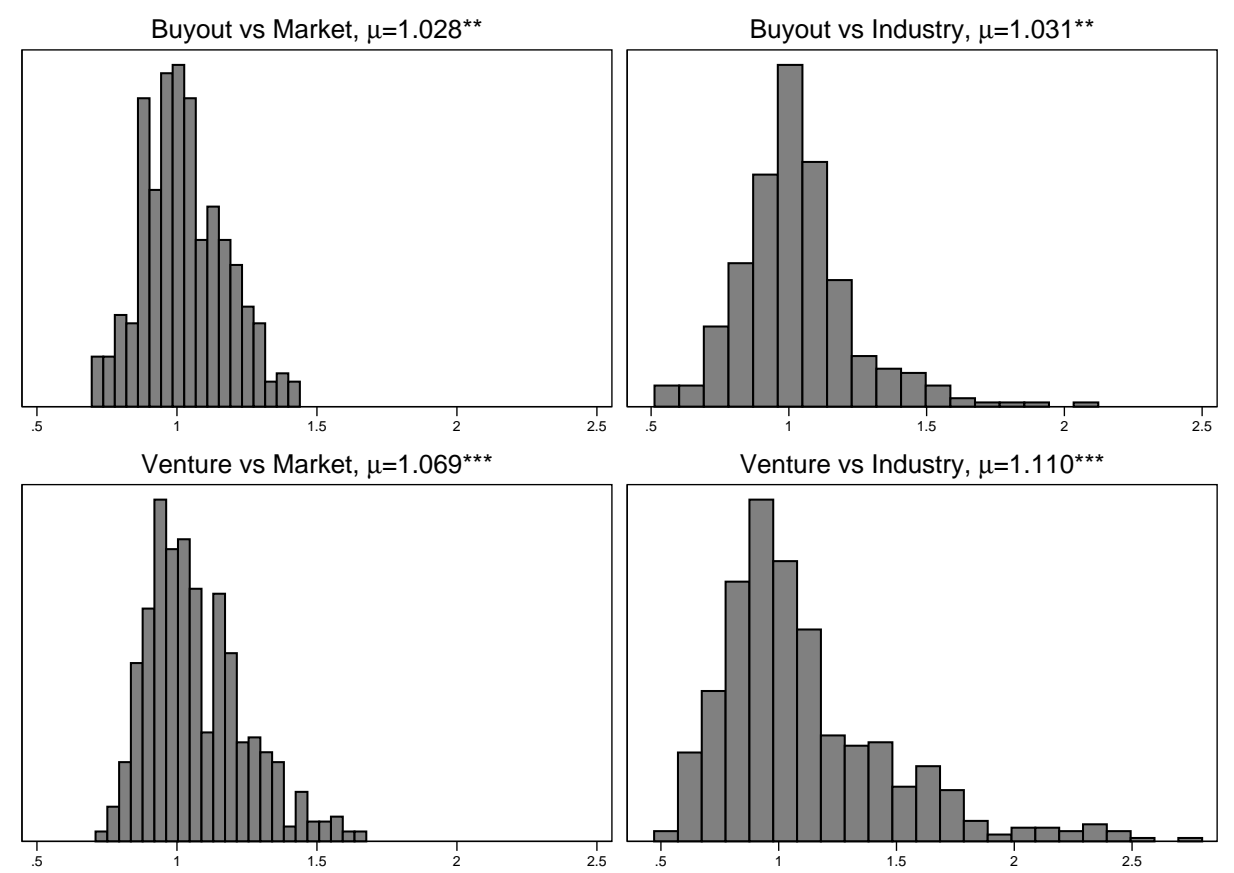

Panel B: Interim versus End-of-Life

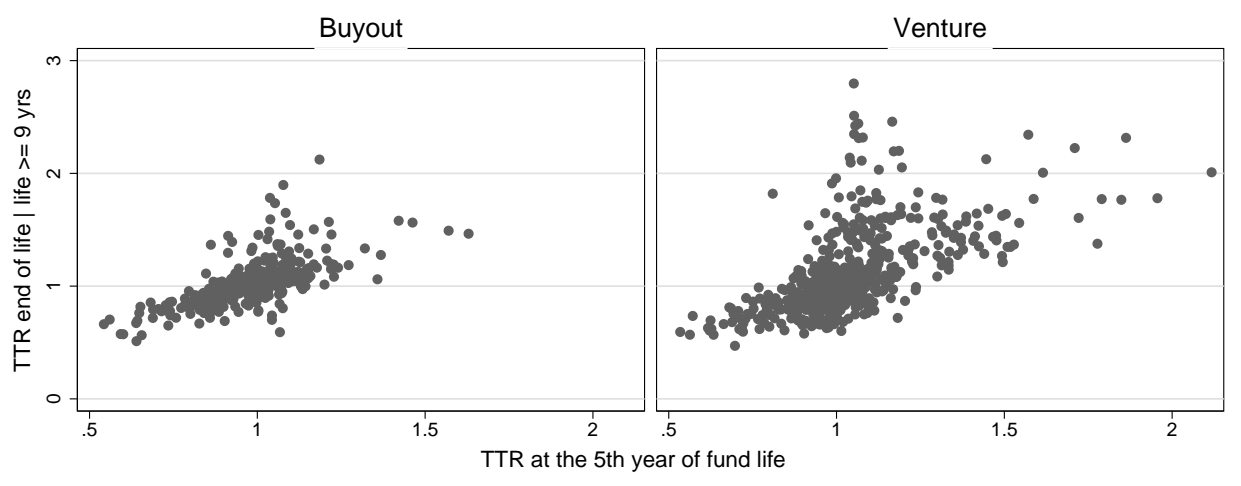


for broad market returns reported in Panel B.

\section{Table 3.1: Timing Track Record: Associations and Persistence}

This table reports linear regression model estimates of the log of funds' end-life TTRs. TTR is defined in Section 3 and measures the gross-return due to selling near the market peaks during the fund life-time and buying near the troughs. The explanatory variables are: $\ln (\text { Size })_{i}\left(\ln (\text { Size })_{i}^{2}\right)-\log (\log$-squared) of the fund $\$$ capital committed; $\ln (\text { Sequence })_{i}$ - chronological order of the fund inception date by given GPs (the private equity management firm); $\ln (P M E)_{i}-\log$ of the fund's Kaplan and Schoar (2005) Public Market Equivalent Index; $\ln (T T R)_{i-1}-\log$ of the GP's previous fund TTR. In Panel A TTR, $\ln (\text { Sequence })_{i}$ and PME are measured with respect to the GICS Industry Sector of the fund specialty while in Panel B - versus the broad market/ all funds by given GPs. Specifications (2) through (6) include fund vintage-year fixed effects. Standard errors in parentheses are clustered by GPs, $* / * * / * * *$ denote significance at $10 / 5 / 1 \%$ confidence level.

Panel A: TTR versus Industry

\begin{tabular}{|c|c|c|c|c|c|c|}
\hline & (1) & (2) & (3) & (4) & (5) & (6) \\
\hline $\ln (\text { Size })_{i}$ & $\begin{array}{l}0.515^{* * * *} \\
(0.162)\end{array}$ & $\begin{array}{c}0.082 \\
(0.150)\end{array}$ & & & & \\
\hline $\ln (\text { Size })_{i}^{2}$ & $\begin{array}{c}-0.014 * * * \\
(0.004)\end{array}$ & $\begin{array}{c}-0.003 \\
(0.004)\end{array}$ & & & & \\
\hline $\ln (\text { IndSequence })_{i}$ & $\begin{array}{l}0.057 * * * \\
(0.021)\end{array}$ & $\begin{array}{l}0.049 * * * \\
(0.018)\end{array}$ & $\begin{array}{l}0.040 * * \\
(0.017)\end{array}$ & & & $\begin{array}{l}0.055^{* *} \\
(0.024)\end{array}$ \\
\hline $\ln (P M E)_{i}$ & & & $\begin{array}{l}0.040 * * * \\
(0.015)\end{array}$ & & $\begin{array}{l}0.059^{* * * *} \\
(0.020)\end{array}$ & $\begin{array}{l}0.054 * * * * \\
(0.020)\end{array}$ \\
\hline $\ln (T T R)_{i-1}$ & & & & $\begin{array}{l}0.135^{* *} \\
(0.052)\end{array}$ & $\begin{array}{l}0.115^{* *} \\
(0.051)\end{array}$ & $\begin{array}{c}0.107^{* *} \\
(0.049)\end{array}$ \\
\hline Vintage FE & No & Yes & Yes & Yes & Yes & Yes \\
\hline $\begin{array}{l}\text { Observations } \\
R^{2}\end{array}$ & $\begin{array}{c}756 \\
0.025\end{array}$ & $\begin{array}{c}756 \\
0.387\end{array}$ & $\begin{array}{c}756 \\
0.386\end{array}$ & $\begin{array}{c}404 \\
0.431\end{array}$ & $\begin{array}{c}404 \\
0.449\end{array}$ & $\begin{array}{c}404 \\
0.457\end{array}$ \\
\hline
\end{tabular}

Panel B: TTR versus Broad Market

\begin{tabular}{|c|c|c|c|c|c|c|}
\hline & (1) & (2) & (3) & (4) & (5) & (6) \\
\hline $\ln (\text { Size })_{i}$ & $\begin{array}{c}0.164^{*} \\
(0.085)\end{array}$ & $\begin{array}{c}0.002 \\
(0.072)\end{array}$ & & & & \\
\hline $\ln (\text { Size })_{i}^{2}$ & $\begin{array}{c}-0.005 * * \\
(0.002)\end{array}$ & $\begin{array}{c}-0.001 \\
(0.002)\end{array}$ & & & & \\
\hline $\ln (\text { Sequence })_{i}$ & $\begin{array}{l}0.048^{* * *} \\
(0.009)\end{array}$ & $\begin{array}{l}0.034 * * * \\
(0.008)\end{array}$ & $\begin{array}{c}0.015^{*} \\
(0.009)\end{array}$ & & & $\begin{array}{c}0.011 \\
(0.014)\end{array}$ \\
\hline $\ln (P M E)_{i}$ & & & $\begin{array}{l}0.037 * * * \\
(0.007)\end{array}$ & & $\begin{array}{l}0.044 * * * \\
(0.010)\end{array}$ & $\begin{array}{l}0.043 * * * \\
(0.010)\end{array}$ \\
\hline $\ln (T T R)_{i-1}$ & & & & $\begin{array}{l}0.108 * * \\
(0.055)\end{array}$ & $\begin{array}{c}0.093^{*} \\
(0.049)\end{array}$ & $\begin{array}{c}0.093^{*} \\
(0.050)\end{array}$ \\
\hline Vintage FE & No & Yes & Yes & Yes & Yes & Yes \\
\hline $\begin{array}{l}\text { Observations } \\
R^{2}\end{array}$ & $\begin{array}{c}756 \\
0.035\end{array}$ & $\begin{array}{c}756 \\
0.468\end{array}$ & $\begin{array}{c}756 \\
0.482\end{array}$ & $\begin{array}{c}404 \\
0.470\end{array}$ & $\begin{array}{c}404 \\
0.516\end{array}$ & $\begin{array}{c}404 \\
0.517\end{array}$ \\
\hline
\end{tabular}

One may suspect that market-timing is a substitute for GP skills required to select and 
nurture fund portfolio companies. The positive coefficients for $P M E$ in specifications (3), (5) and (6) suggest the opposite: funds with good "selection and nurturing" skills, as measured by $P M E$, tend to also be better at timing the industry cycles. Specifications (4) through (6) in Table 3.1 show a positive relation between a GP's previous fund's TTR and the current fund's $T T R$. This is evidence that timing ability is persistent at the GP level. The fact that all of these relations are uniformly weaker when timing is measured against the broad market benchmark (Panel B of Table 3.1) is consistent with greater timing ability by GPs at the industry level. ${ }^{7}$

In summary, this section has developed a simple but potentially powerful measure of GP market timing ability. Timing ability appears to have significant positive value to LPs. Furthermore, it appears more related to industry returns than to market returns and is persistent at the GP level. I now turn to a more detailed discussion of hypotheses, development of empirical tests, and a discussion of results.

\footnotetext{
${ }^{7}$ Panel A of Table A.1 reports similar regressions but with additional control variables that proxy for possible measurement errors in TTRs driven by systematic risk's misspecification: industry return over the fund life-time and its interactions with the respective variable(s) of interest. The results appear largely unchanged from those in Panel A of Table 3.1. The only meaningfully different coefficient is that on PME suggesting that the correlations between TTR and PME may indeed arise spuriously (yet unlikely to be as large). Same conclusion follows from Panel B of Table A.1 where I simulate random exits for actual fund operation dates and industry return paths across different fund risk assumptions. The tests of conditional correlations between past TTRs and future PMEs, as described in Section 5.5.1.1, shall be free of this concern though.
} 


\section{HYPOTHESES AND METHODS}

\subsection{Related Literature}

The question of market timing by private owners connects to a large body of literature on initial public offerings (IPOs) and mergers and acquisition (M\&A) waves in the context of either adverse selection (signalling) problems or some form of investor irrationality. ${ }^{1}$ However, there are few studies of market timing track records of institutional money managers that specialize in investing in private companies with an explicit horizon for exit.

Lerner (1994) examines the choices of venture-backed biotech firms to raise capital by IPO or through private financing during 1978-92. He concludes that venture capitalists can time the market by issuing before the sector declines and that experienced VCs appear more skilled in this way. More recently, Ball, Chiu, and Smith (2011) argue that the biotech sampleperiod of Lerner (1994) was anomalous. Using data on 3,477 IPOs and 4,486 acquisitions of venture-backed companies over 1978-2009, they find evidence consistent with firms reacting to favorable exit conditions ("pseudo-timing") rather than attempting to take advantage of investor over-optimism. This conclusion is based on the lack of evidence that IPOs precede negative market/sector return as well as IPO returns being statistically lower than those after exits through M\&A. Kaplan and Strömberg (2008) summarize empirical evidence consistent with buyout GPs taking advantage of market timing, including the relative (mis)pricing between debt and equity. Combining the results of Kaplan and Stein (1993), Axelson et al.(2010) and Guo et al.(2011), the authors report expansion of the industry capital-to-cash-flow ratios

\footnotetext{
${ }^{1}$ Ritter (1991), Loughran and Ritter (1995) find that the new issues in the low IPO volume periods perform better than those in the high-volume periods. Baker and Wurgler(2000) document evidence consistent with opportunistic market timing by firms as a higher fraction of equity in aggregate issuance preceded periods of low market returns. Lowry (2003) focuses on the role of asymmetric information and concludes that adverse selection costs, although statistically significant, are economically small in front of "demands for capital and investor sentiment".
} 
as an important driver of the mean absolute returns for the sample of buyout deals undertaken in 1980-2006. Kaplan and Strömberg (2008) also elaborate on much higher responsiveness of buyout leverage to the credit market conditions as opposed to that of public corporations which may point to GPs' ability to capitalize on apparent debt mispricing. ${ }^{2}$

\subsubsection{Pseudo-timing}

There are two alternative explanations to the market timing skill of GPs that are also consistent with PE funds TTR exceeding one and persisting (as per Section 3). First, GPs do not have any superior information but a rush-to-exit reflects the variation in broad market and industry condition for exits, consistent with rational (yet uninformed) behavior models of Schultz (2003) and Pastor and Veronesi (2005). ${ }^{3}$ Following Ball et al.(2011), I refer to this alternative as Pseudo-timing. ${ }^{4}$ Simply put, a "sell after market run-ups" trading rule can be implemented without the costly help of the agent.

In fact, such investment timing by GPs may even generate utility losses to LPs since asset valuations may reflect time-varying risk premia. One way to conceptualize this possibility is with the notion of cash flow liquidity risks that LPs have to bear (e.g., with regards to yet undrawn commitments that may not be offset by the distributions from other funds in the portfolio). The cash squeeze that many endowments and pension funds endured in the 2008 financial crisis has sparked a research interest in liquidity premia appropriate for private equity investing. ${ }^{5}$

It is important to realize that gains from Pseudo-timing do not provide a compensation

\footnotetext{
${ }^{2}$ Recently, Ang, Chen, Goetzmann and Phalippou (2013) reconfirm this capital market segmentation hypothesis having extracted the private equity time-varying excess return from pools of fund cash-flows via a Bayesian MCMC estimation.

${ }^{3}$ Schultz (2003) demonstrates that mean-reversion coupled with a decision rule of issuing after market run-ups would be observationally similar to informed trading. Pastor and Veronesi (2005) develop a model of "rational IPO waves" where issuance volume varies endogenously as a function of market conditions without any overreactions by investors or differences in cash-flow signal precisions.

${ }^{4}$ Although we adjust the TTR numerator for the fund lifetime mean market return, it generally does not equal the expected market return in each period.

${ }^{5}$ For example, see Franzoni, Nowak, and Phalippou (2012), and Sørensen, Wang, and Yang (2014)
} 
for these risks. To see this, consider an extension of the Merton portfolio choice framework that encompasses liquid and illiquid risky assets as per Ang, Papanikolau, and Westerfield (2011). ${ }^{6}$ The authors model illiquidity as the stochastic arrival of trading opportunities so that immediate consumption can only be financed with liquid wealth (either risky or risk-free asset). The likelihood of a suboptimally high weight of the illiquid risky asset in states of high marginal utility of consumption causes lower target allocations to risky assets overall and the illiquid one (i.e. private equity) specifically. Therefore, if private equity weights were to increase in these high marginal utility states (i.e. as a result of Pseudo-timing), the equilibrium expected returns required to support a given target allocation to the illiquid asset would need to be higher. ${ }^{7}$ Hence, to assess the economic value-added from market-timing by GPs, it is necessary to separate any such gains from the Pseudo-timing alternative.

\subsubsection{Footprints of PE Activity}

The second group of alternative explanations pertain to the causal effect of private equity fund operations on the behavior of public firms and investors. A number of recent studies document evidence consistent with the peer firms responding to governance threats by changes in investing and operating policies. ${ }^{8}$ In particular, Aldatmaz (2012) finds that private equity investments cause financial and operating changes in publicly listed firms in the same countryindustry. Thus, it could be that the industry cash flow prospects change because private equity funds alter their industry participation. I call this Footprint-on-firms.

Both channels, market-timing and Footprint-on-Firms, may give rise to observationally

\footnotetext{
${ }^{6}$ The key implications are (i) higher allocation to risk free asset, (ii) low and path-dependent substitutability between liquid and illiquid assets, (iii) lower post-rebalancing weights of illiquid asset than a long-term optimal allocation.

${ }^{7}$ Similarly, private equity distributions in states of low marginal utility of consumption are more likely to be reinvested in the liquid risky asset which attenuates the positive effect of timely exits (as the avoidance of period of low market returns).

${ }^{8}$ See Berstein, Lerner, Sørensen and Strömberg (2011), Aldatmaz (2012) in context of private equity participation; Gantchev, Gredil, and Jotikasthira (2013) in context of hedge fund activism. Bernstein et al.(2011) and Aldatmaz (2012) consider the effect of private equity funds' participation on the country-industry performance and find that increases in private equity participation lead to higher productivity and employment growth, contrary to a popular belief that private equity simply takes away from the surplus of other stakeholders.
} 
similar event-time patterns. It could be also a Price Distortion. That is, the market price may temporarily decrease to absorb the increased supply of certain types of assets coming from admittedly informed investors (i.e., private equity GPs), whereas the industry down-turn fails to materialize. Note that neither Footprint-on-Firms nor Price Distortion necessarily imply gains to LPs from GPs' cashing-in earlier.

\subsection{Hypotheses}

In light of the discussion above, it is necessary to rely on cross-sectional tests to disentangle the effect of market-timing and the associated gains to LPs from the alternative explanations. The traditional route in the literature has been to compare IPO exits with other exits. ${ }^{9}$ However, this cross-sectional approach may not be the best for examining GP market-timing ability.

\subsubsection{Are non-IPO Exits Informative?}

Consider a hypothetical 7-year old buyout fund that has yet to liquidate most of its investments. Suppose the GP anticipates the industry-wide cash flows will be notably below market expectations in the near term but healthy in the long-run. Assume there is another fund approaching the end of its investment period that has yet to deploy its capital. GPs of the second fund may agree to buy the holdings of the first fund at prices close to publicly-traded comparables. They may in fact do so while fully sharing the belief about an upcoming downturn and yet still be taking the first-best action from their LPs' perspective. ${ }^{10}$ Hence, the exits by the first fund would be informative of industry return expectations even absent an IPO. Likewise, corporate buyers may have different investment horizons from that of the seller. Thus, exits through trade-sale may be as informative about GPs' expectations as sales through an IPO.

\subsubsection{Exploring Agency Costs for Identification}

The assumption that GPs take first-best actions for LPs is a strong one. Robinson and Sensoy (2013) find that PE funds' distributions cluster too much around "waterfall" dates for

\footnotetext{
${ }^{9}$ For example, Lerner (1994), Ball et al. (2011)

${ }^{10}$ Just the wealth transfer from outside creditors (that overestimate the true collateral value) may exceed how much the second fund "overpays". Also, the portfolio company improvement may yet to be fully realized by the first fund.
} 
that assumption to be realistic. But, the conditional revelation of the GP's private signal could result precisely from the agency relationship. Continuing with the previous example of a 7-year buyout fund, assume that the fund has performed well enough for GPs to have a substantial performance fee in that fund. If fund investment value deteriorates at the end of the fund contractual term (e.g. 10-12 years), the carried interest may vanish too. By rushing to sell the fund holdings, not only do GPs secure performance fees, but they also lock-in a relatively high performance rank among peer funds which can help attract investors in future funds. ${ }^{11}$

In contrast, there is hardly any benefit to GPs from exiting investments before the industry downturn if the performance to-date is poor. Asset liquidation would amount to suboptimal early-exercise of an option (to earn carry and improve performance rank) and reduce asset management fees. ${ }^{12}$ Therefore, it is possible that skilled GPs facing such a survival risk would likely seek to retain fund assets ahead of the turbulent times for the same reason that optionholders want the underlying asset volatility to increase. However, since such an asset hoarding may tarnish GPs' reputation with investors and adversely affect future fundraising, one would expect it to be limited to GPs that face immediate survival risk only (i.e. were unable to raise a follow-on fund). That would be also consistent with the framework of Chung et al. (2011) as well as empirical finding by Aragon and Nanda (2011) in hedge funds context.

\subsubsection{When Do Exits Convey Less Information?}

Suppose that our hypothetical fund has performed very well but already divested its best deals (i.e. those yielding the highest performance fees). The remaining holdings in the fund's portfolio would then likely be comprised of the deals that failed to payout well. Provided that the fraction of this residual in the total distributions to date is small, its option value (which increases in the assets idiosyncratic risk as well) may still dominate any expected loss of value to the fund's carry amount due to the likely deterioration in the industry-wide factors.

\footnotetext{
${ }^{11}$ Chung, Sensoy, Stern, and Weisbach (2011) show that much of GPs' wealth derives from fees in not yet raised funds.

${ }^{12}$ Some funds have the basis for asset management fees switching from committed to invested capital after the investment period elapses. See Robinson and Sensoy (2013).
} 
Thus, as the value of the residual fund assets gets small in front of the amount of carry already cashed-in, the incentive for GPs to reveal a negative market-timing signal diminishes. Meanwhile, a low pace of distributions over the remainder of the fund's life is also consistent with a scenario when GPs have been expecting improvements in the comparable valuations during that period (i.e., may contain a positive market-timing signal). ${ }^{13}$

Similarly, the divestments undertaken earlier in the fund's life, while the residual exposure of GP's carried interest has remained high (or very little carry accrued yet), should contain relatively less of the market-timing consideration. Such differences in the exits motives that depend on the phase of the funds' life naturally yield settings for placebo tests.

\subsubsection{Potential Power Drains}

Even if the incentives to act on the timing signal are in place, the signal may not arrive or some GPs may not notice it (e.g., because of lower skill). Also, GPs might be too diversified or could hedge their undesired exposures elsewhere. ${ }^{14}$ Prior research suggests that persistence in GP performance is particularly strong in the worst quartile of funds. ${ }^{15}$ The substantial heterogeneity of PE fund returns is a statement about the high total risk of these funds, but also allows for considerable heterogeneity in GP skill levels. Gervais and Strobl (2012) study the industrial organization of asset management and show that in equilibrium high-skill and low-skill managers pool into opaque funds, while medium-skill managers separate into transparent funds. It is hard to find a less transparent example of delegated money management than private equity.

\footnotetext{
${ }^{13}$ As industry-wide returns improve (yet remain small in front of the assets' idiosyncratic returns), the exit choice will be increasingly driven by positive realizations of the idiosyncratic risks which, by definition, are uncorrelated across the assets. Hence, the remaining exits would be less clustered in time, all else equal. Equivalently, there will be fewer distributions per unit of time.

${ }^{14}$ However, finance professionals are often legally prohibited to undertake any personal investing activities potentially jeopardizing best actions in the interests of clients or their employer. There is little evidence suggesting how strong and common such clauses are but GP risk-aversion combined with basis risk could also limit these hedging activities.

${ }^{15}$ For example, see Kaplan and Schoar (2005), Phalippou and Gottschalg (2009), Harris et al.(2013a,b).
} 


\subsubsection{Combining Thoughts}

The evidence of successful cash-flow timing track records by PE funds presented in Section 3 combined with the discussion in this section yields the following hypotheses:

H1 : PE managers have valuable private information about public equity valuations (i.e., GPs are Informed).

In other words, some GPs can predict returns of certain public equities because of a superior information about either future cash-flows of these firms, or investors' portfolio demands for such assets, or both. However, in any sample there will be funds that ex-post timed market peaks and troughs (better than others). Therefore, for a cross-sectional test of this hypothesis one needs an ex-ante indicator of fund market-timing skill (i.e., to define Informed GPs versus not). I will use fund TTR-to-date for this purpose and focus on the fund primary industry valuations which allow for a sharper focus on the learning channel than market-wide returns. If $H 1$ holds, ceding the cash-flow timing rights to GPs may result in additional benefits to LPs (or costs). A corollary to $\boldsymbol{H} 1$ is that TTR persists across funds by the same GP as shown in Table 5.1.

$\boldsymbol{H 2}$ : High rates of fund distributions predicts lower market returns when the value of GP's carried interest is at risk.

That is, the benefits of ceding the cash-flow timing rights to GPs are more pronounced when such actions are more concordant with GPs wealth maximization. A corollary to $\boldsymbol{H} 2$ is that when a GP is either not Informed or not incentivized, the fund distributions do not predict market returns. I will proxy for GPs' carried interest accrual (the "skin in-the-game") by levels of the fund net-of-fees performance to date, assuming $0(8 \%)$ hurdle rate for venture (buyout) funds. If this hypothesis holds, we can conclude that (i) the agency aspect of the GP-LP relations is important for PE fund performance (possibly even beyond the markettiming dimension), (ii) nonetheless, LPs should expect the market-timing by GPs to positively contribute to PE fund returns (to the extent that GPs are expected to earn positive carry). 
H3 : Risk-shifting behavior by an Informed GP is more likely to have an adverse effect on LP portfolios as compared to risk-shifting behavior of an uninformed GP.

GPs may seek to retain fund assets ahead of elevated market volatility when their survival is jeopardized. As discussed above, GPs are option-holders that want the underlying asset volatility to increase. Provided that high volatility is typically associated with low returns, these actions (when successful) would tend to result in lower Sharpe-ratios for LPs. The question is whether informed GPs are more successful in correctly predicting such turbulent times in the industry (while being as incentivized as their uninformed peers). If the answer is yes, informed GPs will be a drag on LP portfolio performance.

There are two corollaries to hypothesis $H 3$. $\boldsymbol{H 3 A}$ - when below the performance fee hurdle, informed GPs create less value to their fund investors through holding period abnormal returns than uninformed GPs. H3B - informed GPs that have had poor current fund performance but do not face immediate survival risk are less likely to engage in risk-shifting.

If $H 3$ holds while $H 2$ fails, PE funds in general may command higher risk premia than previously estimated. ${ }^{16}$ If both $H 2$ and $H 3$ hold, private information represents a "double-edged sword" since GPs would return capital before an industry downturn when the fund performance has been good but will retain capital through a market downturn (typically associated with higher volatility) when their overall performance has been bad. In either case, LPs' choice of a PE manager should incorporate GPs' market-timing track record as well as the likelihood of subsequent fundraising difficulties that may trigger the adverse incentives to risk-shift. Note that either $\mathrm{H} 2$ or $\mathrm{H} 3$ imply $\mathrm{H} 1$ but the converse is not true.

The discussion so far has not differentiated between types of funds (e.g., buyout and venture), but it seems plausible that the logic should apply to all cases where managers could have valuable private information (or the skill to extract it). Therefore, I will not distinguish between types of funds in the hypotheses testing. The following definitions are helpful for formulating

\footnotetext{
${ }^{16}$ For example, as in Franzoni et al.(2012), Sørensen et al.(2014).
} 
specific tests.

- Industry Return - return of a representative portfolio of publicly traded equities for the fund's industry.

- Informed Rush - a period of high rate of distributions from a fund to LPs when (a) the fund GP has a positive track record of market-timing, and (b) the fund to-date performance enables the GP to receive carried interest (e.g., if the fund were to resolve immediately).

- Informed Stays - a period of low rate of distributions after the end of investment period when (a) the fund GP has a positive track record of market-timing, and (b) the fund significantly underperforms its peers to-date and has not yet raised a successor fund.

\subsection{Research Design}

Most tests in my analysis are obtained by estimating versions of the following model:

$$
\text { IndustryReturn }_{i j, 1: 12}=\text { BTreated }_{i j} \text { Rush }_{i j}+\gamma_{1} \text { Treated }_{i j}+\gamma_{2} \text { Rush }_{i j}+a_{j}+\epsilon_{i j},
$$

where IndustryReturn $n_{i j, 1: 12}$ is the mean monthly Industry Return over the 12 months following the distribution quarter when the NAV of fund $i$ drops below $X \%$ of the total distributions prior to that quarter,

Treated $_{i j}$ is a binary variable denoting Informed Exits,

Rush $_{i j}$ is the fraction of distributions over the preceding 6 quarters in the funds' total distributions to date,

$a_{j}$ is fund group fixed effects (some specifications will include additional controls), $X \%$ is the distribution threshold defining fund $i$ stopping-time.

This specification amounts to a difference-in-difference estimation which accounts for a time-varying supply of market-timing signals from PE fund cash flows. For some valuation peaks there might not be enough mature funds to consider timing these peaks, particularly, 
when testing at the industry level. Once in the harvesting stage, GPs are generally unconstrained in the choice of the exit year, so time fixed effects would be inappropriate controls. Instead, I cluster standard errors by stopping-quarters.

The definition of Treated uses the information set for fund $i$ stopping-quarter so that there is no look-ahead bias in the construction of the key variables. The appropriate threshold, $X$, is an empirical question so I examine several values (between 5\% and 25\%) and report two: $15 \%$ and $20 \%$. For simplicity and transparency, I use a range of reasonable values over the alternative of modeling fund-specific or group-specific thresholds. The higher the threshold, the more exposure GPs (subjected to the treatment effect) have remaining, the less different the interpretation of their Rush from that in the control group (see below). ${ }^{17}$ The lower the threshold, the lower the sensitivity of the market-timing signal filtration, the greater the ambiguity about the incentives driving the most recent exits (as discussed in the previous section). ${ }^{18}$ Note that the threshold, $X$, affects not only the stopping-time but also the Rush amount. ${ }^{19}$

The primary coefficient of interest is $\beta$ which compares the relation between Rush and Industry Return following the exits by Treated funds with that in a control group. A significantly negative $\beta$ would indicate that Informed Rush precedes lower Industry Return, as per hypothesis $H 2$.

\subsubsection{Identification Strategy}

In one set of tests, the control group includes all funds that did not meet the criteria of Informed GP which means that upon reaching the threshold $X \%$ they either (a) did not have a positive track record of market-timing, or (b) the fund to-date performance was below the hurdle rate. These tests (i) assure that the stopping-time definition based on $X$-threshold is not responsible for the results, and (ii) identify the market-timing effect from a Footprint-onFirms effect. The estimates are presented in Section 5.5.1. They constitute a comprehensive

\footnotetext{
${ }^{17}$ This idea underlies some of the placebo tests discussed in Section 5.5.1.

${ }^{18} \mathrm{Also}$, fewer funds of relatively recent vintage years reach the threshold.

${ }^{19}$ In our sample, for about half of the funds there will be no difference across $15 \%$ and $20 \%$ thresholds since both levels are crossed simultaneously.
} 
examination of hypotheses $H 1$ and $H 2$ while identifying GPs market-timing skills from the effects of Pseudo-timing and Footprint-on-Firms.

Note that for Treated funds, Rush is proportional to carried interest at a very specific time in a fund's life - when it is nearly finished cashing in its carried interest. Hence, a comparison with the effect of control fund Rush times will isolate market-timing from the Footprint-onFirms. In other words, the Footprint-on-Firms effect of Rush will be present in both groups, treatment and control, while the market-timing effect will be in the treatment group only. ${ }^{20}$

Vintage year fixed effects (in place of group fixed effects) account for exit conditions varying across funds that are associated with the Pseudo-timing alternative (i.e. time-varying risk premia). I include additional controls in some specifications to address industry-quarter variation that vintage year fixed effects do not absorb. Conceptually, I need variables with market return predictive power to measure the incremental effect of variation in Rush across Informed Exits. ${ }^{21}$ I follow Goyal and Welch (2008) in the return-predictive variables selection, re-defining variables at industry level where appropriate. The additional controls common across industries include CAY Ratio of Lettau and Ludvigson (2001), VIX index, U.S. Treasury yields and corporate credit spreads. ${ }^{22}$ Industry specific controls include price-earnings and book-to-market ratios de-meaned using the respective 5-year moving average to account for heterogeneity across industries. Following Ball et al.(2011), I also control for pre-exit industry returns by including the industry cumulative excess return versus S\&P500 over 5-years prior to the stopping-quarter.

\footnotetext{
${ }^{20}$ In additional tests, I verify that the results are unlikely to be due to the magnitude of Footprint-on-Firms being cross-sectionally correlated with the treatment assignment by comparing Rush effects in the treatment and control groups in periods different from the stopping-time and considering definition of treatment group that maximize expected Footprint-on-Firms effects.

${ }^{21}$ In arbitrage-free asset-pricing framework, these variables inform about the state of investors marginal utility. Thus, another way to interpret these tests is whether GPs' timing skills add value once controlling for the variation in investors' marginal utility.

${ }^{22}$ It has been shown that much of predictive ability of Lettau-Ludvigson CAY comes from the fact that its construction uses "lookahead (in-sample) estimation regression coefficients". For example, see Goyal and Welch (2008). To the extent $\beta$ estimates continue to hold with and without CAY, the predictive capacity of Rush in Informed Exits is orthogonal to the innovations in the U.S. aggregate consumption and income.
} 
To guard against the Price Distortion alternative, I examine the reversion of initial returns following Informed Rush versus those in the control group. Suppose the subsequent returns were driven purely by a selling pressure, possibly magnified by "copycat" behavior of some investors tracking PE actions. If this were the case, we would expect the valuations in the affected industries to rebound as the pressure subsided while the expected deterioration in the industry fundamentals failed to materialize. Meanwhile, replacing the dependent variable in model (4.1) with funds' holding period abnormal returns and breaking Treated into its skill and incentive components yields a test of $\mathrm{H} 3$ corollary. That is, lower holding period abnormal returns of funds run by informed GPs without the accrued performance fee incentive to optimally exit would be consistent with a deviation from the first-best decision (from the LPs' stand point). ${ }^{23}$

\subsubsection{Alternative Control Group}

As helpful as it can be to identify GP timing skill from Footprint-On-Firms, the control group comprised of a subset of funds is imperfect. Its limitations originate mainly from two (conflicting) objectives: (i) likely high false-negative assignment of treatment, (ii) highly imbalanced fund population over time and industries. It is possible that, conditional on the assumption that exit-Footprint is zero, one can do much better by estimating the market-timing effect against random exits by the same fund (rather than against actual exits by other funds). Therefore, in Section 5.5.2 I run additional tests against hypothetical stopping-time and Rushamounts of the sample funds. These tests provide more accurate and robust (i.e. to Pseudotiming alternative) estimates of $\beta$ but, unlike the results with a control group comprised of actual funds (5.5.1), yield no power to distinguish GPs' market-timing skill from the Footprint alternative. They furnish additional insights about hypothesis $\mathrm{H} 2$ and its corollary, in particular, allowing for testing of Industry Return predictability by Rush unconditional on the treatment

\footnotetext{
${ }^{23}$ In other words, those GPs would then appear to be ignoring the private information regarding the industry valuations in order to keep their option to earn performance fees alive (rather than to maximize the total performance for LPs).
} 
assignment.

To conduct these additional tests, I develop a simulation-based estimator that shares much in common with Simulated Method of Moments, yet better suites this problem. ${ }^{24}$ In short, I (i) estimate a model of fund fixed effects for stopping-time and Rush (henceforth auxiliary model), (ii) independently simulate 1,000 blocks of up to 100 random exits per fund under this model (henceforth, independent simulations), and (iii) pool Model (4.1) (main model) estimates over these independent simulations. The estimates that I obtain are not sensitive to the simulation starting point, are very unlikely to be driven by an ill-specified null hypothesis, and have good finite-sample properties. ${ }^{25}$ In Section 5.5.2, I also test hypothesis $H 3$ using a slight modification of Model (4.1) and a subset of the sample augmented with the simulated exits. The modification amounts to using standard deviations of past Industry Returns as the dependent variable instead of the future means and restricting the sample of actual fund to those that lived long enough.

Finally, to determine what drives Informed Rush, GPs' expectations about industry cashflow news or about discount factor innovations, I utilize model 4.1 but swap the future industry returns with Rush as the the dependent variable and instrument the returns with, respectively, proxies of industry cash-flow news or discount rate news. Such a design allows me to address the problem that there are arguably no proxies of, e.g. cash-flow news uncorrelated with discount-rate news (and visa-verse). Treating the proxy for the other channel as the included instrument enables me to better absorb the unrelated variation while making sure that the channel of interest is, in fact, correlates with Rush tightly enough. These tests are implementable using both types of control exits: those of other funds and the simulated ones for the treated funds. Section 5.5.3 has the results and further details.

In summary, my key identifying assumption is that the alternative explanations to the timing

\footnotetext{
${ }^{24}$ Section 5.5.2 and A.2 provide further details, discussion as well as robustness and falsification tests.

${ }^{25}$ See Appendix A.8.
} 
skill do not depend on the changes in GPs' own wealth exposure to the industry valuations. I verify this assumption via a series of placebo tests and event studies. I obtain the main results (hypotheses $H 1$ and $H 2$ ) using a simple difference-in-difference estimator and then verify them via simulations, essential for testing $H 3$. 


\section{MAIN RESULTS AND ANALYSIS}

\subsection{Informed Exits Versus Uninformed}

Figure 5.1 reports results from simple event studies by examining cumulative Industry returns from -8 to +10 quarters around the stopping-time as defined by a crossing of the $15 \%$ threshold of NAV/(total distributions to-date) for funds with high (above vintage year median) Rush. The light-gray line represent the mean of Treated funds, meaning where TTR-to-date $>1$ and IRR-to-date $>$ Hurdle Rate. We can see that in comparisons to all other funds with high Rush (the dark-gray line), the Industry returns are on average significantly lower following the stopping-quarters of Treated. Panel A reports results for the full sample period. Panel B shows that this clear difference remains even after excluding 2 years associated with particularly dramatic market declines (2001 and 2008). Panels A and B also suggest that the results are unlikely to be driven by differences in the systematic risk, since the cumulative returns are similar from 8 to 3 quarters before the stopping-time. ${ }^{1}$ This evidence is consistent with hypotheses $H 1$ and $H 2$. While this figure shows the main result clearly, the additional tests are necessary for determining if it is robust to alternative explanations.

\footnotetext{
${ }^{1}$ In Figure A.5, I provide further evidence against the risk-based explanation by showing that a quarterly rebalanced portfolio based on Informed Rush yields statistically significant 60-90bps per quarter over FamaFrench 3-factor model.
} 


\section{Figure 5.1: Informed Rush and Industry returns: Event Studies}

This figure plots cumulative Industry returns around the stopping-time for funds with a clustering of exits (henceforth, Rush) above the median for the respective vintage year. Rush is defined as a fraction of distributions over 6 quarters before the stopping-time in the fund total-to-date. The stopping time is defined as the distribution quarter at which NAV dropped below $15 \%$ of the fund total distributions to-date. The Industry returns are those of S\&P500 subindex of the GICS sector that the fund specializes in. The light-gray (Treated) line is the mean across funds that as of the stopping-quarter meet two criteria: (a) positive track record of market timing as proxied by $T T R>1$ (Section 3), (b) the fund to-date performance enables GPs to receive carried interest (if the fund were to resolve immediately) as proxied by net-of-fees $I R R$ above the hurdle-rate. The dark-gray line comprise of funds that do not meet these two criteria. Panel A reports results for the full sample. Panel B excludes stopping times that occurred in 2001 and 2008. The bars denote $95 \%$ confidence intervals.

Panel A: Full Sample of Exits: 1990-2013

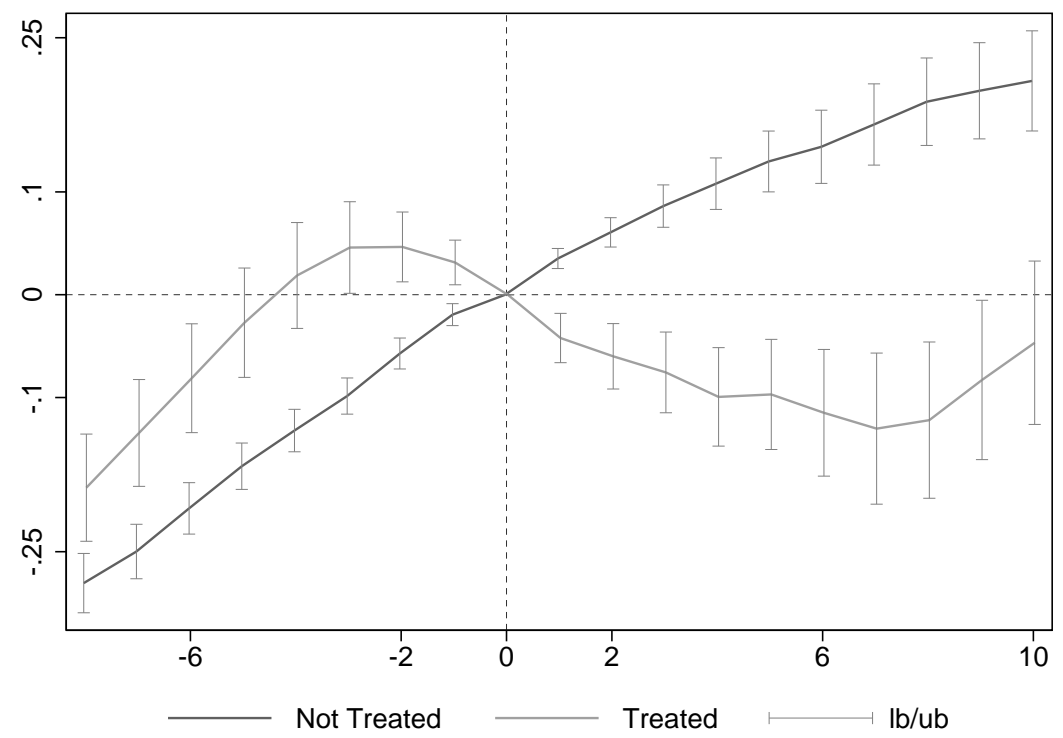

Panel B: Excluding Extremes: 2001 and 2008

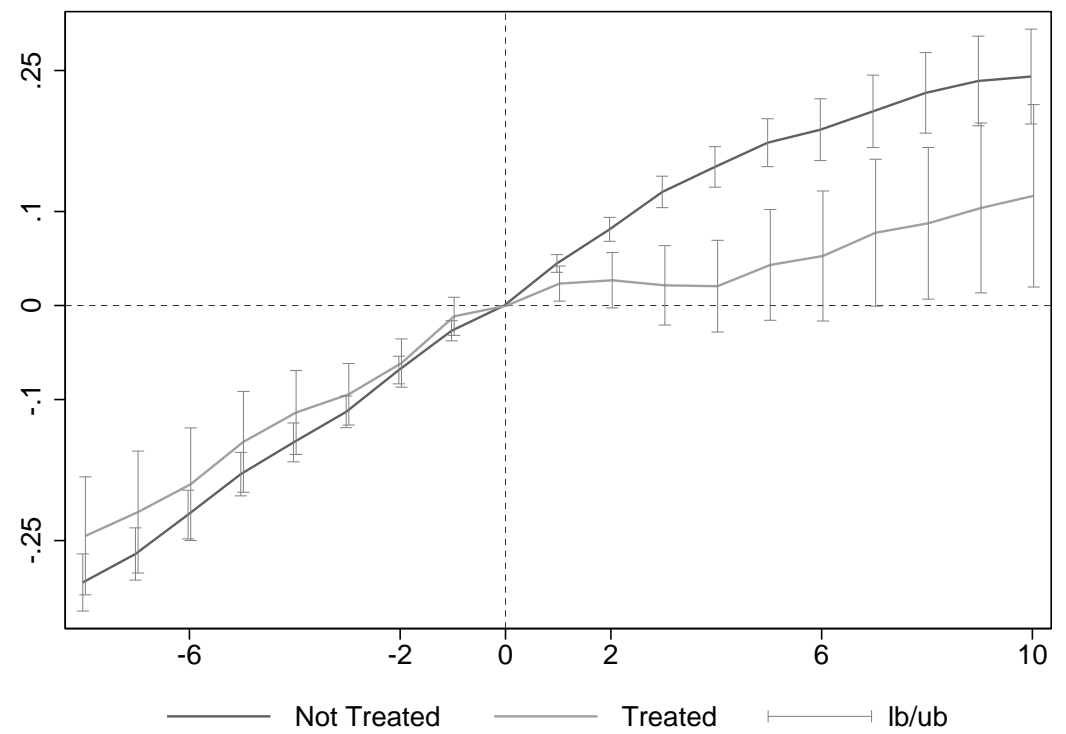


According to Figure 5.1, the industry share price underperformance following Informed Rush fades after 4-6 quarters and does not revert over the 10 quarter horizon plotted. A reversion would be expected if the underperformance were driven by the Price Distortion alternative discussed in Section 4. That explanation is also inconsistent with the pattern in Figure A.4B which plots a similar event study as Figure 5.1A but for the funds that did not "rush to exit" (Rush $<$ vintage median). It appears that when Informed and incentivized GPs procrastinate with trimming relatively small exposure (as manifested by "low-rush"), the industry share price performance tends to improve, just as we conjectured in Section 4.4.2. However the industry returns do not become abnormally good as if there were some short-lived distortions in the valuations caused by "copycat" behavior of some investors. Rather the returns become very close to these around the control group exits which, in turn, appear unchanged from before the stopping-quarter.

As discussed in Section 4, for Informed Exits, Rush is proportional to carried interest at a very specific time in a fund's life - when it is nearly finished cashing in its carried interest. Thus, while the Footprint-on-Firms effect of Rush will be present in both groups, treatment and control, the market-timing effect will be in the treatment group only. The identifying assumption is that the variation in the impact of PE fund participation on the industry is independent from the treatment assignment. Namely, that Rush by funds with good market-timing track records (i.e., high $T T R$ up to the exit date) and sufficiently high performance does not have stronger spillover effects on publicly traded peers than by the funds in the control group. Fortunately, this assumption is relatively easy to verify.

By estimating Model (4.1) within the sample of actual funds, I nest the event studies of Figure 5.1 and A.4 in a multivariate setting. This also allows for isolating the effect of GPs' timing skills from the rational responses to variations in exit condition over time (i.e., the Pseudotiming alternative discussed in Section 4). Table 5.1 reports these estimates. Columns (1) and 
(2) report the baseline specification (with controls comprised of fund vintage-year fixed effects only) for the stopping-quarters corresponding to $15 \%$ - and 20\% NAV/(total distributions to-date) thresholds respectively. Columns (3) and (4) expand the set of controls to include month- and industry-month covariates that previous literature considers informative about expected returns. Subsequently, I will refer to these interchangeably as predictive covariates or Pseudo-timing factors.

Panel A of Table 5.1 reports results for the baseline definition of the treatment group: funds with $T T R>1$ and $I R R>H u r d l e$ as of the respective stopping-time. For expositional clarity, I denote this dummy as a product of two dummies, TTRgI $* \operatorname{IRRgHR}$. Recall that our main coefficient of interest is on its interaction with $R u s h, \beta$. Regardless of the specification, it is significantly negative. Meanwhile, the coefficient on Rush itself is positive but statistically zero. Thus, the data are highly supportive of hypotheses $H 1$ and H2: Informed Rush predicts lower Industry Return once the variation in exit conditions has been accounted for. 


\section{Table 5.1: Informed Rush versus Uninformed}

This table reports predictive regressions of Industry returns by Informed Rush. Industry returns are of S\&P500 subindex corresponding to the GICS Industry sector of the fund specialty. Informed Rush is a proxy for the carried interest "cashed-in" by GPs with a positive track record of market timing in the past, as measured by TTR (Section 3). As discussed in Section 4 and 5.5.1, I estimate $\beta$ from the following difference-in-difference model:

$$
E\left[\text { IndustryReturn }_{i j, 1: 12}\right]=\text { BTreated }_{i j} \text { Rush }_{i j}+\gamma_{1} \text { Treated }_{i j}+\gamma_{2} \text { Rush }_{i j}+a_{j}
$$

where IndustryReturn ${ }_{i j, 1: 12}$ is a mean monthly Industry Return over 12 months following the fund $i$ stoppingtime, $R u s h_{i j}$ - a fraction of distributions (to LPs) over the last 6 quarters in the funds' total-to-date, $a_{j}$ - fund vintage-year fixed effects. In Panel A Treated ${ }_{i j}$ is a single dummy based on whether TTR (IRR) as of stopping quarter exceeds 1 (Hurdle-rate) while Panel B breaks it into the constituent dummies. Stopping-times in odd (even) numbered specifications are fund-quarter when fund NAV drops below $15(20) \%$ of the fund total distributions up to that quarter. Specifications (3)-(4) include additional return-predictive covariates, same in both panels. Standard errors in parentheses are clustered at stopping-quarters, $* / * * * * *$ denote significance at $10 / 5 / 1 \%$.

Panel A: Treated $\equiv(T T R>1) \times(I R R>H R)$

\begin{tabular}{|c|c|c|c|c|}
\hline & (1) & (2) & (3) & (4) \\
\hline TTRg1*IRRgHR*Rush & $\begin{array}{c}-0.025^{* * *} * \\
(0.007)\end{array}$ & $\begin{array}{c}-0.023 * * * \\
(0.007)\end{array}$ & $\begin{array}{c}-0.013 * * \\
(0.005)\end{array}$ & $\begin{array}{c}-0.013^{* *} \\
(0.005)\end{array}$ \\
\hline TTRg1*IRRgHR & $\begin{array}{c}0.002 \\
(0.003)\end{array}$ & $\begin{array}{c}0.003 \\
(0.003)\end{array}$ & $\begin{array}{c}0.003 \\
(0.002)\end{array}$ & $\begin{array}{c}0.003 \\
(0.002)\end{array}$ \\
\hline Rush & $\begin{array}{c}0.004 \\
(0.005)\end{array}$ & $\begin{array}{c}0.002 \\
(0.004)\end{array}$ & $\begin{array}{c}0.007 \\
(0.005)\end{array}$ & $\begin{array}{c}0.006^{*} \\
(0.004)\end{array}$ \\
\hline Industry CAR & & & $\begin{array}{c}-0.219 \\
(0.287)\end{array}$ & $\begin{array}{c}-0.224 \\
(0.252)\end{array}$ \\
\hline Industry $\mathrm{P} / \mathrm{E}$ & & & $\begin{array}{c}-0.005^{* *} \\
(0.002)\end{array}$ & $\begin{array}{c}-0.005^{* * *} * \\
(0.002)\end{array}$ \\
\hline Industry $\mathrm{B} / \mathrm{M}$ & & & $\begin{array}{c}-0.037^{* *} * \\
(0.015)\end{array}$ & $\begin{array}{c}-0.023^{* *} \\
(0.011)\end{array}$ \\
\hline CAY-ratio & & & $\begin{array}{l}0.549 * * * \\
(0.109)\end{array}$ & $\begin{array}{l}0.521 * * * \\
(0.099)\end{array}$ \\
\hline CBOE VIX & & & $\begin{array}{c}0.040^{*} \\
(0.023)\end{array}$ & $\begin{array}{c}0.036 \\
(0.024)\end{array}$ \\
\hline BAA-AAA spread & & & $\begin{array}{l}0.009^{*} \\
(0.005)\end{array}$ & $\begin{array}{l}0.009 * \\
(0.005)\end{array}$ \\
\hline AAA-UST spread & & & $\begin{array}{c}-0.030 * * * \\
(0.005)\end{array}$ & $\begin{array}{c}-0.029 * * * \\
(0.005)\end{array}$ \\
\hline UST 10-year yield & & & $\begin{array}{c}-0.009 * * * \\
(0.002)\end{array}$ & $\begin{array}{c}-0.010^{* * *} \\
(0.002)\end{array}$ \\
\hline UST 3-month yield & & & $\begin{array}{c}-0.003 * * * \\
(0.001)\end{array}$ & $\begin{array}{c}-0.003 * * * \\
(0.001)\end{array}$ \\
\hline Vintage FE & Yes & Yes & Yes & Yes \\
\hline Observations & 893 & 941 & 893 & 941 \\
\hline$R^{2}$ & 0.218 & 0.234 & 0.446 & 0.464 \\
\hline
\end{tabular}


Panel B: Treated $\equiv(T T R>1)+(I R R>H R)+(T T R>1) \times(I R R>H R)$

\begin{tabular}{lccccc}
\hline & $(1)$ & $(2)$ & & $(3)$ & $(4)$ \\
\cline { 2 - 3 } \cline { 5 - 6 } TTRg1*IRRgHR*Rush & $-0.031^{* *}$ & $-0.026^{* *}$ & & $-0.022^{* *}$ & $-0.021^{* *}$ \\
& $(0.012)$ & $(0.012)$ & & $(0.009)$ & $(0.010)$ \\
TTRg1*IRRgHR & 0.006 & 0.005 & & $0.006^{*}$ & 0.005 \\
& $(0.004)$ & $(0.005)$ & & $(0.003)$ & $(0.004)$ \\
TTRg1*Rush & 0.001 & -0.004 & & 0.008 & 0.004 \\
& $(0.011)$ & $(0.010)$ & & $(0.009)$ & $(0.009)$ \\
IRRgHR*Rush & 0.010 & 0.010 & & 0.004 & 0.009 \\
& $(0.010)$ & $(0.009)$ & & $(0.009)$ & $(0.008)$ \\
TTRg1, IRRgHR, Rush & Yes & Yes & & Yes & Yes \\
Vintage Fixed Effects & Yes & Yes & & Yes & Yes \\
Predictive covariates & No & No & & Yes & Yes \\
Observations & 893 & 941 & & 893 & 941 \\
$R^{2}$ & 0.225 & 0.239 & & 0.446 & 0.466 \\
\hline
\end{tabular}

The dependent variable is the subsequent 12-month average return of public firms in the primary industry of the fund. The magnitude of $\beta$ tells us how much lower monthly returns would be as we increase the Informed Rush. The inter-quartile range for the Rush is approximately 0.3 . This translates into $0.3-0.7 \%$ lower returns per month over the course of a year. Thus, the economic significance of the information in Treated is substantial. Ball et al.(2011) also question whether the post-exit returns are negative as possibly a stronger statement about the timing ability. Wald tests reject the null of $\beta+\gamma_{1}+\gamma_{2}=0$ at $5 \%$ confidence level in all specifications but (4). ${ }^{2}$

It is interesting to note that the $\beta$ estimates are about twice as large in specifications (1) and (2) as compared to specifications (3) and (4) indicating that substantial variation in Informed Rush can be explained by the publicly observable signals about expected returns. This fact suggests that GPs tend to not return capital when market observables point to relatively high risk premia (which is consistent with results in Robinson and Sensoy (2013)). Nonetheless, it follows from specifications (3) and (4) that the exit decisions by skilled and incentivized GPs appear to contain a significant information component that is likely absent from the public information set.

Next, Panel B of Table 5.1 breaks down the Treated-dummy definition into its constituents,

\footnotetext{
${ }^{2}$ Hence, the absolute returns are negative up to the vintage year fixed effect.
} 
$T T R>1$ and $I R R>$ Hurdle, and examines the effect of each interaction with Rush separately to formally test the corollary to $\mathrm{H} 2$. In this case, TTRg $1 * R u s h$ measures the predictive effect of Rush by funds that appear skilled but likely do not have as much skin in the game. For them, there is no in-the-money carry option that may vanish before the normal resolution time is past due. We see that none of these individual conditions has Rush associated with lower subsequent returns. But the negative coefficients on TTRg $1 * I R R g H R * R u s h$ (now truly a tripleinteraction) appear even stronger than in Panel A, although the magnitudes are not formally comparable between the two panels. Besides providing further evidence on the significance of GP agency, this result suggests that TTR-to-date is indeed a good proxy of GP market-timing skill since it predicts funds' propensity to sell closer to industry highs and buy around lows.

I scrutinize the assumption about the variation in the industry spillover effects across funds in relation to Footprint-on-firms alternative. First, I verify that lower Industry returns do not follow stopping-quarters of top-PME funds, conditional on TTR $<=1$. That is when treated funds are comprised of those exhibiting highest asset-nurturing skills and yet with a mediocre market-timing track record. Admittedly, these should be GPs with the highest potential for an industry impact through company turnarounds and operational engineering. Panel A of Table A.2 shows that, in settings like Model (4.1), such a treatment definition returns positive (but not consistently significant) estimates of $\beta$ (rather than negative as in the Table 5.1). Second, I examine if Informed Rush outside the stopping-quarter periods is associated with future Industry returns. That is, when there is less difference in the GPs' market-timing incentives between treated and control groups. Results of this placebo test are reported in Panel B of Table A.2 and show no statistically or economically significant relations that could justify reasonable doubts in the interpretations for Table 5.1.

\subsubsection{Does Rush Hurt Holding Period Returns?}

Next, I examine whether the portfolio gains that LPs experience due to the market-timing by Informed GPs (harvesting their performance fees) come at a cost of inferior holding period 
returns of their funds. Generally, if this were the case, we would expect that the gains from company selection and nurturing (as proxied by Kaplan-Schoar PME) to be negatively correlated with the gains from buying near the industry lows and selling at the peaks (as proxied by $T T R)$. Although results in Table 3.1 suggest that this correlation is actually positive, they do not provide evidence of the relation between the extent of exits' clustering as measured by Rush (Informed and not) relates to the funds' holding periods returns which represent a more significant component of the overall abnormal performance (on average). ${ }^{3}$

Moreover, we want to learn the abnormal holding period returns by funds where Informed GPs apparently refrained from exiting ahead of the market downturns. If their decisions "to stay" were driven by the objective to maximize the total performance for LPs, we would expect that the average holding period abnormal returns of their funds to be higher. ${ }^{4}$.

As discussed in section 4.4.2-4.3, a replacement of the industry returns subsequent to the stopping-times with the funds' holding period abnormal performance in model (4.1) yields the required tests.Table 5.1 reports the estimates. ${ }^{5}$ As in Panel B of Table 5.1, Treated-dummy is broken into its constituents, TTR $>1$ and $I R R>$ Hurdle. To zoom at GPs' portfolio company selection and nurturing effects, I add industry fixed effects to vintage-year fixed effects while there is no purpose to condition on the risk-premia covariates at the stopping time anymore. ${ }^{6}$

\footnotetext{
${ }^{3}$ As follows from Table 2.1 and Figure 3.1, average PME exceeds 1.3 for my sample while the average TTR is less than 1.1. Nonetheless, for $44 \%$ of funds in my sample TTR exceeds PME.

${ }^{4}$ So that GPs' informed decisions "to stay" could have been optimal from the overall performance maximization standpoint

${ }^{5}$ For brevity, I only report results for the stopping-quarter definition based on 15\%-NAV-to-Distributions threshold. The results are similar with a threshold between 10 and $20 \%$.

${ }^{6}$ Dropping industry fixed effects leaves the estimates largely unchanged and key takeaways intact.
} 


\section{Table 5.1: Does Informed Rush Sacrifice Holding Period Returns?}

This table reports estimates of the following model:

$$
E\left[H A R_{i j}\right]=\text { Breated }_{i j} \text { Rush }_{i j}+\gamma_{1} \text { Treated }_{i j}+\gamma_{2} \text { Rush }_{i j}+a_{j}
$$

where $H A R_{i j}$ is the holding period abnormal return of fund $i$ as measured by a natural log of Kaplan-Schoar PME at the latest available date (henceforth, Last PME) against the fund industry and the broad market in specifications (1) and (2), respectively. While in specifications (3) and (4), it a log of a ratio of Last PME (industry or market) to the PME as of the fund's $5^{\text {th }}$ anniversary. $R u s h_{i j}$ - a fraction of distributions (to LPs) over the last 6 quarters before the stopping-time in the funds' total-to-date, Treated $_{i j}$ denote dummy variables based on whether TTR (IRR) as of stopping quarter exceeds 1 (Hurdle-rate), $a_{j}$ - fund vintage-year and industry fixed effects. Stopping-time is the first fund-quarter with non-zero cash-flows when fund NAV drops below $15 \%$ of the fund total distributions up to that quarter. The sample includes funds with stopping-times of at least 7 years since inception. The industry and market returns are proxied by, respectively, S\&P500 subindex corresponding to the GICS Industry sector of the fund specialty and CRSP valued-weighed index. Standard errors in parentheses are clustered by fund vintage year, $* / * * * * * *$ denote significance at $10 / 5 / 1 \%$.

\begin{tabular}{|c|c|c|c|c|}
\hline & \multicolumn{2}{|c|}{ PME 0:T } & \multicolumn{2}{|c|}{ PME 5y:T } \\
\hline & $\begin{array}{l}\text { industry } \\
\text { (1) }\end{array}$ & $\begin{array}{l}\text { market } \\
(2)\end{array}$ & $\begin{array}{l}\text { industry } \\
\text { (3) }\end{array}$ & $\begin{array}{l}\text { market } \\
(4)\end{array}$ \\
\hline \multicolumn{5}{|l|}{ Rush Effects: } \\
\hline TTRg1*IRRgHR*Rush & $\begin{array}{c}0.068 \\
(0.602)\end{array}$ & $\begin{array}{c}0.034 \\
(0.624)\end{array}$ & $\begin{array}{c}0.415 \\
(0.568)\end{array}$ & $\begin{array}{c}0.362 \\
(0.536)\end{array}$ \\
\hline TTRg1*Rush & $\begin{array}{c}0.234 \\
(0.440)\end{array}$ & $\begin{array}{c}0.430 \\
(0.428)\end{array}$ & $\begin{array}{c}0.041 \\
(0.359)\end{array}$ & $\begin{array}{c}0.143 \\
(0.392)\end{array}$ \\
\hline IRRgHR*Rush & $\begin{array}{c}0.286 \\
(0.399)\end{array}$ & $\begin{array}{c}0.360 \\
(0.354)\end{array}$ & $\begin{array}{c}-0.058 \\
(0.398)\end{array}$ & $\begin{array}{c}0.053 \\
(0.358)\end{array}$ \\
\hline Rush & $\begin{array}{c}-0.514^{*} \\
(0.256)\end{array}$ & $\begin{array}{c}-0.567 * * \\
(0.242)\end{array}$ & $\begin{array}{c}0.104 \\
(0.224)\end{array}$ & $\begin{array}{c}0.073 \\
(0.205)\end{array}$ \\
\hline \multicolumn{5}{|l|}{ Base Effects: } \\
\hline TTRg1*IRRgHR & $\begin{array}{c}0.150 \\
(0.153)\end{array}$ & $\begin{array}{c}0.087 \\
(0.159)\end{array}$ & $\begin{array}{c}-0.025 \\
(0.175)\end{array}$ & $\begin{array}{c}-0.066 \\
(0.160)\end{array}$ \\
\hline TTRg1 & $\begin{array}{c}-0.342 * * * \\
(0.099)\end{array}$ & $\begin{array}{c}-0.239 * * \\
(0.092)\end{array}$ & $\begin{array}{c}-0.300 * * * \\
(0.086)\end{array}$ & $\begin{array}{c}-0.185^{* *} \\
(0.089)\end{array}$ \\
\hline IRRgHR & $\begin{array}{l}0.659^{* * *} \\
(0.120)\end{array}$ & $\begin{array}{l}0.718 * * * \\
(0.112)\end{array}$ & $\begin{array}{l}0.361^{* *} \\
(0.146)\end{array}$ & $\begin{array}{l}0.404 * * * \\
(0.132)\end{array}$ \\
\hline Vintage FE & Yes & Yes & Yes & Yes \\
\hline Industry FE & Yes & Yes & Yes & Yes \\
\hline $\operatorname{Sum}($ Rush Effects) & 0.074 & 0.257 & 0.502 & 0.631 \\
\hline p-value & 0.757 & 0.422 & 0.000 & 0.001 \\
\hline Observations & 796 & 796 & 796 & 796 \\
\hline$R^{2}$ & 0.383 & 0.433 & 0.271 & 0.279 \\
\hline
\end{tabular}


The differences across specifications in Table 5.1 amount to the dependent variable only. In specifications (1) and (2), it is Kaplan-Schoar PME at the latest available date (henceforth, Last PME) against the fund industry and the broad market, respectively. While the funds that had neither performance in excess of the hurdle rate nor a good timing track-record $(T T R>1)$ indeed appear to attain lower life-time PMEs when their exits cluster a lot towards the last few quarters of active operations (i.e. Rush $\approx 1$ ), all the interaction terms with Rush are positive. The cumulative effect on PME for Informed Rush (reported in the bottom of the table) is actually positive, although not significant statistically. Thus, I conclude that there is no evidence of holding period performance sacrifice by GPs exhibiting Informed Rush.

Meanwhile, the significantly negative coefficient on TTRg1 indicates that the "non-Rushing" Informed GPs who were not making any performance fees, have had significantly lower holding period returns for their investors than that the control funds. This would be expected if those GPs were primarily concerned with keeping their option to earn performance fees alive at a cost of LPs' value maximization objective. ${ }^{7}$ Consistent with the corollary to $\mathrm{H} 3 .^{8}$

In specifications (3) and (4), I focus on holding period returns specifically during the periods of exits (i.e. while Rush is measured). Therefore, I define the dependent variables as a $\log$ of a ratio of Last PME (industry or market) to the PME as of the fund's $5^{\text {th }}$ anniversary. To keep the results comparable across specifications while meaningful in all of them, I constrain the sample to funds with the stopping-time of at least 6.5 years since inception. ${ }^{9}$ The results regarding TTRg1 (and thus corollary to $\mathrm{H} 3$ ) continue to hold firmly in specifications (3)-(4) suggesting that much the performance deterioration for the funds run by those "non-Rushing" Informed (but yet to become very rich) GPs actually occurs after the investment period completion.

\footnotetext{
${ }^{7}$ As discussed earlier, exiting earlier may also reduce the amount of performance-independent fees the GPs charge to their funds.

${ }^{8}$ In the untabulated analysis, I also verify that funds run by informed GPs that appear to rush have significantly shorter life than the control group, whereas when Rush is near zero, the life is longer, albeit insignificantly.

${ }^{9}$ The results in (1)-(2) little change if all funds with 15\%-threshold reached are included.
} 
The results regarding the sensitivity on the funds' PME growths during the resolution period to Rush are somewhat surprising though. The main coefficient is no longer even negative while interactions with just $T T R g 1$ and just $I R R g H R$ are much closer to zero suggesting that Rush-to-exits depends on returns attained earlier during the funds' lives. ${ }^{10}$ Nonetheless, the key results - a positive cumulative effect of Informed Rush remains qualitatively unchanged from specifications (1) and (2), indicating no evidence of holding period fund performance cannibalization from market-timing of exits by Informed GPs. In contrast, the positive effect appears stronger economically and statistically during the resolution period.

In summary, the evidence presented in section 5.5.1 is strongly and consistently supportive of hypotheses $H 1$ and $H 2$. This suggests that GP industry timing skill is present and likely beneficial for LP portfolios and that the cash flow liquidity risks of LPs could be well rewarded. However, I also find a support for H3 corollary indicating that Informed GPs may drag the fund's performance down as well. Overall, the evidence so far is hard to rationalize with Footprint-effects being non-zero as far as private equity exits are concerned. The fact that the skill proxy, TTR-to-date, predicts subsequent exit success is suggestive of GP timing skills with regards to entry as well. ${ }^{11}$

\subsection{Informed Rush versus Random}

There are several limitations to the control group constructed from actual funds. First, it is not entirely clear what drives $\beta$, good timing by the treatment group or bad timing by the control group. Meanwhile, it would be interesting to further examine whether PE funds rushing to exit predict industry returns on average, regardless of GP skill and incentives. Second, the control group may be "contaminated" by funds whose GPs, in fact, do have timing skill

\footnotetext{
${ }^{10}$ These estimates may also be sensitive to cross-sectional differences in NAVs' reporting by GPs, e.g. see Brown et al.(2013).

${ }^{11}$ None of this rules out a presence of Footprint effects upon entry though. In fact, positive $\beta$ estimates in Panel A of Table A.2 are consistent with (some) PE funds having positive and lasting impact on the industry performance.
} 
and proper incentives. Third, the $\beta$ estimates presented above do not recognize how vintageindustry and fund-specific variation may interact with the stopping-time decisions and Rush amounts. Fourth, the treated and control industries may differ in the level of systematic risk. While the second concern suggests that I may be underestimating the magnitude of the effect, the directional effects of the other three are difficult to determine.

Accordingly, I also estimate Model (4.1) using random (hypothetical) stopping-times and Rush amounts in place of the control group exits. ${ }^{12}$ Specifically, I obtain these from simulating residuals under a simultaneous equation model of fund stopping-times and Rush by drawing bi-variate normal shocks from a covariance matrix, which itself is drawn (each time) from a Wishart distribution parametrized by the covariance matrix of the observed residuals. That is, the residuals from actual fund stopping-times and Rush-amounts that were used to estimate the simultaneous equations model. My estimation is asymptotically equivalent to the following just-identified Simulated Method of Moments:

\footnotetext{
${ }^{12}$ Note that the dependent variable in Model (4.1) is essentially stock returns. These resemble a random walk up to some variation in risk-premia. Hence, once risk-premia are controlled for and Footprint effects of PE exits are ruled out, there should be no difference under the null hypothesis of Model (4.1) between the sample Rush/stopping-times from their random combinations. In other words, neither actual nor simulated exits, should explain the future stock returns (residual to the risk-premia) under the null hypothesis of Model (4.1). This is the argument I rely on in efforts to overcome the econometric challenges outlined in the previous paragraph, examine the magnitudes and robustness of estimates presented in Section 5.5.1, and test hypothesis H3. It is important to highlight that the economic question of interest makes these two estimators particularly good complements as they mitigate the vulnerability of assumptions that each one requires. That is, with a control group consisting of hypothetical exits we need to assume-away Footprint-on-Firms while with a control group consisting of actual funds we need to assume-away their differences with respect to the exit-conditions/risk-premia variation.
} 


$$
\begin{gathered}
E\left[Z 1_{j}\left(S T_{j}-f\left(\text { fund characteristics, performance, } \ldots ; \theta_{t}\right)\right)\right]=0 \\
E\left[Z 2_{j}\left(R_{j}-g\left(\text { fund characteristics, performance, }, \ldots ; \theta_{r}\right)\right)\right]=0 \\
E\left[Z 3_{j i}\left(I E R\left(\theta_{t, r}, \Sigma\right)-\beta T \cdot R\left(\theta_{t, r}, \Sigma\right)+\gamma_{1} T+\gamma_{2} R\left(\theta_{t, r}, \Sigma\right)+F F E\right)\right]=0 \\
E\left[\left(\begin{array}{c}
S T\left(\theta_{t, r}, \Sigma\right)_{j i} \\
R\left(\theta_{t, r}, \Sigma\right)_{j i}
\end{array}\right) \perp F F E(j)\right]=0 \\
E\left[\left(\begin{array}{c}
S T\left(\theta_{t, r}, \Sigma\right)_{j i} \\
R\left(\theta_{t, r}, \Sigma\right)_{j i}
\end{array}\right)\left(\begin{array}{c}
\left.\left.S T\left(\theta_{t, r}, \Sigma\right)_{j i}\right)^{\prime} \perp F F E(j)\right] \\
R\left(\theta_{t, r}, \Sigma\right)_{j i}
\end{array}\right)=W_{2}(\Sigma, 1)\right.
\end{gathered}
$$

where the first two restrictions use only the sample data while the remainder involve simulated data and:

$Z 1_{j}, Z 2_{j}$ and $Z 3_{j i}$ denoting the sets of all covariates in the respective moment restriction; FFE is a set of dummies denoting expected stopping month and Rush for each actual fund $j$ as per functions $f(\ldots)$ and $g(\ldots)$ evaluated at the parameters' values $\theta_{t}$ and $\theta_{r}$ respectively;

$W_{2}(\Sigma, 1)$ - a draw from Wishart distribution with 1 degree of freedom, parametrized by $2 x 2$ positive definite $\Sigma$, the covariance matrix of the sample fund residuals: $\left(S T_{j}-\right.$ $\left.E_{j}[S T]\right)$ and $\left(R_{j}-E_{j)}[R]\right)$

$S T\left(\theta_{t, r}, \Sigma\right), R\left(\theta_{t, r}, \Sigma\right)$ - simulated values of stopping-time and Rush under the parameters $\theta_{t}, \theta_{r}$ and $\Sigma$, equal to the sample stopping times and $R u s h$ for the actual funds: $S T_{j}$ and $R_{j}$

$\operatorname{IER}\left(\theta_{t, r}, \Sigma\right)$ - mean Industry Return over 12 quarters following the stopping month according to $S T\left(\theta_{t, r}, \Sigma\right)$ and fund $j$ inception month;

$T$ - a dummy taking value of 1 for actual funds and zero otherwise. 
Although consistency of moment-based estimations does not depend on distributional assumptions (provided that the moment restrictions are valid), simulating stopping-time and rushamount shocks from a randomly drawn covariance matrix is important for correct inference in a situation like this. One way to think of this procedure is that it allows for error-term heteroskedasticity and clustering under Model 4.1 which is certainly possible in the population of funds. Another motivation for these simulation parameter perturbations is that they allow for uncertainty in the covariance matrix estimates $(\Sigma)$. Again, absence thereof would be an unrealistically strong assumption. ${ }^{13}$

The obvious disadvantage of estimating Model 4.1 with a simulated control group is that the null hypothesis for $\beta$ itself then depends on the estimated parameters. ${ }^{14}$ However, unlike in the "one-shot" SMM estimation of Model 5.1, my three-step procedure allows for directly examining the properties of the (simulated) null hypothesis underlying the inference about $\beta$ (Figure A.8). The three steps are as follows: (i) estimate a model of fund fixed effects for stopping-time and Rush (henceforth auxiliary model), (ii) independently simulate 1,000 blocks of up to 100 random exits per fund under this model (henceforth, independent simulations), and (iii) pool Model (4.1) (main model) estimates over these independent simulations (akin Fama-MacBeth) being highly conservative in the asymptotic variance computation.

\subsubsection{Auxiliary Model}

Table the A.3 reports auxiliary model of fund fixed effects that I estimate as two Seemingly Unrelated Regressions (Zellner, 1964). The fact that under the null hypothesis of Model (4.1) stopping-time and Rush do not predict Industry returns should relieve possible concerns about

\footnotetext{
${ }^{13}$ Note that similar ideas underlie imputations via the Gibbs sampler and some Bayesian inference methods. For example, see Lancaster (2004).

${ }^{14}$ It is not uncommon in the literature though. For example, see the analysis of restricted fund access effects on performance in Sensoy, Wang, and Weisbach (2013).
} 
simultaneity in the formations of the dependent variables or other sources of endogeneity. ${ }^{15,16}$ It is insightful to think about this auxiliary model as simply a density-mass filter for possible Stopping-time - Rush combinations.

The number of observations in Table A. 3 reflects that for funds where $15 \%$ and $20 \%$ thresholds were not crossed simultaneously, I have repeated observations of Rush, stopping-time and the covariates. I make use of these data structure to increase the estimates precision. Most of the explanatory power for both equations comes from vintage $\times$ industry fixed effects. ${ }^{17}$ Nonetheless, all other variables that I include significantly explain the stopping time and have signs consistent with the economic intuition. Specifically, fund log-size is positively related to how long it takes to resolve it while superior performance, as measured by PME and IRR-tercile, associates with shorter durations.

Unsurprisingly, the duration of existing funds also correlates with the fundraising success by GPs as the loadings on Follow-on Raised and Follow-on w/n 6 qtrs dummies suggest. ${ }^{18}$ While positive loading on the fraction of capital called by the next fund may speak about the GPs' economic optimism (or asset-hoarding). The same set of covariates has much less success in explaining Rush with $R^{2}$ being only $0.132 .{ }^{19}$ Fewer explanatory variables are significant statistically, although the signs on all coefficients are economically intuitive.

The fitted values by fund-threshold for both stopping-times and Rush represent the projections of fund fixed effects on the set of these covariates that I will use in place of $a_{j}$ dummies in estimating Model (4.1) in each of the independent simulations. The better the fit, the smaller

\footnotetext{
${ }^{15}$ See A.2 for a discussion of the implications for main model estimates arising from possible endogeneity in the auxiliary model.

${ }^{16}$ I functionally transform both dependent variables to insure that any simulated stopping-time is positive while simulated Rush is between zero and one.

${ }^{17}$ I consolidate the buckets as described in A.2 to have at least 9 funds sharing the same vintage-industry dummy.

${ }^{18}$ Follow-on $w / n$ qtrs $=1$ means that as of the stopping-time, the GPs are likely on a eventually successful road show.

${ }^{19}$ This is very much in-line with findings in Robinson and Sensoy (2011) that fund age and calendar time(quarterly) fixed effects explain less than $8 \%$ of the aggregate private equity cash-flow variation.
} 
the covariance matrix of stopping-times and Rush residuals that I will use to parametrize the simulations. Therefore, I exclude fund type dummy (i.e. venture or buyout) among other covariates that add more noise than explanatory power. Importantly, I treat the residual covariance matrix estimate as randomly drawn from a population. ${ }^{20}$ See A.2 for further methodological details and discussions.

\subsubsection{Refining Base Estimates}

Table 5.2 reports the simulation-based estimates of Industry returns predictive regressions I ran in the previous section. As in Table 5.1, specifications (1)-(2) correspond to the stopping times under $15-20 \%$ thresholds for the baseline model whereas specifications (3)-(4) also include additional Pseudo-timing controls. The point estimates and standard errors in Panel A (B) of Table 5.2 are the simulation-based counterparts of Panel A (B) of Table 5.1. ${ }^{21}$ They support a conclusion that the industry market-timing is indeed statistically present among GPs and that both ingredients (incentive and skill) are necessary.

\footnotetext{
${ }^{20}$ Thus, although the sample correlation between the residuals is -0.19 , its value is stochastic over the simulated samples.

${ }^{21}$ Note that in each case the control group is formed only of the pseudo exits that correspond to the treated funds.
} 


\section{Table 5.2: Actual Rush versus Random}

This table reports simulation-based estimates of predictive regressions of Industry returns by Rush, a fraction of distributions over the last 6 quarters in the funds' total-to-date. Industry returns are of S\&P500 subindex corresponding to the GICS Industry sector of the fund specialty. The estimation methodology is described in Section 5.5.2 and A.2. In short, I (1) estimate a model of fund fixed effects for stopping-time and Rush (henceforth auxiliary model) Table A.3, (2) independently simulate 1,000 blocks of up to 100 random exits per fund under this model (henceforth independent simulations), and (3) pool main model estimates over these independent simulations. The main model is:

$$
E\left[\text { IndustryReturn }_{i j, 1: 12}\right]=\text { Breated }_{i j} \text { Rush }_{i j}+\gamma_{1} \text { Treated }_{i j}+\gamma_{2} \text { Rush }_{i j}+a_{j}
$$

where IndustryReturn $n_{i j, 1: 12}$ is a mean monthly Industry Return over 12 months following fund $i$ actual or simulated stopping-time, depending on whether Treated $_{i j}=1$ for the actual funds of interest or Treated $_{i j}=0$ otherwise; $R u s h_{i j}$ - actual or simulated fraction of distributions over the last 6 quarters in the funds' total-to-date, $a_{j}$ - "fund fixed effects" estimates from the auxiliary model. Panel A [B] includes funds that as of stopping-time have (i) a positive track record of market timing as measured by TTR defined in Section 3 and [or] (ii) net-of-fees IRR in excess of the contractual Hurdle-rate. Panel $\mathrm{C}$ includes all funds. Stopping-times in odd (even) numbered specifications are fund-quarter when fund NAV drops below 15 (20)\% of the fund total distributions up to that quarter. Specifications (3)-(4) include additional return-predictive covariates, as in Table 5.1. Standard errors in parentheses are clustered at stopping-quarters, $* / * * / * * *$ denote significance at $10 / 5 / 1 \%$.

\begin{tabular}{|c|c|c|c|c|}
\hline & \multicolumn{2}{|c|}{ FundFE } & \multicolumn{2}{|c|}{ FundFE+PseudoTiming } \\
\hline & $\begin{array}{l}15 \% \text { thld } \\
\text { (1) }\end{array}$ & $\begin{array}{l}20 \% \text { thld } \\
\text { (2) }\end{array}$ & $\begin{array}{l}15 \% \text { thld } \\
\text { (3) }\end{array}$ & $\begin{array}{l}20 \% \text { thld } \\
\text { (4) }\end{array}$ \\
\hline \multicolumn{5}{|c|}{ Panel A: Treated $($ dummy $) \equiv(T T R>1) \times(I R R>H R)$} \\
\hline TTRg1*IRRgHR*Rush & $\begin{array}{c}-0.017 * * * \\
(0.006)\end{array}$ & $\begin{array}{c}-0.017 * * \\
(0.007)\end{array}$ & $\begin{array}{c}-0.016^{* * *} \\
(0.006)\end{array}$ & $\begin{array}{c}-0.014 * * \\
(0.007)\end{array}$ \\
\hline \# of Actual funds & 373 & 387 & 373 & 387 \\
\hline Pseudo funds per 1 Actual & 95.8 & 95.4 & 95.8 & 95.4 \\
\hline \multicolumn{5}{|c|}{ Panel B: Treated $($ dummy $) \equiv(T T R>1)+(I R R>H R)+(T T R>1) \times(I R R>H R)$} \\
\hline TTRg1*IRRgHR*Rush & $\begin{array}{c}-0.032 * * * \\
(0.012)\end{array}$ & $\begin{array}{c}-0.026 * * \\
(0.012)\end{array}$ & $\begin{array}{c}-0.034 * * * \\
(0.010)\end{array}$ & $\begin{array}{c}-0.027 * * * \\
(0.010)\end{array}$ \\
\hline TTRg1*Rush & $\begin{array}{c}0.008 \\
(0.009)\end{array}$ & $\begin{array}{c}0.002 \\
(0.007)\end{array}$ & $\begin{array}{c}0.012 \\
(0.007)\end{array}$ & $\begin{array}{c}0.005 \\
(0.006)\end{array}$ \\
\hline IRRgHR*Rush & $\begin{array}{c}0.006 \\
(0.005)\end{array}$ & $\begin{array}{c}0.007 \\
(0.007)\end{array}$ & $\begin{array}{c}0.006 \\
(0.005)\end{array}$ & $\begin{array}{c}0.007 \\
(0.006)\end{array}$ \\
\hline \# of Actual funds & 756 & 791 & 756 & 791 \\
\hline Pseudo funds per 1 Actual & 95.4 & 94.5 & 95.4 & 94.5 \\
\hline \multicolumn{5}{|c|}{ Panel C: Treated $($ dummy $) \equiv$ All Actual Funds } \\
\hline ActualFund*Rush & $\begin{array}{c}-0.006 \\
(0.004)\end{array}$ & $\begin{array}{c}-0.007 \\
(0.005)\end{array}$ & $\begin{array}{c}-0.005 \\
(0.005)\end{array}$ & $\begin{array}{c}-0.005 \\
(0.004)\end{array}$ \\
\hline \# of Actual funds & 893 & 941 & 893 & 941 \\
\hline Pseudo funds per 1 Actual & 95.0 & 94.3 & 95.0 & 94.3 \\
\hline \multicolumn{5}{|l|}{ Applies to Each Panel: } \\
\hline \# of independent simulations & 1000 & 1000 & 1000 & 1000 \\
\hline Rush, Treated(dummies) & Yes & Yes & Yes & Yes \\
\hline
\end{tabular}


[Insert Table 5.2 here]

In addition, Panel C of Table 5.2 tells what we could not learn with the control group comprised of actual funds - whether aggregate private equity distributions are informative of future Industry returns, unconditionally on the GPs' situation. The loading on ActualFund*Rush, although negative, is economically small (about $0.15 \%$ per month) and appears to be far from being significant statistically. Of course, one cannot rule out that the relation is stronger with Rush defined differently or in some subsets of funds orthogonal to the incentive and skill dimensions that I pursue. However, the magnitudes in Panel $\mathrm{C}$ do indicate that the mean effect for funds that form the control group in 5.5.1 is indeed very close to zero with rather moderate variance.

Note also that, unlike in Table 5.1, the point estimates with additional Pseudo-timing controls are very close to those with just the baseline fixed effects, particularly, for the $15 \%$ threshold case where the effect is stronger (specifications (1) and (3)). This is because the (projections of) fund fixed affects absorb much of the (co)variation in these controls and Rush. In other words, to the extent the expected market (industry) returns tend to change slowly, controlling for the fund fixed effects obtained from our auxiliary model is sufficient. In Figure A.8A I also show that, consistent with a knowledge-based explanation, the return predictability vanishes as one moves to sectors which did not correlate with the funds primary industry in the recent past. Robustness tests are reported in Figure A.7.

\subsubsection{Evidence of Informed Stays}

As per section 5.5.1, Informed GPs without a "skin-in-the-game" do not sell at the market peaks yet do not deliver better holding period returns either, consistent with the corollary to

H3. I now turn to tests of hypothesis $H 3$ that questions whether GP timing skills might also hurt LP interests through more "asset-hoarding" ahead of high volatility times. These tests will determine whether GPs acted as out-of-the money option holders by delaying the exercise 
in the anticipation of higher asset volatility. ${ }^{22}$ Note that even though LPs may also benefit from the option value of a distressed equity claim, it appears unlikely that such risk-shifting by GPs implements a first-best portfolio choice from their LP perspective. Instead of keeping the assets in the fund, most LPs could obtain equivalent systematic and comparable idiosyncratic volatility exposures while not footing the bill for the GP's call-option.

To proceed with the tests, I change the dependent variable in Model (4.1) from future mean of Industry returns to past volatility and redefine the treatment group. I estimate volatility as annualized standard deviation of monthly returns $\{-6$ to 0$\}$ and $\{-12$ to -8$\}$ quarters relatively to the respective fund's stopping-time. The first window corresponds to the period over which the Rush is measured. Hence, it shall speak about how the fund distributions' clustering associates with abnormal industry volatility. The second window is more interesting since high values of Rush imply that there were very few distributions made before the $\{-6$ to 0 quarters $\}$ window while the fund fixed effect projections insure that the volatility is abnormal relative to the fund inception date $\times$ industry and other fund- and firm-level covariates (see Table A.3). The results for the first window can be thought of as a placebo experiment that informs about differences in abnormal volatility within the treated funds during the Rush period which may confound our interpretation of the results for the second window.

The treatment group now consists of funds that (a) have a positive track record of markettiming $\left(T T R_{i} 1\right)$, and/or (b) where GPs face a survival risk beyond the term of the current fund. I assume that the survival risk would be determined by a combination of the following two conditions: (i) whether net-of-fees IRR was in the bottom or top tercile among type $\times$ vintageyear peers (Btm/Top), and (ii) whether a successor fund has been raised (NoNext/YesNext). ${ }^{23}$ To not confound interpretations by high-order interaction terms, I define three non-overlapping

\footnotetext{
${ }^{22}$ Similar to management seeking to increase riskiness of company assets when incentivized by distressed equity as per Jensen and Meckling (1976), Galai and Masulis (1976) among others.

${ }^{23}$ Clearly, an existence of a follow-on fund commitment from investors keeps the GPs "in-business" for the next decade while the current fund performance is a significant determinant of the fundraising odds as per Barber and Yasuda (2014).
} 
groups of interests: BtmNoNext, BtmYesNext, TopNoNext. Also, to avoid a look-ahead bias and unrealistic assumptions, I now measure TTR and IRR as of the 5th anniversary of the respective fund and constrain the sample to funds with actual stopping-times of at least 8 years from inception. This insures that the funds are not too young to make any distributions during the $\{-12$ to -8$\}$ quarters window, while the to-date performance signals are meaningful and yet not overlapping with the volatility observation windows.

Arguably, BtmNoNext-funds face the highest incentive to hoard the fund assets since their GPs likely have no performance fees to collect from the current and future funds. The tradeoff is less clear for BtmYesNext)-funds' GPs. On the one hand, the asset-hoarding benefits the value of their OTM option to earn performance fee in the current fund. On the other hand, such a behavior may tarnish their relationships with investors and negatively affect the odds of future fundraising. Chung et al. (2011) show that the present value of expected fees (performancebased and fixed) from the future funds (yet to be raised) may exceed those of from the current fund. Meanwhile, the examination of the effects for TopNoNext-funds completes the analysis by identifying the role of current performance in the risk-shifting incentives. There should be zero effects to the extent performance fees in the current fund reduce GPs risk-appetite and/or high current performance rank significantly increases the odds of fundraising success.

Table 5.3 reports the results for the stopping-quarter defined based on 15\%-NAV/“total distributions to-date" threshold. All specifications include the projections of fund fixed effect (from the auxiliary model) and the main terms of Rush and Treated. Specifications (3) and (4) also include the levels of VIX index as the fund stopping-quarter and the $\{-12$ to -8 quarters $\}$ or $\{-6$ to 0 quarters $\}$ window respectively to better absorb heterogeneity across treated funds and zoom at the industry-specific innovations to the volatility. As before, I break the treatment dummy into its constituents, incentive and timing skill. Interpretations would be somewhat ambiguous if the coefficients on Treated $\times$ Rush were significantly different from zero in $\{-6$ to 0$\}$ window, either statistically or economically. This is clearly not the case as specifications 
(1) and (3) suggest - the volatility during the Rush periods is neither abnormal (relatively to the hypothetical exits) nor meaningfully different within Treated funds across the incentive and skill dimensions. Therefore, the results for $\{-12$ to -8 quarters $\}$ shall provide us with a clean test of $H 3 .^{24}$

${ }^{24}$ That is whether a risk-shifting behavior by an Informed GP is more likely to have an adverse effect on LP portfolios as compared to risk-shifting behavior of an uninformed GP. 


\section{Table 5.3: Risk-shifting Evidence}

This table reports simulation-based estimates of abnormal volatility of Industry returns. Industry returns are of S\&P500 subindex corresponding to the GICS Industry sector of the fund specialty. The estimation methodology is described in Section 5.5.2.3 and A.2. In short, I (1) estimate a model of fund fixed effects for stopping-time and Rush (henceforth auxiliary model, Table A.3), (2) independently simulate 1,000 blocks of up to 100 random exits per fund under this model (henceforth independent simulations), and (3) pool main model estimates over these independent simulations. The main model is:

$$
E\left[\text { IndustryVolty }_{i j, h}\right]=\beta v \text { Treated }_{i j} \text { Rush }_{i j}+\gamma_{v 1} \text { Treated }_{i j}+\gamma_{v 2} \text { Rush }_{i j}+a_{j}
$$

where IndustryVolty ${ }_{i j, h}$ annualized standard deviation of monthly returns $\{-6$ to -0$\}$ and $\{-12$ to -8$\}$ quarters of fund $i$ actual (i.e. Treated $_{i j}=1$ ) or simulated stopping-time; Rush $h_{i j}$ - actual or simulated fraction of distributions over the last 6 quarters in the funds' total-to-date, $a_{j}$ - "fund fixed effects" estimates from the auxiliary model. The estimation is over funds with actual stopping-time of at least 8 years that as of the 5th anniversary had (i) a POSITIVE track record of market timing as measured by TTR $>1$ (Section 3) or (ii) where the firm faces high survival risk as measured by net-of-fees IRR in the bottom tercile among type $\times$ vintage-year peers $(\mathrm{Btm})$ and/or no successor fund raised up until at least the 6th quarter before the stopping quarter (NoNext). For brevity, the union $(B t m \cap N o N e x t=1),($ Top $\cap$ NoNext $=1),($ Btm $\cap$ YesNext $=1)$ is referred to $($ SurvivalRisk $=1)$.

The stopping quarter is the first quarter with non-zero distributions to LPs when a fund's NAV drops below $15 \%$ of the fund's total distributions up to that quarter. Specifications (1) and (3) report results for the volatility over the $\{-6$ to 0 quarters $\}$ window from the stopping-quarter which corresponds to Rush measurement period. Specifications (2) and (4) report results for the $\{-12$ to -8 quarters $\}$ window which corresponds to at least the sixth year of the fund operations. Note that high values of Rush indicate that relatively few distributions to LPs have been made before quarter- 6 from the stopping. Besides the main terms of Treated constituents, $(T T R>1)$, (SurvivalRisk $=1$ ) and their interaction, the list of control variables includes Rush and the projections of fund fixed effect (from the auxiliary model) while in Specifications (3) and (4) it also includes the levels of VIX index as the fund stopping-quarter and the $\{-12$ to -8 quarters $\}$ or $\{-6$ to 0 quarters $\}$ window respectively. Standard errors in parentheses are clustered at stopping-quarters, $* / * * / * * *$ denote significance at $10 / 5 / 1 \%$.

\begin{tabular}{|c|c|c|c|c|}
\hline & $\begin{array}{c}-6: 0 q \\
(1)\end{array}$ & $\begin{array}{c}-12:-8 \mathrm{q} \\
(2)\end{array}$ & $\begin{array}{c}-6: 0 q \\
(3)\end{array}$ & $\begin{array}{c}-12:-8 \mathrm{q} \\
(4)\end{array}$ \\
\hline \multicolumn{5}{|c|}{ Treated $\equiv(T T R 5 y>1)+$ SurvivalRisk $+(T T R 5 y>1) \times$ SurvivalRisk } \\
\hline TTRg $1 *$ BtmNoNext*Rush & $\begin{array}{c}0.025 \\
(0.027)\end{array}$ & $\begin{array}{l}0.075^{* *} \\
(0.038)\end{array}$ & $\begin{array}{c}0.007 \\
(0.022)\end{array}$ & $\begin{array}{l}0.064 * * \\
(0.030)\end{array}$ \\
\hline TTRg1*TopNoNext*Rush & $\begin{array}{c}0.007 \\
(0.020)\end{array}$ & $\begin{array}{r}-0.010 \\
(0.025)\end{array}$ & $\begin{array}{c}0.012 \\
(0.016)\end{array}$ & $\begin{array}{r}-0.010 \\
(0.019)\end{array}$ \\
\hline TTRg1*BtmYesNext*Rush & $\begin{array}{c}0.006 \\
(0.012)\end{array}$ & $\begin{array}{r}-0.015 \\
(0.017)\end{array}$ & $\begin{array}{c}0.001 \\
(0.009)\end{array}$ & $\begin{array}{c}-0.007 \\
(0.015)\end{array}$ \\
\hline BtmNoNext*Rush & $\begin{array}{c}-0.001 \\
(0.012)\end{array}$ & $\begin{array}{c}-0.009 \\
(0.015)\end{array}$ & $\begin{array}{c}0.006 \\
(0.007)\end{array}$ & $\begin{array}{r}-0.010 \\
(0.012)\end{array}$ \\
\hline TopNoNext*Rush & $\begin{array}{c}-0.006 \\
(0.011)\end{array}$ & $\begin{array}{c}0.018 \\
(0.019)\end{array}$ & $\begin{array}{r}-0.006 \\
(0.007)\end{array}$ & $\begin{array}{c}0.007 \\
(0.016)\end{array}$ \\
\hline BtmYesNext*Rush & $\begin{array}{c}0.006 \\
(0.006)\end{array}$ & $\begin{array}{c}0.016 \\
(0.009)\end{array}$ & $\begin{array}{c}0.000 \\
(0.004)\end{array}$ & $\begin{array}{c}0.002 \\
(0.008)\end{array}$ \\
\hline TTRg1*Rush & $\begin{array}{r}-0.006 \\
(0.007)\end{array}$ & $\begin{array}{r}-0.006 \\
(0.008)\end{array}$ & $\begin{array}{c}0.003 \\
(0.005)\end{array}$ & $\begin{array}{r}-0.003 \\
(0.007)\end{array}$ \\
\hline Rush, Treated(dummies), Fund FE & Yes & Yes & Yes & Yes \\
\hline VIX levels & No & No & Yes & Yes \\
\hline \# of Actual funds & 596 & 596 & 596 & 596 \\
\hline Pseudo funds per 1 Actual & 94.6 & 94.6 & 94.5 & 94.1 \\
\hline
\end{tabular}


Specifications (2) and (4) of Table 5.3 strongly support $H 3$. While the industry volatility associations with the divestment schedules continue to be insignificant for funds that appear to have just timing skill but no incentive to risk-shift (and vice versa), there is a stark difference when both conditions are satisfied. Positive and significant coefficient on TTRgl ${ }^{*}$ BtmNoNext $*$ Rush in specification (2) suggests that an inter-quartile (0.33) increase in Rush by such funds associates with approximately 2.5 percentage points higher per annum volatility of the industry returns in the quarters preceding the Rush. Since the fraction of distributions prior the 6th quarter before the stopping equals 1-Rush, it follows that these GPs had made abnormally few distributions before the industry volatility became abnormally high. Controlling for the systematic volatility levels within the window and at the fund resolution date, as per specification (4), leaves the results essentially unchanged.

The projections of fund fixed effects reflect funds' inception dates. Therefore, the fundspecific control-groups of hypothetical exits account for differences in the volatility paths since fund inception (e.g. as of the 5th anniversary). Besides, negative but insignificant from zero coefficients on $T T R g 1 * T o p N o N e x t * R u s h$ strongly suggest against the effects on TTRgl $1 *$ BtmNoNext*Rush being driven by some unaccounted time variation (i.e. when many funds had no successor by mid-life). Thus, we can conclude that Informed GPs who have incentives to hoard fund assets appear to be significantly more likely to steer their funds through periods of high turbulence in the industry having made abnormally few distributions before the onset of these periods.

Meanwhile, the effectively zero coefficients on $\operatorname{TTRg} 1 *$ BtmYesNext-terms indicate that poorly performing GPs but with a successor fund nonetheless do not exhibit such risk-shifting behaviors, no matter whether Informed or not. This is consistent with the corollary $H 3 \mathrm{~B}$ and suggests that expected flows from future funds do restrain managers from "destroying value" (consistent with the framework of Chung et al., 2011). However, given that $H 2$ and corollary hold as well, these future funds flows alone appear to not be enough to induce "first-best". 
To sum for Section 5.5.2, I confirm that (i) hypotheses $H 1$ and $H 2$ hold, and (ii) the market predictability appears to relate to industry-specific knowledge of GPs and pertain to the cashflow fundamentals. If (and only if) the GPs are Informed and have accrued carry at stake, do PE fund distributions predict Industry Return. Finally, I find support for hypothesis $H 3$ that risk-shifting by Informed GPs is more hazardous for LPs' performance.

\subsection{What Are GPs Informed about: Cash-flows or Discount-rates?}

In the previous sections, I provide evidence of public equity returns predictability by the patterns of private equity fund distributions to their investors. That predictability appears to originate from private information that GPs learn while managing their funds rather than to belong to the public markets information set $E_{t}$. As per Campbell and Shiller (1988), we can attribute the unexpected asset returns to (i) the revision of expectations about current and future cash flows it pays ( $\equiv N_{C F, t+1}$ ), and (ii) the revision in expectations about future discount rates the investors require $\left(\equiv N_{D R, t+1}\right)$ :

$$
\begin{aligned}
r_{t+1}-E_{t+1} & =\left(E_{t+1}-E_{t}\right) \sum_{j=0}^{\infty} \rho^{j} \Delta d_{t+1+j}-\left(E_{t+1}-E_{t}\right) \sum_{j=1}^{\infty} \rho^{j} r_{t+1+j} \\
& =N_{C F, t+1}-N_{D R, t+1}
\end{aligned}
$$

where $\rho=1 / \exp \{\overline{d-p}\}, d_{t}\left(p_{t}\right)$ is the asset log dividend (price) in period $t$, while $r_{t}$ is the required $\log$ rate of return for the period.

I this section, I study whether the GPs are able to foresee $N_{C F, t+1}$ and/or $N_{D R, t+1}$. As discussed earlier, both channels could be at play as a result of GPs potential involvement in the operational management of the portfolio companies company and their special position in capital market that enables them to observe portfolio demands of various public and private investors. To accomplish such tests, one could simply replace future returns in (4.1) with $N_{C F, t+1}$ and than with $N_{D R, t+1}$. However, empirically, there are no proxies of cash-flow news would be uncorrelated with discount-rate news (and visa-verse). For example, even though the 
information on realized earnings are readily available, analysts forecasts thereof likely depend on the expected returns. Similarly, forward price-earning ratio also reflect the expected cash flows and, hence, their innovations.

To attain a stronger evidence regarding the links of Informed Rush to a particular channel (cash-flows or discount rate) in the realized industry returns, I swap the future industry returns with Rush as the the dependent variable in model (4.1) and instrument the returns (now on the RHS) with, respectively, proxies of industry cash-flow news or discount rate news. Treating the proxy for the other channel as the included instrument enables me to better absorb the unrelated variation while making sure that the returns' channel of interest, in fact, correlates with Rush strongly enough. ${ }^{25}$ I proxy for cash-flow news by Industry EPS Surprise and Industry Forward PE $\Delta$, respectively. Both are computed from EPS estimates for the respective S\&P500 GICS Industry sector subindex: 12-month trailing values and the next two fiscal year analysts' consensus forecasts as obtained from Bloomberg. ${ }^{26}$

Table 5.4 reports the results. The coefficients on Treated $\times$ IndRet and IndRet are essentially a reverse regression estimates of the coefficients on Treated $\times$ Rush and Rush in model (4.1). Although their magnitudes are now less convenient to interpret, the basic intuition remains unchanged - significantly negative coefficient indicates that Rush preempts a period of lower returns in the Industry. All specifications include industry expected returns covariates to proxy for $E_{t} r_{t+1} \cdot{ }^{27}$ Specifications (1) and (3) use actual fund exits as the control group, corresponding to the approach in Table 5.1, while specifications (2) and (4) report simulationbased analysis of the question, as described in Section 5.5.2. First-stage regression results are summarized by the partial F-statistic (via Kleibergen-Paap Wald test) and show no evidence of the instruments' weakness in either case. ${ }^{28}$

\footnotetext{
${ }^{25}$ Since the standard errors are computed based on residuals from returns rather than the fitted values.

${ }^{26}$ The results are robust to alternative definitions of the proxies and different specification of the IV-estimator.

${ }^{27}$ Industry 5-year CAR, P/E, B/M; CAY-ratio CBOE VIX, BAA-AAA spread, AAA-UST spread, 10-year and 3-month UST.

${ }^{28}$ For simulation-based estimates, reported sample size and F-statistics are averages across 1,000 simulations.
} 


\section{Table 5.4: What Are PE Managers Informed About: Cash Flows or Discount Factor}

This table reports instrumental variable regression estimates of Rush on next 12 months Industry returns:

$$
E\left[\text { Rush }_{i j}\right]=\beta_{\text {riv }} \text { Treated }_{i j} \text { IndRet }_{i j, 1: 12}+\gamma_{\text {riv2 }} \text { IndRet }_{i j, 1: 12}+\gamma_{r 1} \text { Treated }_{i j}+\text { Controls }
$$

, where Rush is a fraction of distributions over the last 6 quarters in the funds' total-to-date; Industry returns are of S\&P500 subindex corresponding to the GICS Industry sector of the fund specialty; Treated is dummy that proxies for incentives and market-timing skill of the fund's GP, as per Panel A of Table 5.1 and the Informed Rush definition in 4.4.2.5.

In specifications (1) and (2), the excluded instruments are Industry EPS Surprise and its interaction with Treateddummy, while Industry Forward PE $\Delta$ and its interaction with Treated-dummy are added to the 1st and 2nd stage regressions along with the other return-predictive covariates (see Table 5.1) and the fund group fixed effects. Therefore, specifications (1) and (2) test whether GPs foresee the industry cash-flow news and act accordingly. While specifications (3) and (4) treat the terms with Industry Forward PE $\Delta$ as excluded instruments while including Industry EPS Surprise in the set of other covariates and, thus, test whether GPs foresee innovations in the discount-rates for the industry cash-flows. Industry EPS Surprise and Industry Forward PE $\triangle$ are computed from EPS estimates for the respective S\&P500 GICS Industry sector subindex: 12-month trailing values and the next two fiscal year analysts' consensus forecasts as obtained from Bloomberg.

Specifications (1) and (3) use other sample funds as the control group and fund inception year fixed effects while specifications (2) and (4) use hypothetical fund exits (for Treated funds only) as the control group (reported are the pooled estimates across 1,000 simulations, the methodology is described in Section 5.5.2 and A.2). Standard errors in parentheses are robust to heteroskedasticity and autocorrelation, $* * * * * * *$ denote significance at $10 / 5 / 1 \%$.

\begin{tabular}{|c|c|c|c|c|}
\hline & \multicolumn{4}{|c|}{ Excluded Instrument: } \\
\hline & \multicolumn{2}{|c|}{ Industry EPS Surprise } & \multicolumn{2}{|c|}{ Industry Forward PE $\Delta$} \\
\hline & (1) & (2) & (3) & (4) \\
\hline Treated $\widehat{d \times I} n d R e t$ & $\begin{array}{c}-3.825 * * \\
(1.733)\end{array}$ & $\begin{array}{c}-2.465^{* *} \\
(1.042)\end{array}$ & $\begin{array}{c}-1.194 \\
(2.968)\end{array}$ & $\begin{array}{c}0.846 \\
(2.569)\end{array}$ \\
\hline$\widehat{\text { IndRet }}$ & $\begin{array}{c}0.315 \\
(1.249)\end{array}$ & $\begin{array}{l}0.097 \\
(.228)\end{array}$ & $\begin{array}{c}-1.517 \\
(1.842)\end{array}$ & $\begin{array}{c}0.300 \\
(0.343)\end{array}$ \\
\hline Treated & $\begin{array}{c}0.012 \\
(0.023)\end{array}$ & $\begin{array}{c}0.017 \\
(0.038)\end{array}$ & $\begin{array}{c}-0.032 \\
(0.026)\end{array}$ & $\begin{array}{c}-0.025 \\
(0.015)\end{array}$ \\
\hline Included Instruments & \multicolumn{2}{|c|}{ Forward PE $\Delta$} & \multicolumn{2}{|c|}{ EPS Surprise } \\
\hline Included Inst. $\times$ Treated & Yes & Yes & Yes & Yes \\
\hline Predictive covariates & Yes & Yes & Yes & Yes \\
\hline Control Funds & Actual & Simulated & Actual & Simulated \\
\hline Fixed Effects & Vintage & Fund & Vintage & Fund \\
\hline SE Cluster & Quarter & Fund & Quarter & Fund \\
\hline 1st stage K-P Wald stat. & 17.9 & 332.4 & 6.8 & 15.3 \\
\hline Observations & 848 & 32,832 & 848 & 32,832 \\
\hline$R^{2}$ (\# of Simulations) & 0.158 & $(1,000)$ & 0.15 & $(1,000)$ \\
\hline
\end{tabular}


In specifications (1) and (2), the excluded instruments are Industry EPS Surprise and its interaction with Treated-dummy, while Industry Forward PE $\Delta$ and its interaction with Treateddummy are added to the 1 st and 2 nd stage regressions along with other covariates and the fund group fixed effects. Significantly negative coefficients on Treated $\times$ IndRet indicate that skilled GPs foresee the industry cash-flow news that cause the industry returns to fall. The point estimates suggest that aggregate earnings surprise that would trigger a $10 \%$ fall in industry index is on average preceded by 25-38 percentage points higher Informed Rush.

Specifications (3) and (4) use the terms with Industry 1-year Forward PE $\Delta$ as excluded instruments while including Industry EPS Surprise in the set of other covariates and, hence, test whether GPs foresee innovations in the discount-rates that investors require for the industry cash-flows. Although the point estimates on Treated $\times$ IndRet and IndRet are negative according to Specification (3), they are far from being significant statistically, so as their sum (untabulated). Furthermore, these coefficients are not even negative (while also insignificant) according to specification (4) which uses hypothetical exits as the control group that should better absorb the fund heterogeneity and variations in $E_{t+1}$.

Thus, it appears that the GPs' forecasting edge is limited to the cash-flow process in the industry of specialization. Whereas their public and capital market activities do not seem to yield important insights about swings in the marginal public market investor's risk preferences. It is quite plausible that discount-rates' shocks rarely originate in a particular industry but are rather driven by events outside the industry. It is also consistent with results in Section 5.5.2.2, showing that predictability of returns by Informed Rush decays outside of the native industry. 


\section{CONCLUSION}

In this paper, I document evidence consistent with private equity fund managers (GPs) being more informed about certain publicly traded firms' valuations than marginal investors in public markets. This can create value for the private equity fund investors beyond the ways that have been analyzed in the literature. Learning through the private investment/divestment process appears to be the source of this knowledge which enables GPs to have some ability to time industry peaks and troughs. This knowledge appears to persist and pertain to the industry cash-flow fundamentals as measured by public firms' aggregate earnings news.

However, while such a market-timing yields economically significant benefits for the funds' investors (LPs), it is not always concordant with the GPs' objectives. The incentives are adverse if the current fund's return is below the performance fee hurdle and the GPs are unable to raise a subsequent fund. In these cases, skilled GPs are likely to delay fund distributions ahead of elevated industry volatility periods. Hence, the results in this paper have strong implications for managers and contract choice by LPs. Investing with highly reputable GPs that are less likely to face fundraising difficulties reduces the ex-ante probability of the asset hoarding with more adverse consequences for LPs. Conversely, fund terms should contain more provisions protecting against the asset hoarding in general (i.e. at a cost of limiting the potential gains from more delegation) if the likelihood for such adverse incentives to emerge is relatively high. I show that private fund cash flows tend to predict subsequent returns in the industry only when the GPs have performance fees to harvest. This finding demonstrates the importance of an

explicit performance-based compensation in delegated investment management in general (in comparison to an "implicit" compensation in the form of future fund flows).

My tests isolate GPs' market-timing skills from reactions to time-varying market conditions 
and causal effects of private equity funds activity spillovers on public firm policies. However, this informed trading by GPs is unlikely to go completely unnoticed by other investors in capital markets. If so, private equity funds may have a positive causal effect on the informational efficiency of the capital market, providing a channel for how private information gets impounded into the public market prices. For example, the tech-bubble of the late 1990s and the financial intermediation frenzy of 2006-07 might have been even greater if not for the flood of private equity exits trying to preempt the busts. Hence, the role and the importance of professionally managed private capital pools in the modern capital markets (increasingly subject to Moral Hazard) might have been underappreciated. 


\section{APPENDIX}

\section{A.1 Additional Data and Discussion of the Institutional Background}

In a buyout, a company is acquired using a relatively small portion of equity and a large portion of outside debt financing. In a typical transaction, the private equity fund buys the majority control of a mature firm (not necessarily publicly traded). In contrast, venture funds typically invest in young or emerging companies often through convertible debt or preferred shares, and usually do not seek to obtain a majority control. In both cases, however, the fund managers, GPs, closely monitor and exert influence on the acquired company activities, normally through active membership on the board of directors. See Gompers and Lerner (1996), Kaplan and Strömberg (2008), Metric and Yasuda (2009) for detailed accords on private equity business models. Sorensen (2007), Acharya, Gottschalg, Hahn and Kehoe (2008), Hochberg, Ljungqvist, and Lu (2010), Gompers, Kovner, and Scharfstein (2010), Cai, Sevilir and Tian (2012), Ewens and Rhodes-Kropf (2013) among others suggest a micro-foundation for GPs impact on portfolio companies that relates to entrepreneur rational self-selection, institutional network effects as well as financial, operational and "managerial" engineering.

The company would typically be one of many investments the funds undertake which, in turn, is a small portion of candidates that would get screened during the approximately 5-year investment period. Unlike for portfolio investors in public companies, the information set of the fund GPs would not be limited by standard disclosure requirements even if the fund have yet to become a stake-holder. On a confidential basis, GPs are free to request any data about the company business in possession of the management. GPs tend to specialize in certain industries and types of businesses. This makes the signals about business fundamentals obtained through the monitoring and prospective investments due diligence quite complementary. This complementarity potentially makes GPs' information sets even better than that of a individual company's management as well as that of investors in public markets.

Both funds, buyout and venture, would target a total life of about 10 to 13 years from the 
investment period start date. The holding durations tend to be 4 to 7 years with some exits occurring earlier than 2 years after the original investment while some - after 10 years. For investments that do not go bankrupt, the exit routes are either IPO or an acquisition. The latter can be further broken-down by the type of acquirer: (i) another private equity fund or group of investors (financial investors) or (ii) an operating firm, possible private too, that is strategically interested in the production capacity of the target's assets (strategic investors). Transactions with non-financial buyers constitute the most frequent type of exits and often referred to as "trade-sales". The IPO route typically fetches the highest return on investment, yet other exit routes (except bankruptcy) are on average profitable as well. For example, see Ball et al.(2011) for a comprehensive venture deals sample and Degeorge et al.(2013) for buyouts.

Before the investment period concludes, buyout and venture GPs would normally attempt to raise a new fund. The interval between fund starts would be 2 to 5 years with the average being 3.5 years for both buyout and venture funds. For example, see Brown et al.(2013). There are, of course, numerous reasons for GPs (and LPs) to want the lives of the funds to overlap. One of the consequences of this practice is a continuous flow of information about similar companies fundamentals, on the one hand, and investor portfolio demands, on the other (Including signals about fellow private equity firms capital growth trend as it relates to prospective competition among financial buyers for the current portfolio companies). These largely non-public information flows that GPs regularly participate in both, buyout and venture, can be summarized via the following scheme. 
Figure A.1: Private Information Cycle

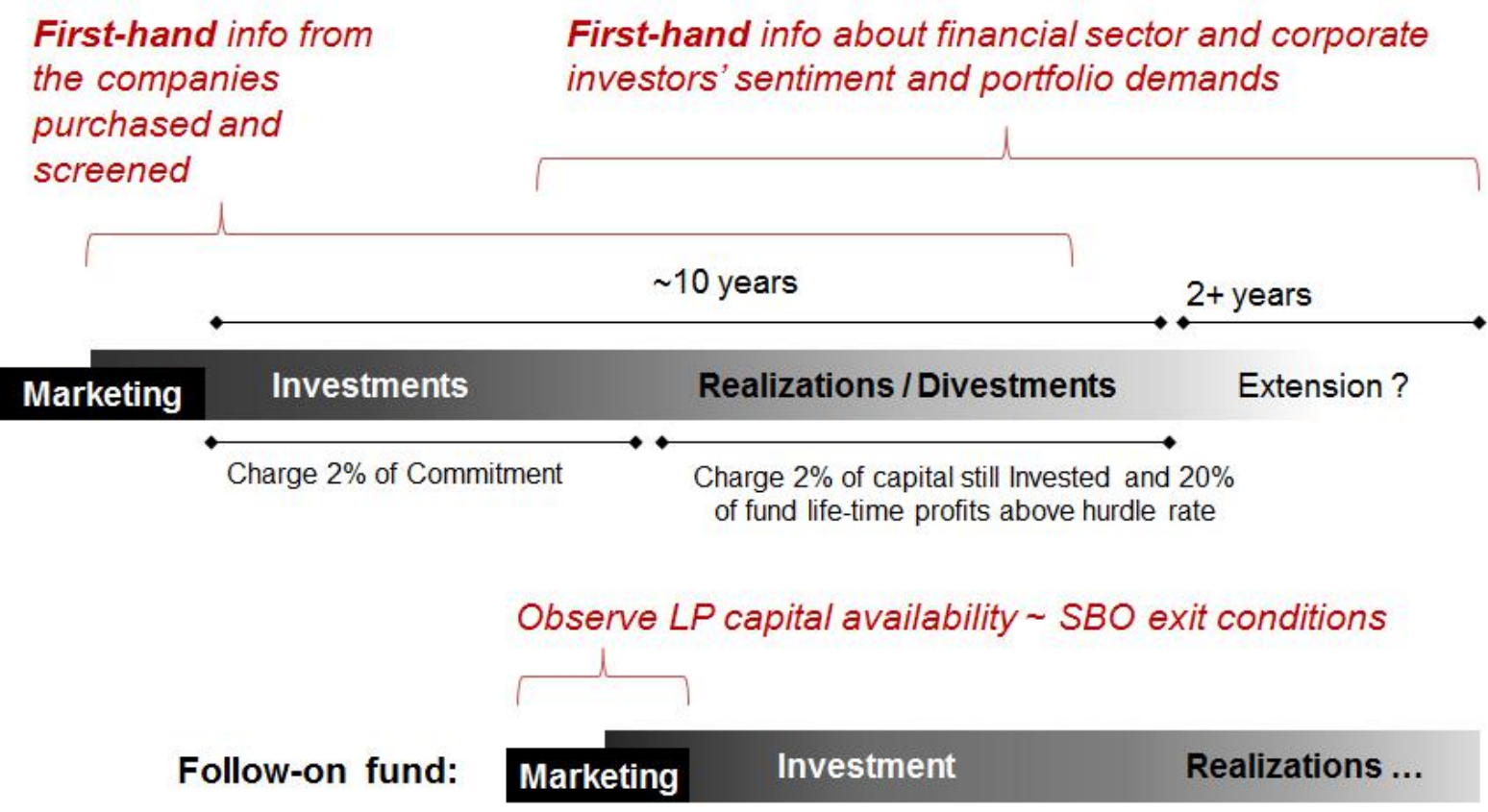




\section{Figure A.2: Timing Track Records: Examples}

This figure plots pair-wise comparisons of Timing Track Record (TTR) values for 8 hypothetical fund capital calls $\left(\right.$ CCall $\left._{t}\right)$ and distribution (Distrib $\left.b_{t}\right)$ schedules (\#1-\#8) and a common (mean-zero) market return $\left(r_{t}\right)$ schedule. The cash-flow schedules are from the LPs' perspective so that the negative values represent capital calls that sum to $\$ 50$ for all but fund \#2. All are derived from the following value process:

$$
\text { FundValue }_{t}=\text { FundValue }_{t-1}\left(1+r_{m, t}\right)+\text { CCall }_{t}-\text { Distrib }_{t}
$$

As discussed in Section 3, in this case the fund money-multiple equals TTR and reflects the gross-return due to selling near the market peaks during the fund life-time and buying near the troughs. Formally, TTR is determined according to the following formula:

$$
T T R=\frac{\sum_{t=1}^{T} \text { Distrib }_{t} \cdot e^{r_{1, T} \cdot(1-t / T)}}{\sum_{1}^{T} \text { CCalls }_{t} \cdot e^{r_{1, T} \cdot(1-t / T)}} / \frac{\sum_{t=1}^{T} \text { Distrib }_{t} \cdot e^{r_{t, T}}}{\sum_{1}^{T} \text { Calls }_{t} \cdot e^{r_{t, T}}},
$$

where $r_{t, T}\left(r_{1, T}\right)$ is market return from cash flow date(fund inception) until fund resolution. Top-left panel demonstrates that very different schedules can be equally market-timing neutral. Top-right panel reviews the case of buying at trough. Bottom-left panel demonstrates the effect of selling at peak whereas bottom-right panel combines timing of both, entry and exit.
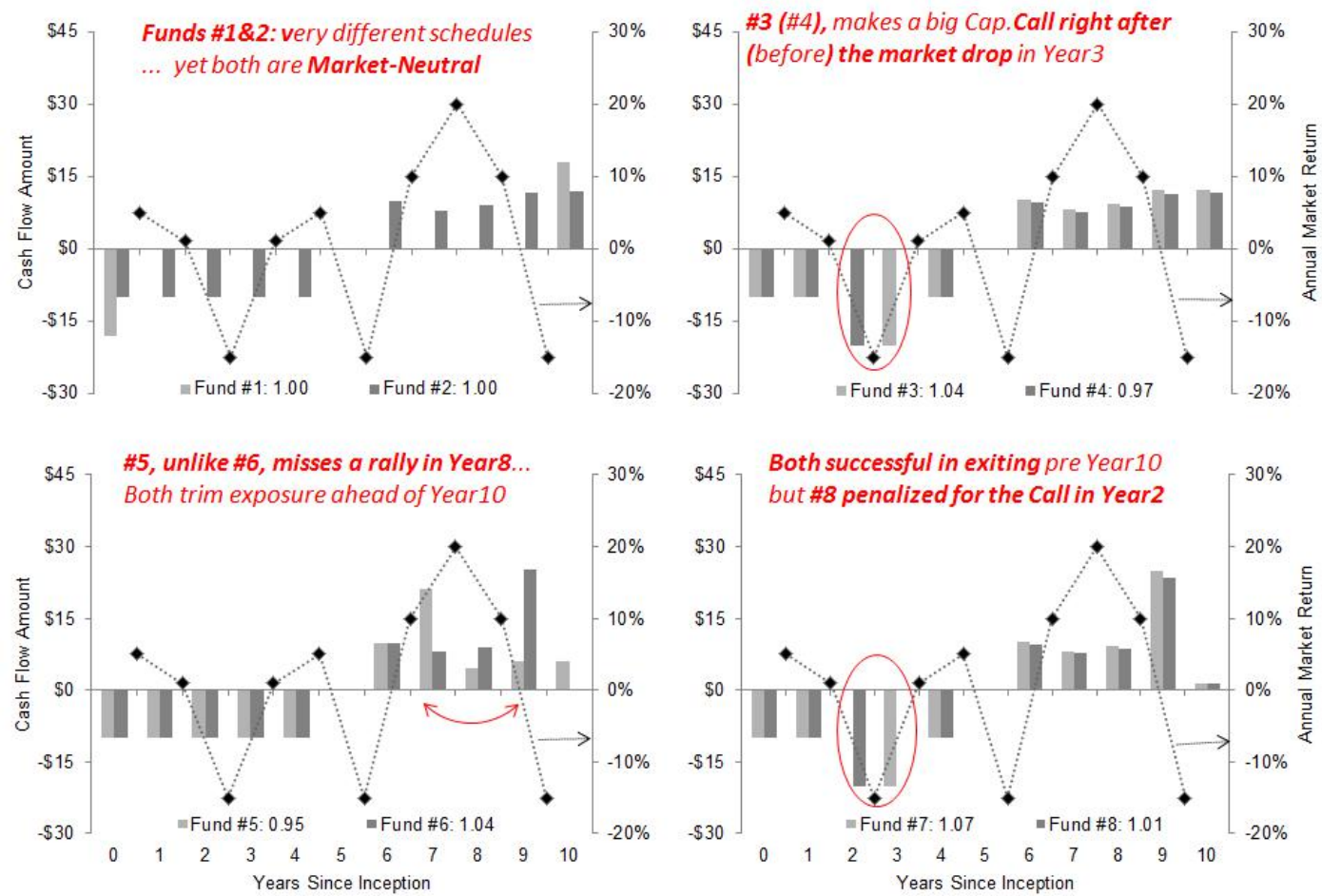


\section{Figure A.3: Industry Returns and Fund Inceptions}

This figure reports intertemporal distributions of Industry returns in Panel A and the sample private equity funds in Panel B. Each observation in the box-plot of Panel A represents a 12-month return of S\&P500 GICS industry sector subindex. The increment between intervals is one month so that there are 12 observations for each of the 10 industry sectors. Panel B plots total number of funds in the sample by vintage-year as well as the number of funds with a positive track record of market timing in the past, as measured by TTR - the gross-return due to selling near the market peaks during the fund life-time and buying near the troughs as per Equation (3.1) (Section 3).

Panel A: Industry Returns

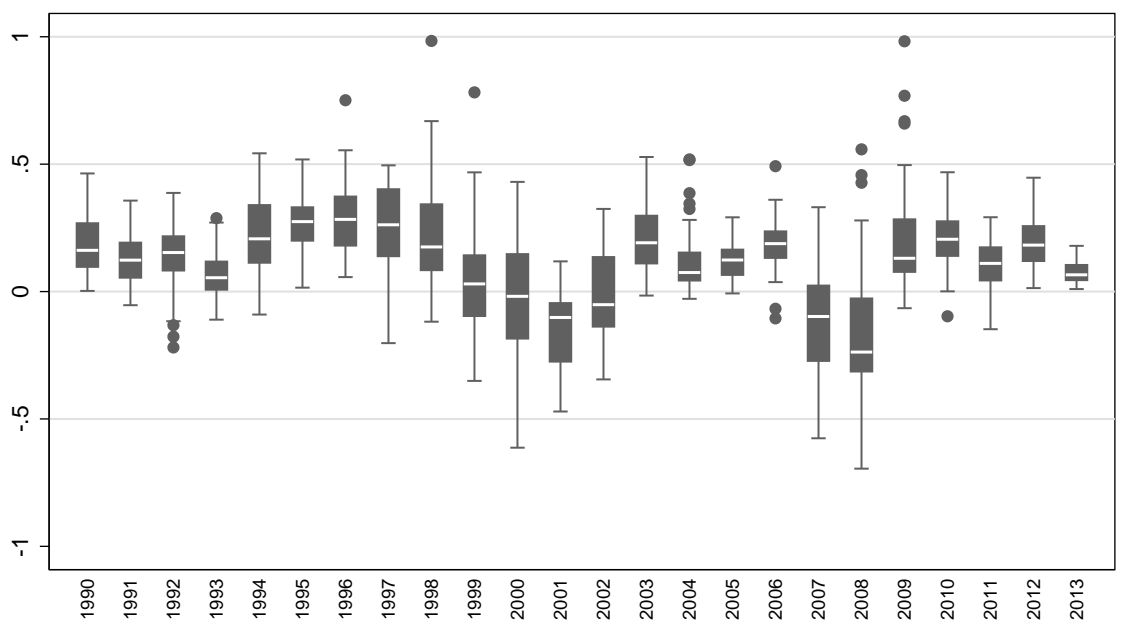

Panel B: Funds by vintage and TTR group

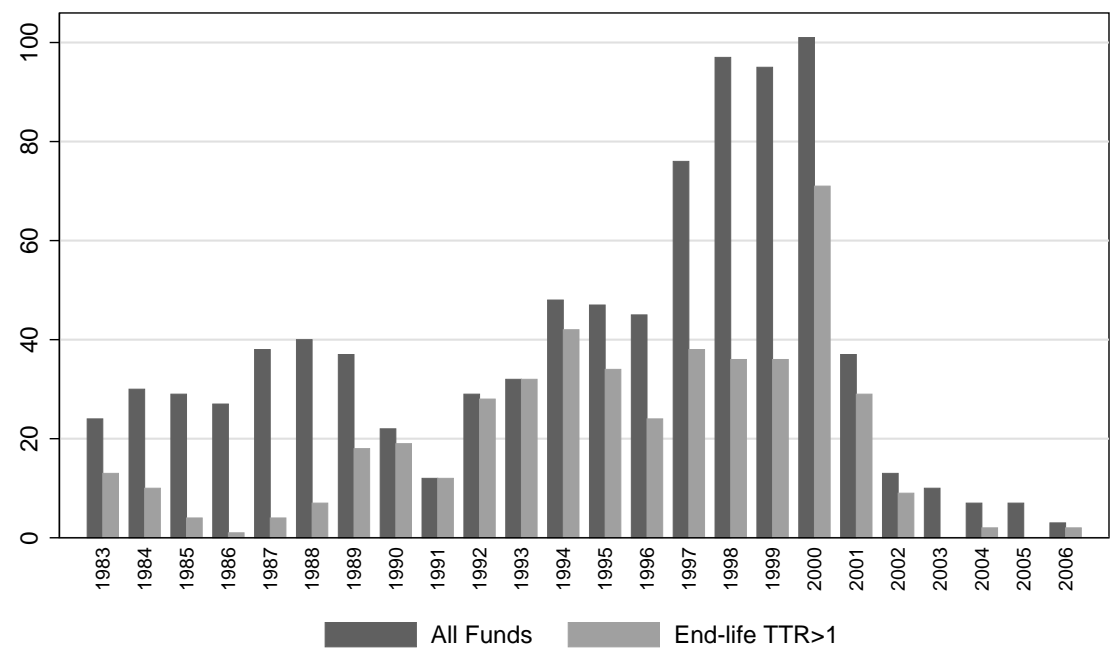




\section{Figure A.4: Timer's Rush and Industry Returns: Additional Event Studies}

This figure plots cumulative Industry returns around the stopping-time for funds that had Rush above (below) the fund vintage year median in Panel A (Panel B). Rush is a fraction of distributions over 6 quarters before the stopping-time in the fund total-to-date. The stopping time is defined as the distribution quarter at which NAV dropped below $15 \%$ of the fund total distributions to-date. The Industry returns is S\&P500 subindex of the GICS sector that the fund specializes in. The light-gray (Treated) line is the mean across funds that as of the stoppingquarter meet two criteria: (a) positive track record of market timing as proxied by TTR $>1$ (Section 3), (b) the fund to-date performance enables GPs to receive carried interest (if the fund were to resolve immediately) as proxied by net-of-fees $I R R$ above Hurdle-rate. The dark-gray line comprise of funds that do not meet these two criteria. Panel A reports results for funds with above-median Rush the full sample by stopping-year triplets while Panel B pools across all stopping times and below-median Rush (See Table 5.1 for above-median Rush). The bars denote $95 \%$ confidence interval.

Panel A: High Rush by Exit Year
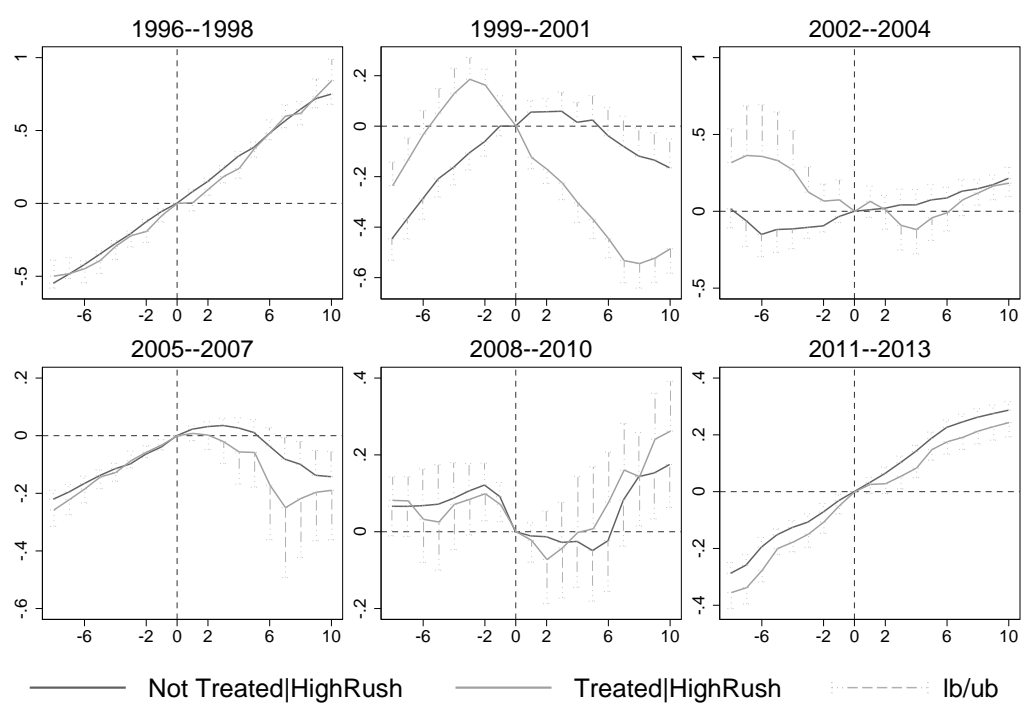

Panel B: Full Sample: What if No Rush?

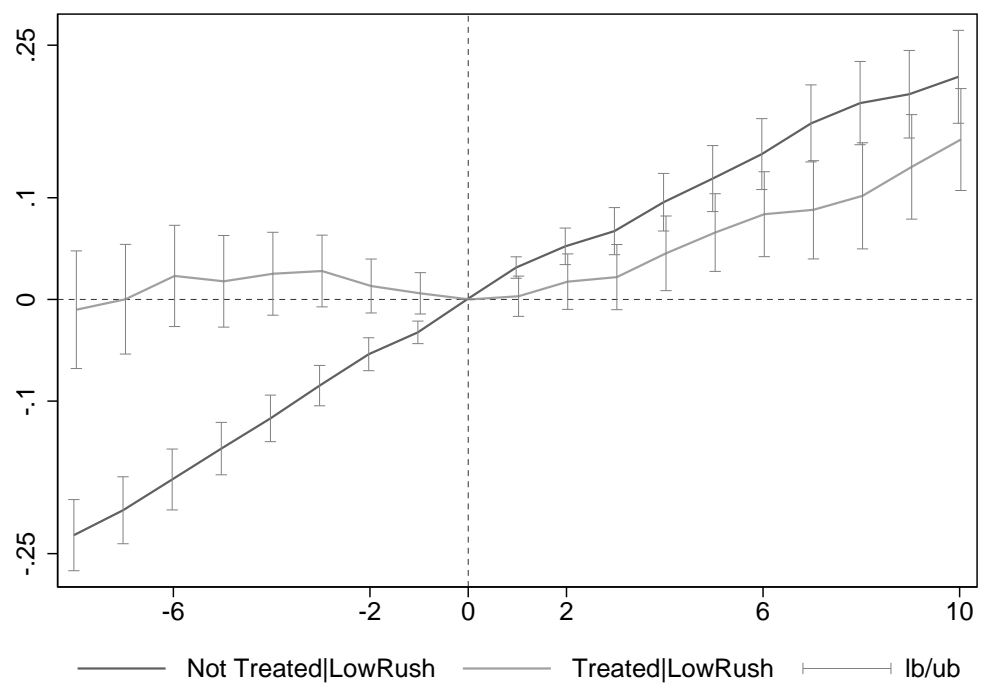




\section{Figure A.5: Timer's Rush and Industry Returns: Quarterly Portfolios}

This figure reports performance of a portfolio that is rebalanced quarterly based on Informed Rush signal (portfolio $B$ ) in comparison to an equally-weighted 10 GICS sector portfolio $(A)$, also rebalanced quarterly. Portfolio B sells Industry sectors where two or more Treated funds exhibited above-median Rush at their stopping-time over the past 3 or 7 quarters (i.e. $[0,+2 q]$ or $[0,+6 q]$ observation window respectively) and buys the remaining sectors (equally-weighted). Rush is defined as a fraction of distributions over 6 quarters before the stopping-time in the fund total-to-date distributions. The median is computed over all funds of the same type (venture or buyout) incepted in the same year. The stopping time is defined as the distribution quarter at which NAV dropped below $15 \%$ of the fund total distributions to-date. Treated funds satisfy the following criteria: (a) positive track record of market timing as proxied by $T T R>1$ (Section 3), (b) the fund to-date performance enables GPs to receive carried interest (if the fund were to resolve immediately) as proxied by net-of-fees $I R R$ above the hurdle-rate. Panel A reports cumulative returns since 1999Q1 through 2013Q1 for both portfolios (A\&B), their Sharpe-ratios and the number of sectors shorted in B end of each quarter. Panel B reports abnormal return estimates of portfolio $\mathrm{B}$ in excess of risk-free rate $(r f)$ or portfolio A relatively to value-weighted CRSP or three-factor Fama-French model. Standard errors in parentheses are robust to autocorrelation, $* / * * / * * *$ denote significance at $10 / 5 / 1 \%$ confidence level.

Panel A: Cumulative Returns by Holding Period Window
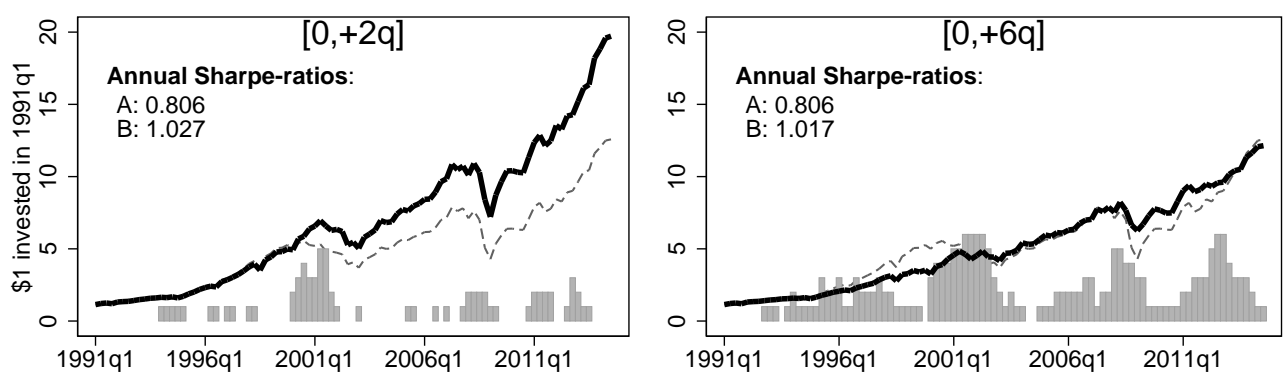

----10 GICS All Long - EW portfolio (A) \# of GICS Shorted based on PECF signal: [TTRtd $>1]^{*}[\text { IRRtd }>\text { HR] }]^{*}[$ Rush $>$ VinMedian] by $>1$ fund PECF-based Long-Short GICS porfolio (B)

Panel B: Abnormal Return Estimates

\begin{tabular}{|c|c|c|c|c|c|c|}
\hline & \multicolumn{3}{|c|}{$[0,+2 q]$} & \multicolumn{3}{|c|}{$[0,+6 q]$} \\
\hline & B-rf & B-rf & B-A & B-rf & B-rf & B-A \\
\hline alpha & $\begin{array}{c}0.012 * * \\
(0.005)\end{array}$ & $\begin{array}{l}0.009 \text { *** } \\
(0.003)\end{array}$ & $\begin{array}{l}0.006^{* * *} \\
(0.002)\end{array}$ & $\begin{array}{l}0.011^{* *} \\
(0.005)\end{array}$ & $\begin{array}{l}0.008 * * \\
(0.004)\end{array}$ & $\begin{array}{c}0.005^{*} \\
(0.003)\end{array}$ \\
\hline mktrf & $\begin{array}{l}0.689 * * * \\
(0.086)\end{array}$ & $\begin{array}{l}0.757 * * * \\
(0.060)\end{array}$ & $\begin{array}{c}-0.164 * * * \\
(0.042)\end{array}$ & $\begin{array}{l}0.465^{* * * *} \\
(0.083)\end{array}$ & $\begin{array}{l}0.530^{* * * *} \\
(0.081)\end{array}$ & $\begin{array}{c}-0.391 * * * \\
(0.070)\end{array}$ \\
\hline smb & & $\begin{array}{c}-0.179 * * * \\
(0.045)\end{array}$ & $\begin{array}{c}0.058^{*} \\
(0.034)\end{array}$ & & $\begin{array}{c}-0.162 * * \\
(0.072)\end{array}$ & $\begin{array}{c}0.075 \\
(0.056)\end{array}$ \\
\hline $\mathrm{hml}$ & & $\begin{array}{l}0.257^{* *} \\
(0.101)\end{array}$ & $\begin{array}{c}0.114^{*} \\
(0.065)\end{array}$ & & $\begin{array}{l}0.273^{* *} \\
(0.113)\end{array}$ & $\begin{array}{c}0.130 \\
(0.081)\end{array}$ \\
\hline $\mathrm{N}$ & 95 & 95 & 95 & 95 & 95 & 95 \\
\hline
\end{tabular}




\section{Table A.1: TTR Cross-Section: Robustness and Placebo}

This table reports linear regression model estimates of the log of funds' end-life TTRs. TTR is defined in Section 3 and measures the gross-return due to selling near the fund industry peaks during the fund life-time and buying near the troughs. The industry returns are proxied by those of GICS Sector index corresponding to the fund specialty. The explanatory variables are: $\ln (\text { Sequence })_{i}$ - chronological order of the fund inception date by given GPs (the private equity management firm); $\ln (P M E)_{i}-\log$ of the fund's Kaplan and Schoar (2005) Public Market Equivalent Index; $\ln (T T R)_{i-1}-\log$ of the GP's previous fund TTR; the respective industry return over the fund life-time (Trend) and its interaction with the respective variables of interest. Panel A reports regression estimates using actual values of TTR. Panel B reports the corresponding coefficients from simulations based on hypothetical exit schedules but actual funds' operation dates and industry return paths. The exit schedules are calibrated to match the sample means conditional only on time since a fund inception. The underlying fund holding period return-generating process $\left(\alpha, \sigma_{i}\right.$ and $\beta$ ) is specified relatively to the industry. Specifications (2) through (6) include fund vintage-year fixed effects. Standard errors in parentheses are clustered by GP, $* / * * * * * *$ denote significance at $10 / 5 / 1 \%$ confidence level.

Panel A: TTRs based on the Actual Exit Schedules

\begin{tabular}{|c|c|c|c|c|c|c|}
\hline & (1) & (2) & (3) & (4) & (5) & (6) \\
\hline $\ln (\text { IndSequence })_{i}$ & $\begin{array}{l}0.060^{* *} \\
(0.023)\end{array}$ & $\begin{array}{l}0.061 \text { *** } \\
(0.021)\end{array}$ & $\begin{array}{l}0.051^{* *} \\
(0.021)\end{array}$ & & & $\begin{array}{l}0.053^{* *} \\
(0.024)\end{array}$ \\
\hline $\ln (P M E)_{i}$ & & & $\begin{array}{l}0.058^{* * * *} \\
(0.017)\end{array}$ & & $\begin{array}{l}0.083^{* * *} \\
(0.024)\end{array}$ & $\begin{array}{l}0.080^{* * * *} \\
(0.025)\end{array}$ \\
\hline $\ln (T T R)_{i-1}$ & & & & $\begin{array}{l}0.149 * * * \\
(0.050)\end{array}$ & $\begin{array}{c}0.103^{*} \\
(0.052)\end{array}$ & $\begin{array}{c}0.093^{*} \\
(0.051)\end{array}$ \\
\hline Vintage FE & No & Yes & Yes & Yes & Yes & Yes \\
\hline Industry Trend & Yes & Yes & Yes & Yes & Yes & Yes \\
\hline Sequence $\times$ Trend & Yes & Yes & Yes & No & No & Yes \\
\hline PME $\times$ Trend & No & No & Yes & No & Yes & Yes \\
\hline Past TTR $\times$ Trend & No & No & No & Yes & Yes & Yes \\
\hline Observations & 756 & 756 & 756 & 404 & 404 & 404 \\
\hline$R^{2}$ & 0.049 & 0.384 & 0.397 & 0.440 & 0.463 & 0.470 \\
\hline
\end{tabular}

Panel B: TTRs based on Random Exit Schedules - Mean(SD) Coefficient Across 1,000 Simulations

\begin{tabular}{|c|c|c|c|c|}
\hline & (2) & (3) & (4) & (5) \\
\hline Ind. Seq. & $\begin{array}{c}0.009 \\
(0.011)\end{array}$ & & & $\begin{array}{c}0.009 \\
(0.011)\end{array}$ \\
\hline Curr. PME & $\begin{array}{c}0.016 \\
(0.052)\end{array}$ & & $\begin{array}{c}0.016 \\
(0.052)\end{array}$ & $\begin{array}{c}0.016 \\
(0.053)\end{array}$ \\
\hline Past TTR & & $\begin{array}{r}-0.017 \\
(0.048)\end{array}$ & $\begin{array}{r}-0.018 \\
(0.048)\end{array}$ & $\begin{array}{r}-0.018 \\
(0.048)\end{array}$ \\
\hline \multicolumn{5}{|c|}{$\alpha=250 b p, \sigma_{i}=40 \%, \beta=1.0$} \\
\hline & (2) & (3) & (4) & (5) \\
\hline Ind. Seq. & $\begin{array}{c}0.009 \\
(0.012)\end{array}$ & & & $\begin{array}{c}0.009 \\
(0.012)\end{array}$ \\
\hline Curr. PME & $\begin{array}{c}0.019 \\
(0.036)\end{array}$ & & $\begin{array}{c}0.019 \\
(0.036)\end{array}$ & $\begin{array}{c}0.019 \\
(0.037)\end{array}$ \\
\hline Past TTR & & $\begin{array}{c}-0.018 \\
(0.050)\end{array}$ & $\begin{array}{c}-0.018 \\
(0.050)\end{array}$ & $\begin{array}{r}-0.019 \\
(0.050)\end{array}$ \\
\hline
\end{tabular}

\begin{tabular}{|c|c|c|c|c|}
\hline & (2) & (3) & (4) & (5) \\
\hline Ind. Seq. & $\begin{array}{c}0.009 \\
(0.012)\end{array}$ & & & $\begin{array}{c}0.009 \\
(0.012)\end{array}$ \\
\hline Curr. PME & $\begin{array}{c}0.017 \\
(0.037)\end{array}$ & & $\begin{array}{c}0.017 \\
(0.037)\end{array}$ & $\begin{array}{c}0.017 \\
(0.037)\end{array}$ \\
\hline Past TTR & & $\begin{array}{r}-0.016 \\
(0.050)\end{array}$ & $\begin{array}{r}-0.017 \\
(0.050)\end{array}$ & $\begin{array}{r}-0.017 \\
(0.050)\end{array}$ \\
\hline \multicolumn{5}{|c|}{$\alpha=250 b p, \sigma_{i}=40 \%, \beta=1.5$} \\
\hline & (2) & (3) & (4) & (5) \\
\hline Ind. Seq. & $\begin{array}{c}0.016 \\
(0.018)\end{array}$ & & & $\begin{array}{c}0.016 \\
(0.018)\end{array}$ \\
\hline Curr. PME & $\begin{array}{c}0.030 \\
(0.020)\end{array}$ & & $\begin{array}{c}0.030 \\
(0.020)\end{array}$ & $\begin{array}{c}0.030 \\
(0.020)\end{array}$ \\
\hline Past TTR & & $\begin{array}{c}-0.018 \\
(0.058)\end{array}$ & $\begin{array}{r}-0.017 \\
(0.057)\end{array}$ & $\begin{array}{r}-0.019 \\
(0.057)\end{array}$ \\
\hline
\end{tabular}




\section{Table A.2: Do Exits Cause Downturns?}

This table reports predictive regressions of Industry returns by placebo-substitutes for Informed Rush to provide further support for the identification scheme deployed in Table 5.1. The underlying difference-in-difference estimation, the dependent variable (mean Industry Return 12-months forward return), and all other controls as the same as in the respective specification of Table 5.1A. But either the stopping-time and Rush or the treatment group is defined differently. In both panels, specifications (3)-(4) have predictive covariates added but otherwise are identical to (1)-(2).

In Panel A, I conjecture that funds with the greatest Footprint-on-Firms shall be those with best abnormal returns on invested capital. Since PME and TTR are correlated (as per Table 3.1), I only look at the subset of those funds where $T T R<=1$ to not confound the treatment group with that in 5.1A. Hence, Treated $d_{i j}$ is a dummy taking value of 1 if as of stopping quarter (i) Kaplan-Schoar PME is in the respective fund-type $\times$ vintage-year top tercile and (ii) TTR is less than 1 (Section 3). While $R u s h_{i j}$ is defined as before, a fraction of distributions over the last 6 quarters in the funds' total-to-date. Correspondingly, the stopping-times in odd (even) numbered specifications are fund-quarter when fund NAV drops below 15 (20)\% of the fund total distributions up to that quarter.

In Panel B, I keep the same definition of the treatment group as in 5.1A but look at fund distributions at different times rather than the stopping. Recall that under the Footprint-on-firms alternative, exits per se should have impact on Industry performance rather than the extent they remove GPs carried interest exposure to adverse market moves. Specifically, I look at a 4-quarter period with maximum cumulative distributions outside $(-18,12)$ months window around the stopping time defined by $15 \%$ threshold (i.e. before $15 \%$, after $15 \%$ ). Also, I now measure rush amounts in $\$$ so that they are more proportional to the industry market capitalization (and hence, potential impact). To have magnitudes and distributions close to those of actual Rush, I define MaxRush as the probit function of $\log (\$ m \ln / 10)$.

Standard errors in parentheses are clustered at stopping-quarter level, $* / * * / * * *$ denote significance at 10/5/1\%.

Panel A: Treated $\equiv P M E \in T o p T e r \cdot T T R<1$

\begin{tabular}{lccccc}
\hline & $(1)$ & $(2)$ & & $(3)$ & $(4)$ \\
\cline { 2 - 3 } \cline { 5 - 6 } TopPME*TTR11*Rush & $0.017 * *$ & $0.015^{*}$ & & 0.007 & 0.010 \\
& $(0.007)$ & $(0.008)$ & & $(0.007)$ & $(0.007)$ \\
TopPME*TTR11 & -0.002 & -0.002 & & -0.000 & -0.001 \\
& $(0.003)$ & $(0.003)$ & & $(0.003)$ & $(0.003)$ \\
Rush & $-0.010^{* *}$ & $-0.012^{* *}$ & & -0.000 & -0.001 \\
& $(0.005)$ & $(0.005)$ & & $(0.003)$ & $(0.003)$ \\
Vintage FE & Yes & Yes & & Yes & Yes \\
Predictive covariates & No & No & & Yes & Yes \\
Observations & 893 & 941 & & 893 & 941 \\
$R^{2}$ & 0.196 & 0.214 & & 0.442 & 0.462 \\
\hline
\end{tabular}

Panel B: Treated $\equiv(T T R>1) \times(I R R>H R)$, Rush outside exit period

\begin{tabular}{lccccc}
\hline & before $15 \%$ & after15\% & & before $15 \%$ & \multicolumn{2}{c}{ after15\% } \\
& $(1)$ & $(2)$ & & $(3)$ & -0.000 \\
\cline { 2 - 3 } \cline { 5 - 5 } TTRg1*IRRgHR*MaxRush & -0.001 & -0.001 & & -0.002 & $(0.005)$ \\
TTRg1*IRRgHR & $(0.005)$ & $(0.005)$ & & $(0.005)$ & -0.003 \\
& 0.002 & -0.001 & & 0.002 & $(0.004)$ \\
MaxRush & $(0.003)$ & $(0.003)$ & & $(0.003)$ & 0.004 \\
Vintage FE & 0.001 & -0.001 & & 0.001 & $(0.003)$ \\
Predictive covariates & $(0.002)$ & $(0.004)$ & & $(0.002)$ & Yes \\
Observations & Yes & Yes & & Yes & Yes \\
$R^{2}$ & No & No & & Yes & 500 \\
\hline
\end{tabular}




\section{Table A.3: The Model of Fund Fixed Effects}

This table reports a model of funds' stopping-time and rush amounts estimated as Seemingly Unrelated Regressions for all funds in my sample. The dependent variables are (1) the natural logarithm of number of quarters since the fund's inception when a threshold of the NAV to total distributions has been crossed from above (has to be a quarter with non-zero distributions to LPs); (2) a probit function of a fraction of distributions (to LPs) over the last 6 quarters in the funds' total-to-date. The explanatory variables are same in both linear equations: $\ln \left(\mathrm{Size}_{i}-\log\right.$ of the fund \$ capital committed; PME-to-date - Kaplan-Schoar PME against S\&P500 subindex corresponding to the fund GICS Industry sector specialty; TopTercl IRR-to-date - dummy that equals 1 if the fund IRR is in the top tercile over the fund-type $\times$ vintage-year peers; Follow-on Raised-dummy that equals 1 if at least one more fund by the same GPs have started investments 2 years after the current fund inception date; Follow-on w/n 6 qtrs - dummy that equals 1 if another fund by the same GPs will start investments within 6 quarters from the current fund stopping-quarter; Follow-on CapCalled - capital called by the last-most follow-on fund by GPs as a fraction of committed (0 if no follow-on exists); Industry-Year FE - the fund specialty GICS Industry-sector $\times$ vintage-year fixed effects. I include two observations per fund where $15 \%$ and $20 \%$ thresholds were not crossed simultaneously and the resulting stopping-times are different. This the auxiliary model to obtain the fitted values of "fund fixed effects" (with respect to the stopping times and rush amounts) and parametrize random exit simulations (via the covariance matrix of SUR residuals) - see Section 5.5.2 and A.2 for discussions and details. $* / * * / * * *$ denote significance at $10 / 5 / 1 \%$.

\begin{tabular}{lcccccc}
\hline & \multicolumn{2}{c}{$\ln ($ Stopping } & - time $)$ & & \multicolumn{2}{c}{$\Phi^{-1}($ Rush $)$} \\
& Coefficient & SE & & Coefficient & SE \\
\cline { 2 - 3 } \cline { 5 - 6 } $\ln ($ Size $)$ & $0.017 * * *$ & $(0.006)$ & & $-0.092^{* * * *}$ & $(0.023)$ \\
PME-to-date & $-0.036^{* * *}$ & $(0.004)$ & & $0.128^{* * *}$ & $(0.016)$ \\
TopTercl IRR-to-date (d) & $-0.165^{* * *}$ & $(0.014)$ & & $-0.151^{* * *}$ & $(0.052)$ \\
Follow-on Raised (d) & $-0.056^{* *}$ & $(0.024)$ & & 0.122 & $(0.086)$ \\
Follow-on w/n 6 qtrs (d) & $-0.110^{* * *}$ & $(0.021)$ & & $0.143^{*}$ & $(0.075)$ \\
Follow-on CapCalled (\%) & $0.063^{* * *}$ & $(0.016)$ & & -0.054 & $(0.057)$ \\
Industry-Year FE & Yes & & & Yes & \\
Observations & 1242 & & & & \\
$R^{2}$ & 0.442 & & & 0.132 & \\
\hline
\end{tabular}




\section{A.2 Simulation-related Supplements and Discussions}

\section{A.2.1 Recap and Robustness}

In this section I provide additional details about the simulations-based estimation method that I deploy in Section 5.5.2 to refine the estimates of the key coefficient of interest that measures the sensitivity of subsequent Industry Returns to Informed Rush. The method involves three steps.

First, I estimate models of expected $\ln ($ stopping - time $)$ and $\Phi^{-1}($ Rush $)$ for all funds in our sample as linear functions of: (i) Vintage-Industry fixed effects; (ii) Fund size, PME-to-date, IRR-rankto-date; (iii) GPs follow-on fund start dates and investments activity where available. ${ }^{1}$ We treat the two equations as Seemingly Unrelated Regressions as per Zellner (1964), but the main model estimates are essentially unchanged if I allow simultaneity in the stopping-time and Rush and use IV-estimates of the expected values (untabulated). I utilize the pseudo-panel structure of Rush and stopping-time observations per fund where the pattern of fund distribution permits so. ${ }^{2}$. Besides the expected values, I also obtain the covariance matrix of the residual $\ln ($ stopping - time $)$ and $\Phi^{-1}($ Rush $)$. This auxiliary model estimates are presented in Table A.3.

Second, I draw a sample of 100 random bivariate normal shocks from a covariance matrix that is itself randomly drawn each time from Wishart distribution parametrized by the the covariance matrix of residuals estimated in the first step. In doing so, I allow for uncertainty about the first-step estimates and for heteroskedastic error term in the unobserved population, essential in the third step. ${ }^{3}$ The same shocks are merged to each fund-threshold in the sample. Adding fund-threshold-specific estimates of expected $\ln ($ stopping - time $)$ and $\Phi^{-1}($ Rush $)$ and reverting the functional transformations, I obtain the simulated (aka placebo) values of stopping-time and Rush for each fund-threshold in the sample that reflect (a) Industry-GPs-fund characteristics, (b) sample covariance of unpredicted portion of stoppingtime and Rush, and (c) random shocks drawn from a random mixture of normal distributions.

\footnotetext{
${ }^{1}$ The sample industry-vintage universe is rather sparse before 1990 (relatively few funds to begin with) and post 2003 (as relatively few funds reach the stopping-time threshold). Whenever the industry-vintage bucket includes fewer than nine funds, I (i) consolidate "Energy" and "Materials" into "Industrials", "Consumer Staples" into "Consumer Discretionary" and (if still fewer than nine funds) (ii) consolidate vintages into triennial groups to allow for better estimations precision.

${ }^{2}$ Namely, when a fund reaches $15 \%$ and $20 \%$ threshold of residual NAV to total distributions-to-date is different

${ }^{3}$ See also a discussion in Section 4.
} 
Applying actual inception dates, for each fund-threshold-placebo exit I obtain the corresponding stopping-months and match 12-month forward mean Industry Return as well as the respective month and industry-month covariates that control for Pseudo-timing alternative. ${ }^{4}$ The data end in October 2013, with the last actual fund stopping-month being March 2013. If the stopping-month is later than June 2013, this placebo exit is truncated so that the forward mean return is computed over at least 4 months. Hence, some of the funds post 2003 vintage will tend to have notably fewer than 100 placebo exits. $^{5}$

The $\log$ (inverse-probit) transformation in the first step insures that simulated stopping-times (Rush) are all positive (between 0 and 1). Although consistency of the third step will not depend on whether the distribution of actual stopping-times and Rush are close to the simulated ones, it is useful to examine this question as it may affect inference. Figure A.6 reports comparisons of univariate distributions and bivariate relations of actual stopping-times and Rush (Actual Funds) vis-a-vis those of placebo exits (Simulated Funds) for a simulated sample. It appears that simulated bivariate distributions tend to have more weight in tails which is unlikely to bias-down the parameter variance estimates.

Third, I compare how subsequent Industry Returns associate with Rush of actual funds of interest (denoted by Treated-dummy) as opposed to that in placebo exits corresponding to these funds via Model

\section{1 (main model):}

$E\left[\right.$ IndustryReturn $\left._{i j, 1: 12}\right]=\beta$ Treated $_{i j}$ Rush $_{i j}+\gamma_{1}$ Treated $_{i j}+\gamma_{2}$ Rush $_{i j}+a_{j}$.

The panel subscript $j$ denotes a given actual fund $\left(\right.$ Treated $\left._{i j}=1\right)$ and the placebo exits $\left(\right.$ Treated $\left._{i j}=0\right)$ corresponding to this fund. In Section 5.5.2 I study different groups of actual funds, subsetting the control group accordingly each time (rather than re-simulating it). In this section, I will focus on the funds that as of the actual stopping-time had positive timing track record $(T T R>1$, Section 3$)$ and $I R R>$ HurdleRate. Specifically, I will examine statistical properties of the main coefficient of interest, $\beta$.

To insure that $\beta$ estimates are robust to the simulation starting point (seed value) and yet to keep the procedure computationally attractive, I repeat the second and third steps 1,000 times. Each time I

\footnotetext{
${ }^{4}$ CAY-ratio, VIX, U.S. Treasury yields, corporate credit spreads, the industry index price-earnings and bookto-market ratios. See Section 2 for details and summary statistics.

${ }^{5}$ The results are robust to dropping these funds (untabulated).
} 
randomly choose simulation seeds for shocks and the covariance matrix draws which also alleviates the autocorrelation problem in pseudo-random number generators. Hence, I obtain independent estimates of Model (4.1) over 1,000 samples of identical data for actual funds augmented with different simulated pseudo exits (henceforth independent simulation).

The estimates (confidence intervals) for $\beta$ that I report in Tables 5.2 and 5.3 in the main text and in Figures A.7 and A.8A are (based on) equally weighted means of $\beta_{s}\left(\operatorname{avar}(\beta)_{s}\right)$ over these 1,000 independent simulation. ${ }^{6}$ In essence, I run Fama-Macbeth (1973) procedure which is asymptotically equivalent and typically as efficient as panel Least-Squares methods. ${ }^{7}$. While the aggregation of point estimates is standard, my choice for the variance reflects the fact that $\beta$-estimates across our independent simulation must be perfectly correlated asymptotically. ${ }^{8,9}$

Besides $\beta$ and the asymptotic variance-based confidence interval, Figure A.7 plots the range for $\beta_{s}$ across independent simulation. This range indicates how sensitive the estimates are to the seed value choice when we draw at most 100 random exits for each fund. In both Panels, A and B, top-left(right) charts report results for the baseline model with stopping-time defined as crossing 15 (20)\% threshold of $\mathrm{NAV/(total} \mathrm{distributions} \mathrm{to-date),} \mathrm{while} \mathrm{bottom-left} \mathrm{(right)} \mathrm{-} \mathrm{for} \mathrm{the} \mathrm{baseline} \mathrm{model} \mathrm{augmented} \mathrm{with}$ Pseudo-timing controls and 15 (20)\% threshold. Panel A investigates how robust the estimates are to exclusion of selected vintage years. Panel B - dummies-out selected exit years.

Figure A.3 plots Industry return ranges by exit year (Panel A) and by-vintage distribution of funds with $T T R>1$ (Panel B). It motivates a question if our timing skill estimates might be solely driven by a few clusters of funds or exits. In each chart/panel of A.7, Case 1 corresponds to the baseline estimates of $\beta$ (as reported in Table 5.2B). Cases 2 through 10 in Panel A exclude the following (groups of) vintage years:

- 1993

${ }^{6}$ Each $\operatorname{avar}(\beta)_{s}$ estimate is robust to error clustering at exit quarter.

${ }^{7}$ See Skoulakis (2008)

${ }^{8}$ A GLS version of Ferson and Harvey (1999) yields almost identical point estimates in the cases I reviewed (untabulated).

${ }^{9}$ This variance estimator can also be viewed as obtained through a parametric bootstrap, e.g. see Efron and Tibshirani (1994). 
- 1992

- 1990

- 2001

- $1993 \& 1992$

- 1990\&2001

- $1990 \& 1993 \& 2001$

- 1990\&1992\&2001

- 1990\&1992\&1993\&2001

In Panel B, cases 2 through 10 add the following year dummies:

- 2007

- 1999

- 2000

- 2008

- 2007\&1999

- $2000 \& 2008$

- $2000 \& 2007$

- 2000\&2007\&1999

- $2000 \& 2007 \& 2008$

- $2000 \& 2007 \& 1999 \& 2008$ 
The estimates are virtually unchanged across all cases in both panels. Hence, the results are not driven by a few calendar clusters.

Next, in Figure A.8 Panel A I examine how the predictability changes when I assign non-native Industry returns. For each month I compute 5-year rolling pairwise correlations for 10 GICS sectors portfolios so that for each fund-month the Industry portfolios are ranked by correlation proximity to the native-industry (Case 1). Clearly, if the effect I estimate has to do with GPs' expertise, the strongest predictability should be with respect to the native industry. That is what we observe for both threshold specifications, 15 and $20 \%$ on left and right charts respectively. The coefficients decay towards zero almost monotonically.

Finally, I seek to address concerns about the parameter-dependence of the null hypothesis that the estimation features. Panel B of Figure A.8 plot $\beta$ estimates over independent simulations when actual fund stopping month and Rush are replaced by their expectations estimated in the first step. These expected values indicate the location of the density masses for the simulated funds. Clearly, they are always zero statistically and, if anything, tend to be slightly negative - just as our estimates for actual fund stopping month and Rush. As with expected stopping month and Rush, I can compute coefficient and variance estimates for each one of the 100 bivariate draws. Panel $\mathrm{C}$ plots the fraction of simulated funds that have t-statistic lower than that of the actual funds by each independent simulation. We can see that these random rejection rates are consistent with (two-sided) 5\% confidence level for the $15 \%$ threshold case as per asymptotic variance estimates in Table 5.2B, but somewhat higher for the $20 \%$ threshold case where with asymptotic variance estimate we can reject at $10 \%$ level.

There is not much subjectivism with the simulation framework I propose. Once could have simply taken covariance matrix of stopping-times and Rush (rather than residuals) to parametrize the simulations and end-up having near-uniform bivariate distribution which would make $a_{j}$ fixed effects pointless (beyond controlling for the fund inception date). The only way one can shrink this covariance matrix is by including relevant covariates that nonetheless leave enough within-variation to identify the coefficients of interest in the main model. By the same line of arguments, it is not that important whether we neglect possible endogenity in the auxiliary model since the covariance of residuals shall pick it up. 
The suggested estimation approach is highly attractive computationally and immediately yields convenient model diagnostics and null hypothesis verification tools. They all suggest good finite sample properties of the $\beta$ and $\operatorname{var}(\beta)$ estimates reported in Section 5.5.2 of the main text.

\section{A.2.2 Alternative Approaches}

Another viable econometric strategy to compare market returns following actual fund exits and rush from those under a random exit assumption would borrow tools from the survival analysis. In fact, a discrete time hazard-rate model would imply a very similar dataset (spanning the plausible range of stopping-times for each fund) to the one I use to estimate the main model but the observation weights would be governed by a parametric distribution (i.e. logistic) instead of a mixture of normals that my simulations imply. Even though the interpretation of coefficients would be less intuitive as in Model 4.1, it may be worth close consideration given its wide usage and well developed asymptotic properties. ${ }^{10}$

However, neither is such a discrete hazard-rate model more robust to functional form misspecification or variables omissions, nor is it less restrictive as it comes to the parameter variance estimation. Moreover, non-linear MLEs are prone to the incidental parameter problem with large set of fixed effects (unlike OLS that I run). ${ }^{11}$ Finally, by-passing an auxiliary model of my approach would not be possible with a hazard-rate model still, because even the values of hypothetical Rush are not known even

for the stopping-times that do not exceed the actual. ${ }^{12}$ The discussion in Section 4.4.2 suggests a high importance of the variation in Rush for timing signal extraction and so do the findings in Robinson and Sensoy $(2011,2013)$.

\footnotetext{
${ }^{10}$ The dummy Treated and mean Industry Return would have to switch sides since the dependent variable needs to be binary.

${ }^{11}$ For example, see Wooldrich (2002).

${ }^{12}$ Essentially, for each quarter we observe a rolling window sum of distributions to the total sum of distributions to-date, conditional the actual "stopping quarter". What we need to observe is that amount conditional on "stopping" in that particular quarter.
} 


\section{Figure A.6: Actual Exits versus Simulated}

This figure reports comparisons of stopping-times (Effective Life) and fractions of distributions over 6 quarters preceding it in the fund total distributions to-date (Rush-to-Exit) for actual and simulated exits. The simulation proceeds as follows. I draw a sample of 100 random bivariate normal shocks from a covariance matrix that is itself randomly drawn each time from Wishart distribution parametrized by the the covariance matrix of residual $\ln \left(\right.$ stopping - time) and $\Phi^{-1}($ Rush $)$ from the fund fixed effect model reported in Table A.3. The sample correlation between the residuals is -0.19 . The same shocks are merged to each fund-threshold in the sample. Adding fund specific estimates of expected $\ln \left(\right.$ stopping - time) and $\Phi^{-1}($ Rush $)$ and reverting the functional transformations, I obtain simulated (i.e. placebo) values of stopping-time and Rush for each fund in the sample that reflect (a) Industry-GPs-fund characteristics, (b) sample covariance of unpredicted portion of stopping-time and Rush, and (c) random shocks drawn from a random mixture of normal distributions. Panel A reports kernel density estimates of Effective Life (left-hand chart) and Rush-to-Exit with solid (dashed) line being a separate estimate over the actual (simulated) values. Panel B plots local polynomial regressions estimates of Effective Life and Rush-to-Exit relations for actual and simulated values on the left- and right-hand charts respectively.

\section{Panel A: Univariate Distributions}

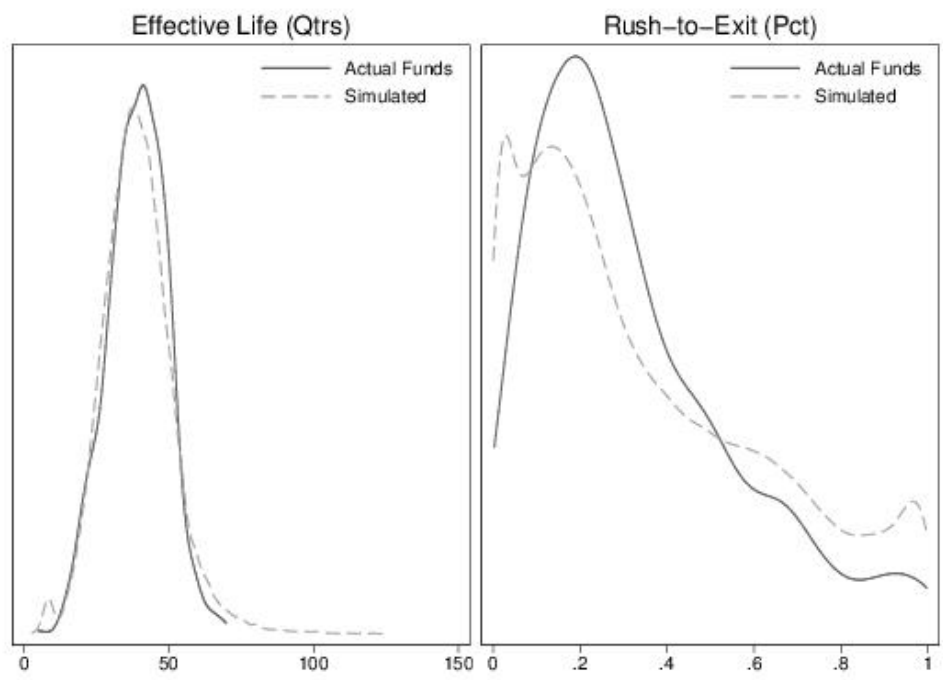

Panel B: Bivariate Relations
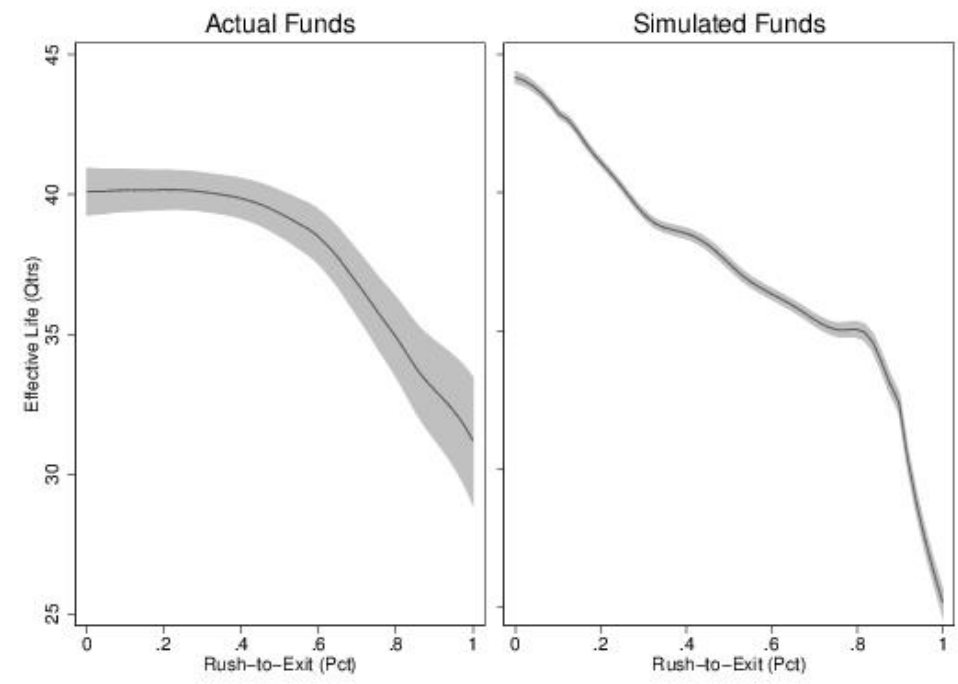


\section{Figure A.7: Robustness}

This figure reports robustness tests for the simulation-based estimates of predictive regressions of Industry returns by Rush reported in Table 5.2A. Top-left (right) and bottom-left (right) correspond to specifications 1 (2) and 3 (4) respectively. In both panels, Case 1 corresponds to the baseline estimates of $\beta$ tabulated in 5.2A. The solid black line is the mean coefficient value across 1,000 independent simulations, while the area denotes the range of the values. The $95 \%$ confidence interval is based on a mean of asymptotic variance estimates across the simulations. For Cases 2 through 10, Panel A reports estimates for the same model but the following fund vintage year being excluded from the estimation: '93 - '92 - '90 - '01 - '93'92 - '90'01 - '90'93'01 - '90'92'01 - '90'92'93'01. While in Panel B, Cases 2 through 10 include all vintages but augment the model with a dummy denoting the actual fund stopping-quarters falling in the following years: '07 - '09 - '00 - '08 - '07'09 - '00'08 - '00'07 '00'07'09 - '00'07'08 - '00'07'09'08.

\section{Panel A: Exclude Selected Vintage Years}

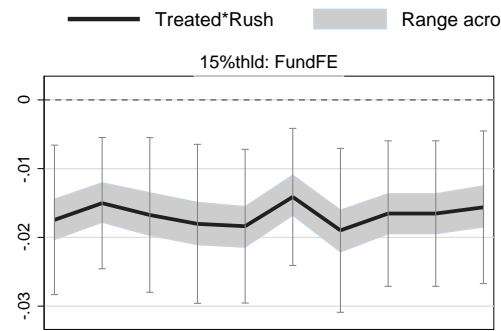

15\%thld: FundFE+PseudoTiming

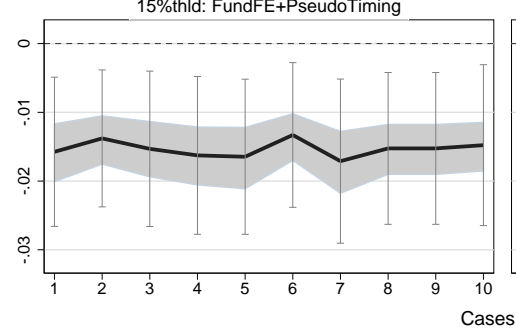

Panel B: Dummy-out Selected Exit Years

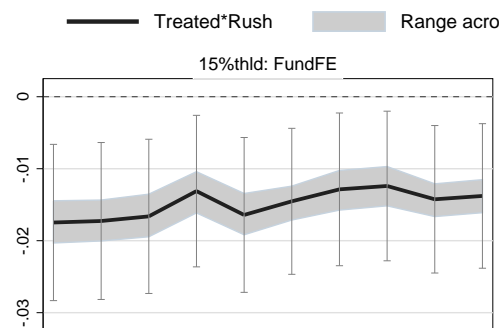

15\%thld: FundFE+PseudoTiming

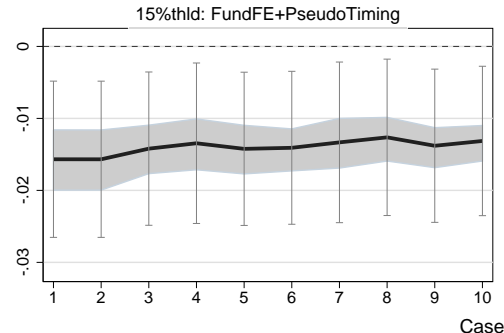

$95 \% \mathrm{Cl}$ from aVar

20\%thld: FundFE

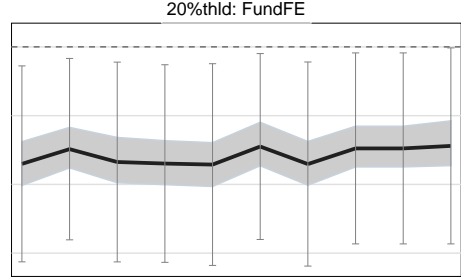

20\%thld: FundFE+PseudoTiming

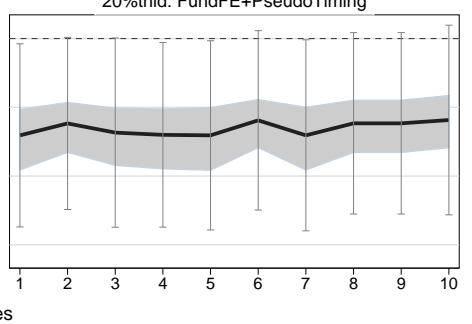

s

simulations $\longmapsto 95 \% \mathrm{Cl}$ from aVar

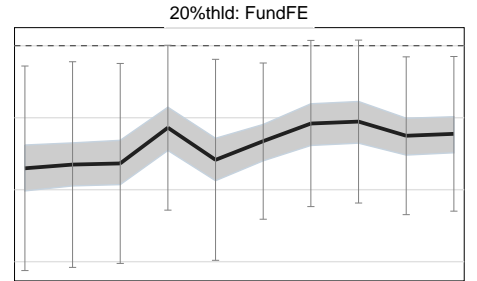

20\%thld: FundFE+PseudoTiming

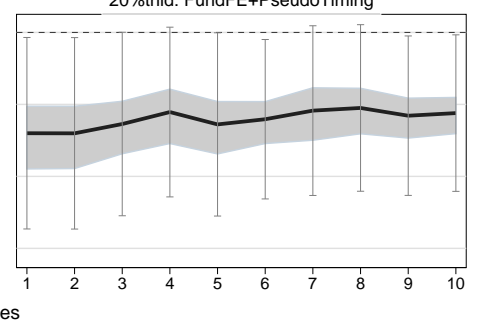




\section{Figure A.8: Placebo Tests}

This figure reports placebo tests for the simulation-based estimates of predictive regressions of Industry returns by Rush reported in Table 5.2A. Left (right)-hand charts correspond to specification 3(4). Case 1 of Panel A corresponds to the baseline estimates of $\beta$ tabulated in 5.2A. Cases 2 though 10 replace the fund native GICS industry sector returns, as measured by S\&P500 subindex, with those of the correlation proximity-ranked sector so that 10 corresponds to the sector with the lowest correlation of monthly returns over the 5-year rolling window as of the actual stopping-quarters. The solid black line is the mean coefficient value across 1,000 independent simulations, while the area denotes the range of the values. The $95 \%$ confidence interval is based on a mean of asymptotic variance estimates across the simulations. Panel B plots $\beta$ estimates and $95 \%$ confidence intervals over these independent simulations if the actual funds stopping-times and distributions were replaced by the expected ones from the fund fixed effect model reported in Table A.3. Panel C plots the fraction of placebo exits that have t-statistic lower than that of the actual funds by each independent simulation (100 bivariate draws) as well as the mean value across them. See A.2 text for a discussion.

\section{Panel A: Proximity-ranked Industries}

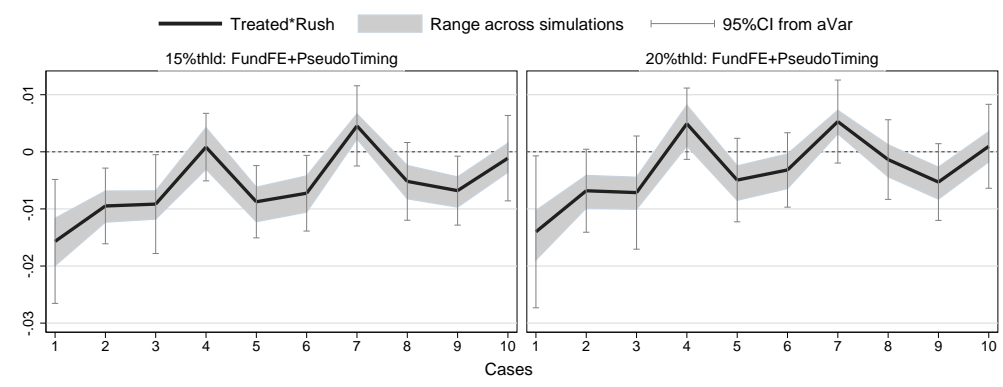

Panel B: Fund Fixed-Effect Predictions

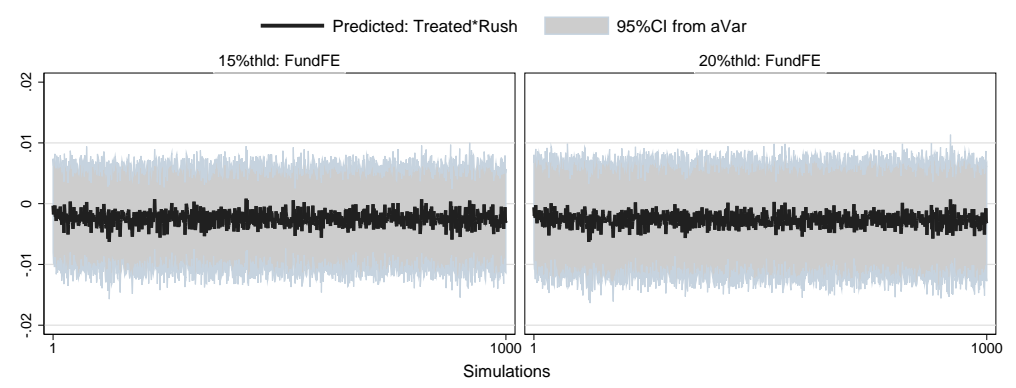

Panel C: Fraction of Random Draws with t-statistic $<$ Actual Fund

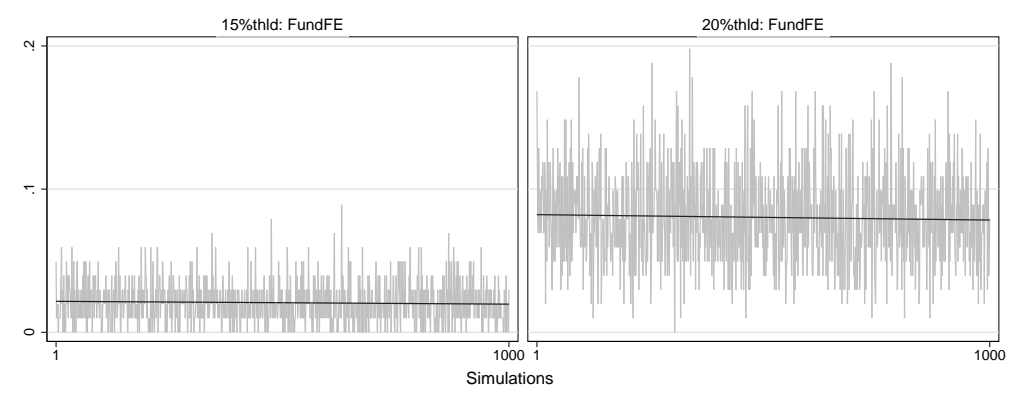




\section{REFERENCES}

Acharya, V. V., Gottschalg, O. F., Hahn, M., and Kehoe, C. (2013). Corporate governance and value creation: Evidence from private equity. Review of Financial Studies, 26(2):368-402.

Ang, A., Chen, B., Goetzmann, W. N., and Phalippou, L. (2013). Estimating private equity returns from limited partner cash flows. Columbia University working paper.

Ang, A., Papanikolaou, D., and Westerfield, M. (2011). Portfolio choice with illiquid assets. Columbia University working paper.

Ang, A. and Sorensen, M. (2012). Risks, returns, and optimal holdings of private equity: A survey of existing approaches. Quarterly Journal of Finance Vol. 2, No. 3.

Aragon, G. O. and Nanda, V. (2011). Tournament behavior in hedge funds: High-water marks, fund liquidation, and managerial stake. Review of Financial Studies, page hhr111.

Axelson, U., Jenkinson, T., Strömberg, P., and Weisbach, M. S. (2010). Borrow cheap, buy high? the determinants of leverage and pricing in buyouts. National Bureau of Economic Research working paper.

Axelson, U., Strömberg, P., and Weisbach, M. S. (2009). Why are buyouts levered? the financial structure of private equity funds. The Journal of Finance, 64(4):1549-1582.

Baker, M. and Wurgler, J. (2000). The equity share in new issues and aggregate stock returns. The Journal of Finance, 55(5):2219-2257.

Ball, E., Chiu, H. H., and Smith, R. (2011). Can vcs time the market? an analysis of exit choice for venture-backed firms. Review of Financial Studies, 24(9):3105-3138.

Barrot, J.-N. (2012). Investor horizon and innovation: Evidence from private equity funds. Massachusetts Institute of Technology working paper.

Bernstein, S., Lerner, J., Sorensen, M., and Strömberg, P. (2011). Private equity and industry performance. Harvard Business School Entrepreneurial Management working paper No. 10-045.

Brav, A. (2000). Inference in long-horizon event studies: A bayesian approach with application to initial public offerings. The Journal of Finance, 55(5):1979-2016.

Brav, A. and Gompers, P. A. (1997). Myth or Reality? The long-run underperformance of initial public offerings: Evidence from venture and nonventure capital-backed companies. The Journal of Finance, 52(5):1791-1821.

Brown, G. W., Gredil, O. R., and Kaplan, S. N. (2013). Do private equity funds game returns? University of North Carolina working paper. 
Cai, Y., Sevilir, M., and Tian, X. (2012). Do entrepreneurs make good VCs? Indiana University working paper.

Campbell, J. Y. and Shiller, R. J. (1988). The dividend-price ratio and expectations of future dividends and discount factors. Review of financial studies, 1(3):195-228.

Cao, J. and Lerner, J. (2009). The performance of reverse leveraged buyouts. Journal of Financial Economics, 91(2):139-157.

Chung, J.-W., Sensoy, B., Stern, L., and Weisbach, M. (2011). Pay for performance from future fund flows: The case of private equity. Review of Financial Studies 25 (11), 3259-3304.

Degeorge, F., Martin, J., and Phalippou, L. (2013). Agency costs and investor returns in private equity: Consequences for secondary buyouts. ECGI - Finance working paper No. 384.

Efron, B. and Tibshirani, R. J. (1994). An introduction to the bootstrap, volume 57. CRC press.

Ewens, M. and Rhodes-Kropf, M. (2013). Is a vc partnership greater than the sum of its partners? Carnegie Mellon University working paper.

Fama, E. F. and MacBeth, J. D. (1973). Risk, return, and equilibrium: Empirical tests. The Journal of Political Economy, pages 607-636.

Fang, L., Ivashina, V., and Lerner, J. (2012). The disintermediation of financial markets: direct investing in private equity. INSEAD working paper.

Ferson, W. E. and Harvey, C. R. (1999). Conditioning variables and the cross section of stock returns. The Journal of Finance, 54(4):1325-1360.

Franzoni, F. A., Nowak, E., and Phalippou, L. (2012). Private equity performance and liquidity risk. Journal of Finance, 67(6):2341-2373.

Galai, D. and Masulis, R. W. (1976). The option pricing model and the risk factor of stock. Journal of Financial economics, 3(1):53-81.

Gantchev, N., Gredil, O., and Jotikasthira, C. (2013). Governance under the gun: Spillover effects of hedge fund activism. University of North Carolina working paper.

Gervais, S. and Strobl, G. (2012). The industrial organization of money management. Duke University working paper.

Gompers, P., Kaplan, S., and Mukharlyamov, V. (2014). What do private equity firms do? Harvard Business School working paper.

Gompers, P., Kovner, A., and Lerner, J. (2009). Specialization and success: Evidence from venture capital. Journal of Economics \& Management Strategy, 18(3):817-844. 
Gompers, P., Kovner, A., Lerner, J., and Scharfstein, D. (2008). Venture capital investment cycles: The impact of public markets. Journal of Financial Economics, 87(1):1-23.

Gompers, P., Kovner, A., Lerner, J., and Scharfstein, D. (2010). Performance persistence in entrepreneurship. Journal of Financial Economics, 96(1):18-32.

Gompers, P. and Lerner, J. (1999). An analysis of compensation in the us venture capital partnership. Journal of Financial Economics, 51(1):3-44.

Grossman, S. J. and Stiglitz, J. E. (1980). On the impossibility of informationally efficient markets. The American economic review, 70(3):393-408.

Guo, S., Hotchkiss, E. S., and Song, W. (2011). Do buyouts (still) create value? The Journal of Finance, 66(2):479-517.

Harford, J. and Kolasinski, A. (2013). Do private equity sponsors sacrifice long-term value for short-term profit? Management Science, Forthcoming.

Harris, R. S., Jenkinson, T., and Kaplan, S. N. (2013). Private equity performance: What do we know? forthcoming in the Journal of Finance.

Harris, R. S., Jenkinson, T., Kaplan, S. N., and Stucke, R. (2012). Has persistence persisted in private equity? evidence from buyout and venture capital funds. University of Virginia working paper.

Hochberg, Y. V., Ljungqvist, A., and Lu, Y. (2010). Networking as a barrier to entry and the competitive supply of venture capital. The Journal of Finance, 65(3):829-859.

Hochberg, Y. V., Ljungqvist, A., and Vissing-Jorgensen, A. (2013). Informational hold-up and performance persistence in venture capital. The Review of Financial Studies, forthcoming.

Jensen, M. C. and Meckling, W. H. (1976). Theory of the firm: Managerial behavior, agency costs and ownership structure. Journal of Financial Economics, 3(4):305-360.

Kaplan, S. N. and Lerner, J. (2010). It ain't broke: The past, present, and future of venture capital. Journal of Applied Corporate Finance, 22(2):36-47.

Kaplan, S. N. and Schoar, A. (2005). Private equity performance: Returns, persistence, and capital flows. The Journal of Finance, 60(4):1791-1823.

Kaplan, S. N. and Stein, J. C. (1993). The evolution of buyout pricing and financial structure in the 1980s. The Quarterly Journal of Economics, 108(2):313-357.

Kaplan, S. N. and Strömberg, P. (2008). Leveraged buyouts and private equity. Journal of Economic Perspectives 22(4). 
Korteweg, A. and Nagel, S. (2013). Risk-adjusting the returns to venture capital. Standford University working paper.

Korteweg, A. and Sorensen, M. (2010). Risk and return characteristics of venture capitalbacked entrepreneurial companies. Review of Financial Studies, 23(10):3738-3772.

Lancaster, T. (2004). An introduction to modern Bayesian econometrics. Blackwell Oxford.

Lerner, J. (1994). Venture capitalists and the decision to go public. Journal of Financial Economics, 35(3).

Lerner, J., Schoar, A., and Wang, J. (2008). Secrets of the academy: The drivers of university endowment success. Journal of Economic Perspectives 22(3).

Lerner, J., Schoar, A., and Wongsunwai, W. (2007). Smart institutions, foolish choices: The limited partner performance puzzle. The Journal of Finance, 62(2):731-764.

Lettau, M. and Ludvigson, S. (2001). Consumption, aggregate wealth, and expected stock returns. the Journal of Finance, 56(3):815-849.

Ljungqvist, A. and Richardson, M. (2003). The cash flow, return and risk characteristics of private equity. NBER working paper.

Loughran, T. and Ritter, J. R. (1995). The new issues puzzle. The Journal of Finance, 50(1):2351.

Lowry, M. (2003). Why does ipo volume fluctuate so much? Journal of Financial Economics, 67(1):3-40.

Malkiel, B. G. and Fama, E. F. (1970). Efficient capital markets: A review of theory and empirical work*. The journal of Finance, 25(2):383-417.

Merton, R. C. (1971). Optimum consumption and portfolio rules in a continuous-time model. Journal of economic theory, 3(4):373-413.

Metrick, A. and Yasuda, A. (2010). The economics of private equity funds. Review of Financial Studies, 23:2303-2341.

Pagano, M., Panetta, F., et al. (1998). Why do companies go public? An empirical analysis. The Journal of Finance, 53(1):27-64.

Pástor, L. and Veronesi, P. (2005). Rational IPO waves. The Journal of Finance, 60(4):17131757.

Phalippou, L. (2013). Performance of buyout funds revisited. forthcoming in Review of Finance. 
Phalippou, L. and Gottschalg, O. (2009). The performance of private equity funds. Review of Financial Studies, 22(4):1747-1776.

Ritter, J. R. (1991). The long-run performance of initial public offerings. The journal of finance, 46(1):3-27.

Robinson, D. and Sensoy, B. (2011). Cyclicality, performance measurement, and cash flow liquidity in private equity. NBER working paper.

Robinson, D. and Sensoy, B. (2013). Do private equity fund managers earn their fees? compensation, ownership, and cash flow performance. forthcoming in The Review of Financial Studies, (2011-14).

Schultz, P. (2003). Pseudo market timing and the long-run underperformance of ipos. the Journal of Finance, 58(2):483-518.

Sensoy, B. A., Wang, Y., and Weisbach, M. S. (2013). Limited partner performance and the maturing of the private equity industry. Journal of Financial Economics, forthcoming.

Skoulakis, G. (2008). Panel data inference in finance: Least-squares vs fama-macbeth. University of Maryland working paper.

Sorensen, M. (2007). How smart is smart money? a two-sided matching model of venture capital. The Journal of Finance, 62(6):2725-2762.

Sorensen, M. and Jagannathan, R. (2013). The public market equivalent and private equity performance. Columbia University working paper.

Sorensen, M., Wang, N., and Yang, J. (2014). Valuing private equity. Review of Financial Studies, page hhu013.

Welch, I. and Goyal, A. (2008). A comprehensive look at the empirical performance of equity premium prediction. Review of Financial Studies, 21(4):1455-1508.

Wooldridge, J. M. (2002). Econometric Analysis of Cross Section and Panel Data. MIT Press, Cambridge, M.A., USA.

Zellner, A. (1962). An efficient method of estimating seemingly unrelated regressions and tests for aggregation bias. Journal of the American Statistical Association, 57(298):348-368. 